San Jose State University

SJSU ScholarWorks

Master's Theses

Master's Theses and Graduate Research

1998

\title{
Electrochemical impedance spectroscopy of stainless steel 316 in deionized water
}

Fahmida Rahman

San Jose State University

Follow this and additional works at: https://scholarworks.sjsu.edu/etd_theses

\section{Recommended Citation}

Rahman, Fahmida, "Electrochemical impedance spectroscopy of stainless steel 316 in deionized water" (1998). Master's Theses. 1667.

DOI: https://doi.org/10.31979/etd.8wpt-9rbk

https://scholarworks.sjsu.edu/etd_theses/1667

This Thesis is brought to you for free and open access by the Master's Theses and Graduate Research at SJSU ScholarWorks. It has been accepted for inclusion in Master's Theses by an authorized administrator of SJSU ScholarWorks. For more information, please contact scholarworks@sjsu.edu. 


\section{INFORMATION TO USERS}

This manuscript has been reproduced f-om the microfilm master. UMI films the text directly from the original or copy submitted. Thus, some thesis and dissertation copies are in typewriter face, while others may be from any type of computer printer.

The quality of this reproduction is dependent upon the quality of the copy submitted. Broken or indistinct print, colored or poor quality illustrations and photographs, print bleedthrough, substandard margins, and improper alignment can adversely affect reproduction.

In the unlikely event that the author did not send UMI a complete manuscript and there are missing pages, these will be noted. Also, if unauthorized copyright material had to be removed, a note will indicate the deletion.

Oversize materials (e.g., maps, drawings, charts) are reproduced by sectioning the original, beginning at the upper left-hand corner and continuing from left to right in equal sections with small overiaps. Each original is also photographed in one exposure and is included in reduced form at the back of the book.

Photographs included in the original manuscript have been reproduced xerographically in this copy. Higher quality 6" $x$ 9" black and white photographic prints are available for any photographs or illustrations appearing in this copy for an additional charge. Contact UMI directly to order.

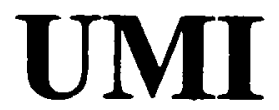

A Bell \& Howell Information Company 300 North Zeeb Road, Ann Arbor MI 48106-1346 USA

$313 / 761-4700 \quad 800 / 521-0600$ 
ELECTROCHEMICAL IMPEDANCE SPECTROSCOPY OF STAINLESS STEEL 316 IN DEIONIZED WATER

\author{
A Thesis \\ Presented to \\ The Faculty of the Department of Chemical Engineering \\ San Jose State University \\ In Partial Fulfillment \\ of the Requirements for the Degree of \\ Master of Science
}

by

Fahmida Rahman

May, 1998 
UMI Number: 1389678

UMI Microform 1389678

Copyright 1998, by UMI Company. All rights reserved.

This microform edition is protected against unauthorized copying under Title 17, United States Code.

\section{UMI \\ 300 North Zeeb Road \\ Ann Arbor, MI 48103}


(C) 1998

Fahmida Rahman

ALL RIGHTS RESERVED 
APPROVED FOR THE DEPARTMENT OF CHEMICAL ENGINEERING

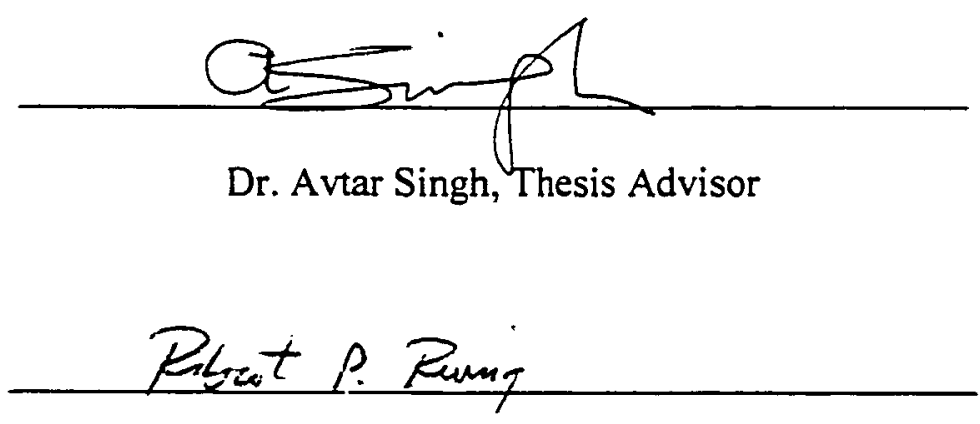

Dr. Robert A. Romig, Committee Member

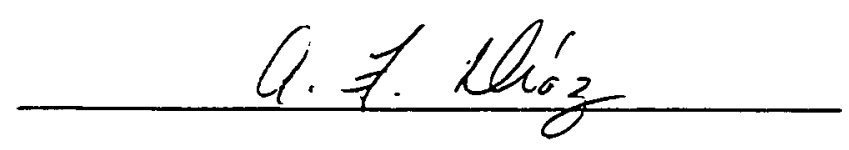

Dr. Art Diaz, Committe Member

APPROVED FOR THE UNIVERSITY

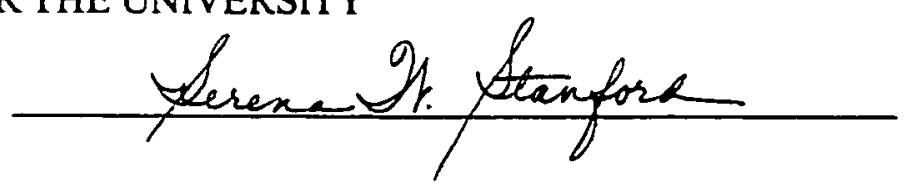




\begin{abstract}
Electrochemical Impedance Spectroscopy of Stainless Steel 316 in Deionized Water

by
\end{abstract}

Fahmida Rahman

Investigation and improvement of monitoring techniques, which could not be utilized in the past for lack of supporting equipment can be revitalized with the advent of new sophisticated equipment. Electrochemical impedance technique is one such technique. This thesis work is dedicated to using this technique in investigating the interfacial layer of stainless steel 316 and deionized water system.

A two electrode cell was prepared for the investigation of the system. Several electrolytes were tested for comparison. The electrochemical impedance responses were investigated from the Nyquist and Bode plots. A twenty one day run was conducted with deionized water and three different sodium chloride solutions. An equivalent circuit model with two constant phase elements was developed to represent the SS 316 passivation in DI water system at room temperature. Recommendations are made for further investigations with the aim of developing a monitoring technique of SS 316 corrosion in DI water. 


\section{ACKNOWLEDGEMENTS}

The author would like to thank her advising professor, Dr. Avtar Singh, for introducing the area of electrochemical impedance spectroscopy and his constant encouragement and support during the period of investigations. The author would like to thank committee member, Dr. Art Diaz for his guidance and support with the literature materials and use of laboratory facilities. The author would like to thank Dr. Robert A. Romig for his input in the project completion; and Dr. Melanie A. McNeil, the author's graduate advisor for her advice and direction under special circumstances; and Jerri Carmo Interim Director of Contracts and Grants of San Jose State University Foundation for her participation in obtaining donation of equipment time.

The author would like to offer her special thanks to Mr. Derek Johnson of Scribner Associates Inc. for the gracious donation of his time and use of his equipment. His input to this study and the use of his facilities were invaluable for the research.

The author would like to thank the Department of Chemical Engineering and Department of Materials Engineering for supporting this research. The author also acknowledges the San Jose State University Foundation for its support in obtaining the donated external help for this study. 
Acknowledgments are extended to the engineering technicians, Ray Brindos, Erwin Toeffel, and Alan Martin for their aid in constructing the experimental apparatus.

The author deeply appreciates her friend Hilary Langhorst for her valuable suggestions in coping with the English language and proof reading this thesis.

Finally, the author is grateful to her mother, husband, and brother for their continuous inspiration and financial support which made this dissertation possible. 
TABLE OF CONTENTS

Page

ABSTRACT

iv

ACKNOWLEDGEMENTS

v

TABLE OF CONTENTS vii

LIST OF TABLES $\quad X$

LIST OF FIGURES $\quad$ xi

CHAPTER 1. INTRODUCTION AND BACKGROUND 1

1.1 Introduction 1

1.2 EIS Method 3

1.3 Recent Application of EIS 6

$\begin{array}{lll}1.4 & \text { Research Focus } & 7\end{array}$

CHAPTER 2. LITERATURE REVIEW

$\begin{array}{llr}2.1 & \text { Literature Trends } & 8\end{array}$

2.2 Equivalent Circuit Models Discussed by Silverman et al. 9

2.3 Study of SS 304 in Pure Water by EIS 26

2.4 Study of SS 446 in Borate/boric Acid Buffer by EIS 30

2.5 Copper and Tap Water Investigated by EIS 32

2.6 Thesis Study $\quad 32$ 
CHAPTER 3. MATERIALS AND METHODS 34

3.1 Introduction 34

3.2 Hypothesis 34

3.3 Experimental Setup 44

3.4 Experimental Procedure $\quad 48$

3.5 Determining the Components of Equivalent Circuit 50

3.6 Validation of the Model 53

3.7 Bode Plot 54

CHAPTER 4. EXPERIMENTAL RESULTS AND DISCUSSION 56

4.1 Introduction $\quad 56$

4.2 AC RMS Value Determination 57

4.3 The Passive Impedance Spectrum 58

4.4 Comparison of DI Water with Tap Water and Evaporated Tap Water

4.5 A Comparative Analysis of SS 316 in DI Water and Sodium Chloride Solution Over 21 Days $\quad 71$

4.6 Equivalent Circuit Model for SS 316 and DI Water System

CHAPTER 5. CONCLUSIONS AND RECOMMENDATIONS 86

$\begin{array}{lr}\text { REFERENCES } & \mathbf{8 8}\end{array}$ 
$\begin{array}{ll}\text { APPENDICES } & 90\end{array}$

Appendix A: Derivation of Nyquist Equations from Impedance Equations

Appendix B: Raw EIS Data Obtained from Gain Phase Analyzer

Appendix C: Experimental and Simulated (Using Equivalent Circuit with Two CPEs) Nyquist and Bode Plot Response of SS 316 and DI Water System 


\section{LIST OF TABLES}

Page

Table 2.1. Circuit parameters and corrosion rates from impedance data for SS 316 in dilute organic acid solution (Adapted from Silverman et al., 1987).

Table 2.2. Estimates of Resistance and corrosion rate for SS 316 and inhibitor (Adapted from Silverman et al., 1987).

Table 2.3. Corrosion Rates of carbon steel and water (Adapted from Silverman el al., 1987).

Table 3.1. Accumulated amounts of chromium and molybdenum in the surface region measured by $\gamma$-spectrometry (Adapted from Hultquist et al., 1984).

Table 4.1. Randle's circuit parameters.

Table 4.2. (a) Circuit element $R s, R p_{1}, \tau_{1} / R p_{1}$, and $B_{1}$ values and their error percents for circuit in Figure 4.21.(b).

Table 4.2. (b) Circuit elements $R s, R p_{2}, \tau_{2} / R p_{2}$, and $B_{2}$ values and their error percents for circuit in Figure 4.21.(b) and the chi-square value of curve fit.

Table 4.3(a) Circuit element Rs, $R p_{1}, C_{1}$ and $\beta_{1}$ values and their error percents for circuit in Figure 4.22.

Table 4.3.(b) Circuit elements $C_{2}$, and $B_{2}$ values and their error percents for circuit in Figure 4.22 and the chi-square value of curve fit. 


\section{LIST OF FIGURES}

Figure 2.1. (a) Nyquist plot for a circuit with one constant phase element in series with a resistor, (b) the corresponding circuit.

Figure 2.2. (a) Nyquist plot for a circuit with two constant phase elements in series with a resistor, (b) the corresponding circuit.

Figure 2.3. (a) Nyquist plot for a circuit with a constant phase element and a diffusion element, (b) the corresponding circuit.

Figure 2.4. (a) Nyquist plot for a circuit with inductance and capacitance, (b) the corresponding circuit.

Figure 2.5. (a) Frequency response in the Nyquist plot of SS 316 in dilute organic acid at $96^{\circ} \mathrm{C}$, (b) same frequency response in the Bode plot (Silverman et al., 1987).

Figure 2.6. (a) Frequency response in the Nyquist format of SS 316 in $3 w t \%$ sodium hydroxide at $80^{\circ} \mathrm{C}$, (b) same frequency response in the Bode format (Silverman et al., 1987).

Figure 2.7. (a) Frequency response in the Nyquist format of carbon steel in neutral water at $32{ }^{\circ} \mathrm{C}$ at stagnant condition, (b) same frequency response in the Bode format (Silverman et al., 1987).

Figure 2.8. (a) Frequency response in the Nyquist format of carbon steel in water at with $25 \mathrm{ppm}$ chromate and $10 \mathrm{ppm}$ zinc ion at $32{ }^{\circ} \mathrm{C}$, (b) same frequency response in the Bode format (Silverman et al., 1987).

Figure 2.9. Nyquist plot of measured impedance spectra as function of time for metals exposed to a high temperature water with various concentrations of dissolved oxygen(DO), (a) for platinum, (b) for SS 304 and (c) for carbon steel (Mabuchi et al., 1994). 
Figure 2.10. (a) and (b) Components of circuit model for SS304 and carbon steel in high temperature water, (c) complete circuit model and (d) physical corrosion model for SS 304 and carbon steel (Mabuchi et al., 1994).

Figure 2.11. Proposed physical models, equivalent circuits and $\chi^{2}$ values for the four types of sample (Capobianco et al., 1993).

Figure 3.1. (a) An electrical circuit with one constant phase element in series with a resistor, (b) the corresponding Nyquist plot.

Figure 3.2. (a) An Equivalent circuit with two constant phase elements in series with a resistor, and (b) the corresponding Nyquist plot.

Figure 3.3. (a) An electrical equivalent circuit with a constant phase element and a diffusion element, (b) the corresponding Nyquist ploi.

Figure 3.4. (a) An electrical circuit with inductance and capacitance

(b) corresponding Nyquist plot.

Figure 3.5. Schematic of two electrode cell assembly.

Figure 3.6. Schematic of the experimental setup used in the study.

Figure 3.7. A geometrically fitted impedance curve in the complex plane showing the parameters $\mathrm{Rp}, \mathrm{Ro}, \mathrm{Xo}$ and $\mathrm{Yo}$.

Figure 3.8. The impedance response in Bode plot for the circuit in Figure 3.2.

Figure 4.1. Nyquist plot for various voltages applied to the DI water and SS 316 system.

Figure 4.2. Impedance response in Nyquist plot for SS 316 and DI water system where SS 316 sample was not polished. 
Figure 4.3. Plot of imaginary part of impedance versus $\left(1 / \omega^{1 / 2}\right)$ for SS 316 and DI water system.

Figure 4.4. Section of Nyquist plot at high frequency region for SS 316 and DI water system.

Figure 4.5. Randles Equivalent Circuit.

Figure 4.6. Impedance data plotted in Bode format for DI water, tap water nand evaporated tap water.

Figure 4.7. Nyquist plot for SS 316 in three different electrolytes.

Figure 4.8. Nyquist plot for SS 316 and DI water.

Figure 4.9. Nyquist plot for SS 316 in DI water (high frequency region).

Figure 4.10. Nyquist plot for SS 316 and (a) tap water, (b) evaporated tap water.

Figure 4.11. Z" versus $1 /\left(\omega^{1 / 2}\right)$ plot for SS 316 in (a) tap water, (b) evaporated tap water.

Figure 4.12. SS 316 and DI water system observed over 21 days, (a) Nyquist plot and, (b) Bode plot.

Figure 4.13. Nyquist plot for SS 316 in DI water with high frequency region magnified.

Figure 4.14. Impedance response for SS 316 in $.01 \mathrm{~N}$ sodium chloride solution in (a) Nyquist plot and (b) Bode plot.

Figure 4.15. Impedance response for SS 316 in $0.1 \mathrm{~N}$ sodium chloride solution in (a) Nyquist plot and (b) Bode plot.

Figure 4.16. Impedance response for SS 316 in $1.0 \mathrm{~N}$ sodium chloride solution in (a) Nyquist plot and (b) Bode plot.

Figure 4.17. Nyquist plot for SS 316 and DI water system for short run. 
Figure 4.18. Nyquist plot for SS 316 and $0.1 \mathrm{~N}$ sodium chloride system in short run.

Figure 4.19. Nyquist plot for SS 316 and DI water system, 21 day run and short run superimposed.

Figure 4.20. Bode plot for SS 316 and DI water system, 21 day run and short run superimposed.

Figure 4.21. Circuit with two CPE (a) in series and (b) in nested connection.

Figure 4.22. Circuit with one CPE and a modified capacitor. 


\section{CHAPTER 1. INTRODUCTION AND BACKGROUND}

\subsection{Introduction}

As we look ahead to the 21 st century, many of the United States 110 nuclear power plants approach the expiration of their operating licenses. Renewal of these licenses is being considered as an alternative to capital investment in new plants. A good plant monitoring and maintenance approach can establish a safe and extended life for the existing plants. Improved and innovative techniques must be considered for their economical and reliable operation. A good monitoring technique would help to "avoid the unpleasant surprise of individual catastrophic equipment failures," according to Gerald Neils, an executive engineer at Northern States Power (NSP). Extending power plant life 10-30 years beyond its license term can reduce expense by cutting capital investment. With cost-effective techniques the operations and management expenses can also be reduced (Moore et al., 1991). An in-situ or in place technique to monitor the change would be very valuable to the nation's many nuclear power plants.

Electrical Impedance Spectroscopy (EIS) is a powerful in-situ technique for investigating a wide range of interfacial systems. The impedance response can be easily stored in a computer. With the development of new computing technology and highly sensitive electrical measuring equipment the EIS can be used for observing interfacial response of electrochemical systems. These responses then can be compared with existing stored data 
in order to detect any change. Thus EIS can be considered a powerful monitoring technique for the future.

Stainless steel 316 (SS 316 ) is a common material for fabricating nuclear power plants and chemical plants. The general composition of stainless steel 316 is as follows:

$$
\begin{array}{llll}
\text { Cr } & 16-18 \% w t & \mathrm{Ni} & 10-14 \% \mathrm{wt} \\
\text { Mo } & 2-3 \% w t & \mathrm{C} & 0.08 \% w t(\max .) \\
\text { Mn } & 2 \% w t & \mathrm{Si} & 1.0 \% \mathrm{wt}(\max .) \\
\mathrm{S} & .03 \% \mathrm{wt}(\max .) \mathrm{P} & .05 \% \mathrm{wt}(\max .) \text { and the rest is Iron (Lula, 1986). }
\end{array}
$$

The high percentage of Chromium helps to form a stable oxide layer on SS 316 in air or water. Under long exposure the $\mathrm{Fe}^{2+}$ ion may diffuse through this layer and pitting is observed. Normally the chromium oxide offers a good corrosion protection. The replenishing of the oxide layer is relevant to this study. Understanding the formation of the passive layer with the help of electrochemical impedance spectroscopy can prove to be valuable information for future monitoring usage.

The interfacial behavior of SS 316 with deionized (DI) water is of interest for chemical and nuclear plant design. The author believes that the study of the interfacial behavior of SS 316 and DI water would be helpful for understanding long term corrosion behavior. This understanding in turn will help in the development of continuous monitoring and control techniques. 
Deionized water is a common solvent used in the power plant and chemical industry. The purity of this water most commonly is less than I PPM of each contaminant. The degree of purity is measured in resistivity. A good quality DI water will have a resistivity of 15 Mohm.cm, whereas a poor quality may be as low as 1 Mohm.cm.

\subsection{EIS Method}

The popularity of the Electrochemical Impedance Spectroscopy (EIS) technique is growing for studying corroding systems. EIS technique uses the rapid relaxation phenomena which can be varied over a wide range of frequency. Impedance is determined by applying an ac voltage on a system at a specific frequency and measuring the current. From the voltage and the current an impedance can be calculated for that frequency. The impedance has two parts: A real part which represents the resistance and the imaginary part which represents the reactance. By means of EIS technique a spectrum of impedance of the system under a series of frequencies can be observed.

The spectrum of impedance obtained is analyzed and possible equivalent electrical circuits are developed. The equivalent circuit components can be used to interpret

physical behavior of the system under investigation. If an equivalent circuit can be confirmed for a specific system, that circuit can be used for simulation of similar systems. The ac method applied by EIS delineates each process according to time constants whereas the dc methods applied by other electrochemical techniques average all the 
impedances associated with interfacial reaction, diffusion and film properties (Taylor et al., 1992).

The advantage of the EIS method is that the ac perturbation applied to the system is reversible in nature. Since the system is not taken away from equilibrium by this method, the measurable reaction rates and parameters are not altered by the measurement itself. The author believes that EIS technique can be applied to monitor DI water and SS 316 system. This method is presently used to study reaction mechanism, rate of reaction, double layer structure, and diffusion characteristics. EIS is also used for a rapid method of corrosion rate measurement coupled with DC polarization (Silverman et al., 1987).

Weight loss methods are employed for determining the corrosion of a material. Traditional weight loss methods are time consuming and such methods are not possible to use on any size of sample or equipment.

Corrosion rate is greatly affected by change in temperature, $\mathrm{pH}$. media etc. To measure the day to day effect, an in-situ probe would be desirable in the industry. EIS is also a powerful tool for electrically characterizing a dynamic system. esnecially a very fast changing one. If the system is well defined by an equivalent circuit model, a small change in the system can be detected by the model. 
The main disadvantage of EIS method is the ambiguity in data interpretation for mechanism of corrosion. A set of circuits can give the same impedance spectrum, i.e. for one impedance spectrum there may be different circuits. The circuit modeling should be based on possible physical phenomenon as well. The electrical components must correspond to the components in the physical system. Convergent fits of the simulated and observed impedance obtained through least square fitting must be possible. The individual circuit component values should vary in an explicable self consistent manner when the conditions of an experiment are varied.

To calculate corrosion rate the corrosion current and the slopes of Tafel plot from anodic and cathodic polarization are required. The corrosion current can be obtained from the charge transfer resistance or polarization resistance measured by EIS method. The charge transfer resistance or polarization resistance can be quickly obtained from EIS data. But the polarization method is required for slopes of Tafel plot for anodic and cathodic polarization in order to calculate corrosion. The values for the slopes of Tafel plot cannot be obtained from the EIS method.

\subsection{Recent Application of EIS}

With the improvement of the gain analyzer or frequency response analyzer (FRA) and the coupling potentiostat/galvanostat or electrochemical interface, the accuracy of current measurement has improved. A major concern in the past was that, if the same size of resistor is used for high frequency and low frequency range current measurements, high 
frequency artifacts could arise which extended to low frequency current measurements for a high dielectric electrolyte. The artifacts were a result of "parasitic" conduction pathways in the potentiostat, equipment leads and the electrochemical cell (Taylor et al., 1992). This problem in measuring current accurately has been solved in the recent equipment. The new equipment switches resistors from high to low when the current changes from high to low at low frequency. Investigation of high dielectrics require reliable low frequency current measurement. That is why, recently, more and more systems with high dielectric electrolytes are able to be studied.

Electrochemical Impedance Spectroscopy is becoming an integral part of corrosion and electrochemical interface studies. For example, in coating research this method is employed for monitoring coating on metals. The information obtained from the impedance spectrum is applied to investigate surface coverage, oxidation-reduction reaction at high frequency, and corrosion reaction at low frequency (Mabuchi et al., 1994).

\subsection{Research Focus}

The focus of this research is to investigate the SS 316 and DI water interface at room temperature using the EIS technique. The impedance data will be analyzed to develop an electrical circuit model. Components of the electrical circuit will be compared with the corresponding system components. The change in the electrical component values compared with the change in the physical system will give the consistency of the model. 
This approach of studying SS 316 in DI water will be valuable in determining the mechanism of passivation and in-situ probe development for monitoring the SS 316 and DI water interface. 


\section{CHAPTER 2. LITERATURE REVIEW}

\subsection{Literature Trends}

Literature trends show that EIS method studies using DI water as electrolyte are recent compared to the application of this method to the more conducting electrolytes. In the past it was difficult to obtain accurate impedance response at low frequency from systems having DI water as electrolyte. The difficulty in obtaining the required measurement, which is the current response was due to the limitation of electrical equipment capability. Only a few current studies have been found where DI water or pure water was used as the electrolytic media for the cell. In recent years the equivalent circuit models also have become more popular. This advancement can be attributed to the availability of adequate software to develop and confirm the models.

An article by Silverman et al. (1987) will be discussed in detail as it contains a study of SS 316 in different media. The article by Mabuchi et al. (1994) will be discussed second, since the investigation in their research is close to the research undertaken for this thesis. The authors of the second article have discussed the high temperature effect on SS304 in pure water. The third article discussed is by Capobianco et al. (1993). This article takes a direct approach in investigating the passivation mechanism of stainless steel 446 in borate/boric acid buffer. The last article discussed is by Feng et al. (1996). The authors of the last article have studied a tap water and copper system by EIS and other methods. This approach was also unique since the study was carried at different $\mathrm{pH}$. 


\subsection{Equivalent Circuit Models Discussed by Silverman et al. (1987).}

Silverman et al. studied SS 316 in different media using EIS. The Nyquist plots from EIS for the four types of models considered by Silverman et al. are shown in Figure 2.1. to Figure 2.4. The plots have the real part of impedance $\left(Z^{\prime}\right)$ on the $x$-axis and the imaginary part of impedance $\left(Z^{\prime \prime}\right)$ on the y-axis. The corresponding circuit models are also shown in the respective figures. The model parameters have been explained by Kendig et al. (1983) for the first two models, by Randle (Rubinstein I., 1995) for the third model and by D. D. Macdonald (1978) for the fourth model. The relationship of the circuit elements to EIS data has also been established by these authors, who have not used conventional R-C circuits for simulation. They estimated the resistor and capacitor value by semicircular curve fitting to the Nyquist plot data. The experimental Nyquist plot shows depressed semicircles for Figure 2.1 and Figure 2.2. Kendig et al. (1983) had accounted for this by introducing a time constant $\tau$ and a power value $\beta$. Simply, it can be said if a capacitor (C) and resistor (Rp) were connected in parallel, the equivalent impedance $(Z)$ of this circuit would be as shown in Equation 2.1, where $\omega=2 \pi \mathrm{f}$ and $\mathrm{f}=$ frequency.

$$
\begin{aligned}
& Z=R p(1 / j \omega C) /\{R p+(1 / j \omega C)\} \text { or } \\
& Z=(R p) /(1+j \omega R p C)
\end{aligned}
$$

The constant phase element is a modification of Equation 2.1 and the impedance for that is given by Equation 2.2. 


$$
\begin{aligned}
& Z=(R p) /\left\{1+(j \omega R p C)^{\beta}\right\} \quad \text { or } \\
& Z=(R p) /\left\{1+(j \omega \tau)^{\beta}\right\}
\end{aligned}
$$

One constant phase element is analogous to one $\mathrm{R}-\mathrm{C}$ element but not the same. $\mathrm{RpC}$ is replaced by time constant $\tau$ and $(j \omega \tau)$ is raised to the power $\beta$ in Equation 2.2. This modification fits the interfacial impedance plot better than the electrical impedance plot, represented by $\mathrm{Rp}$ and $\mathrm{C}$. More than one constant phase element (CPE) may be detected in electrochemical systems. To determine the corrosion rate the $\mathrm{Rp}$ value for low frequency region is used. Multiple CPE can be used for determining the mechanism or to interpret physical phenomenon at the interface. 


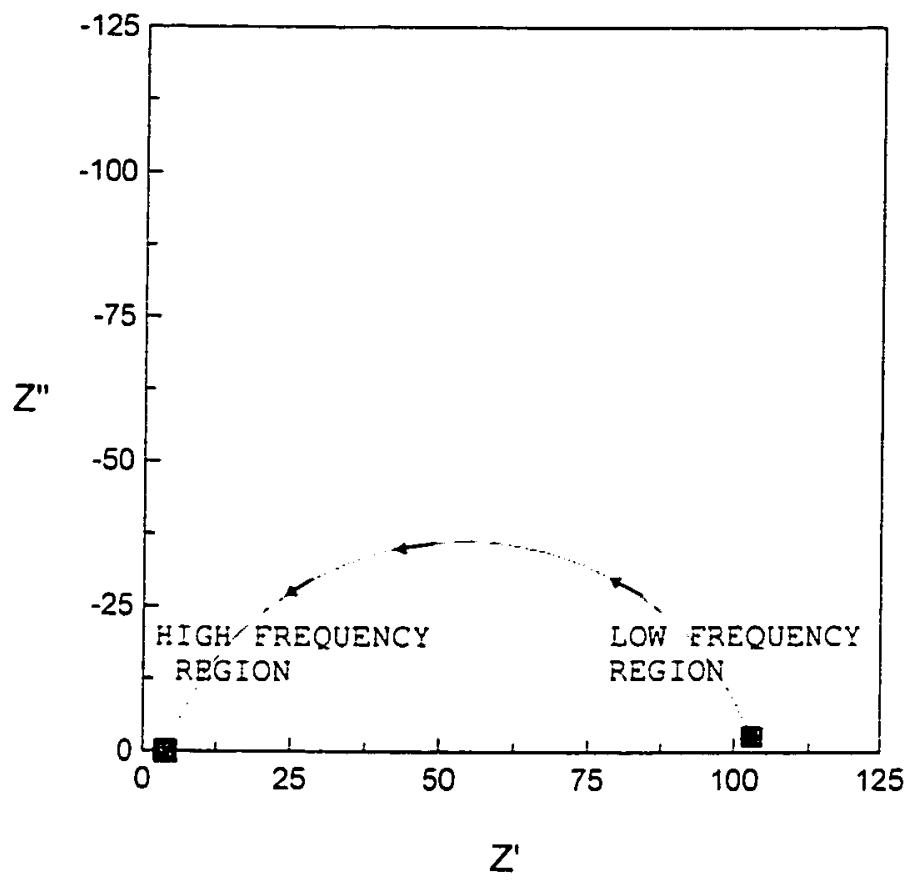

(a)

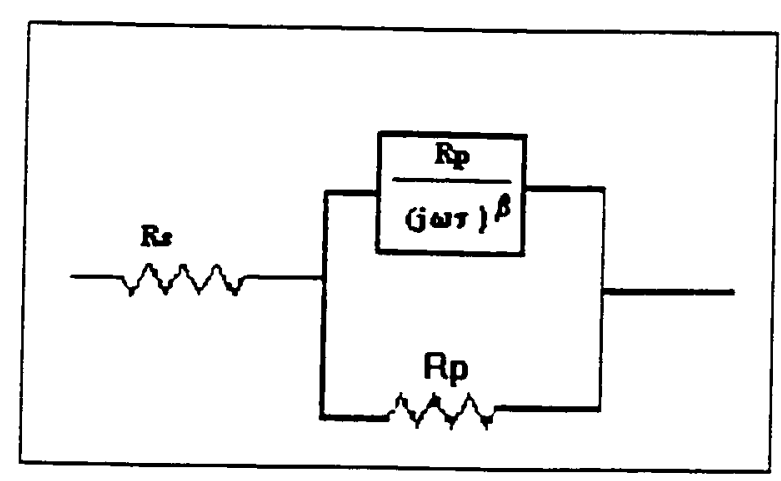

(b)

Figure 2.1. (a) Nyquist plot for a circuit with one constant phase element in series with a resistor, (b) the corresponding circuit. 


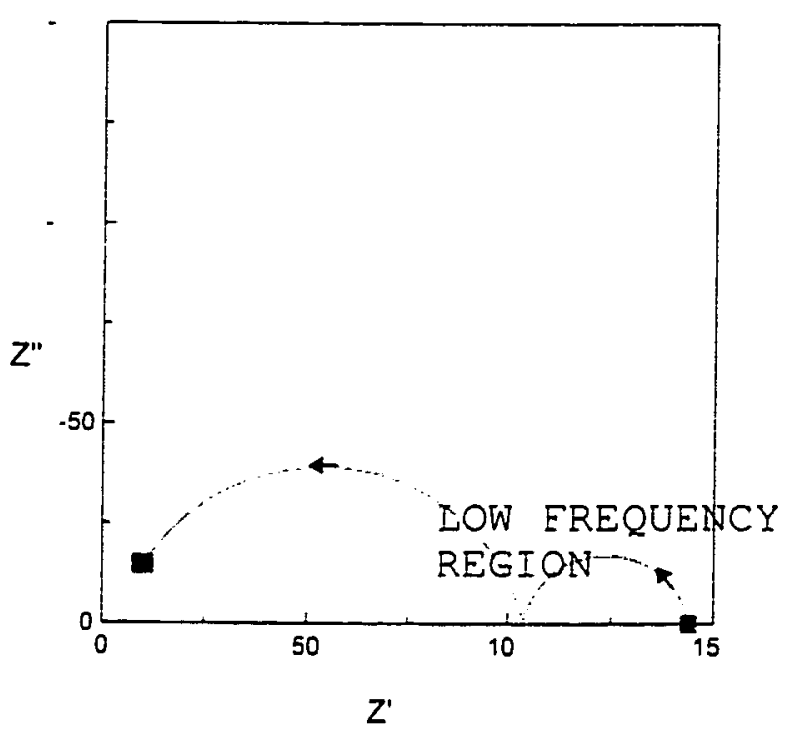

(a)

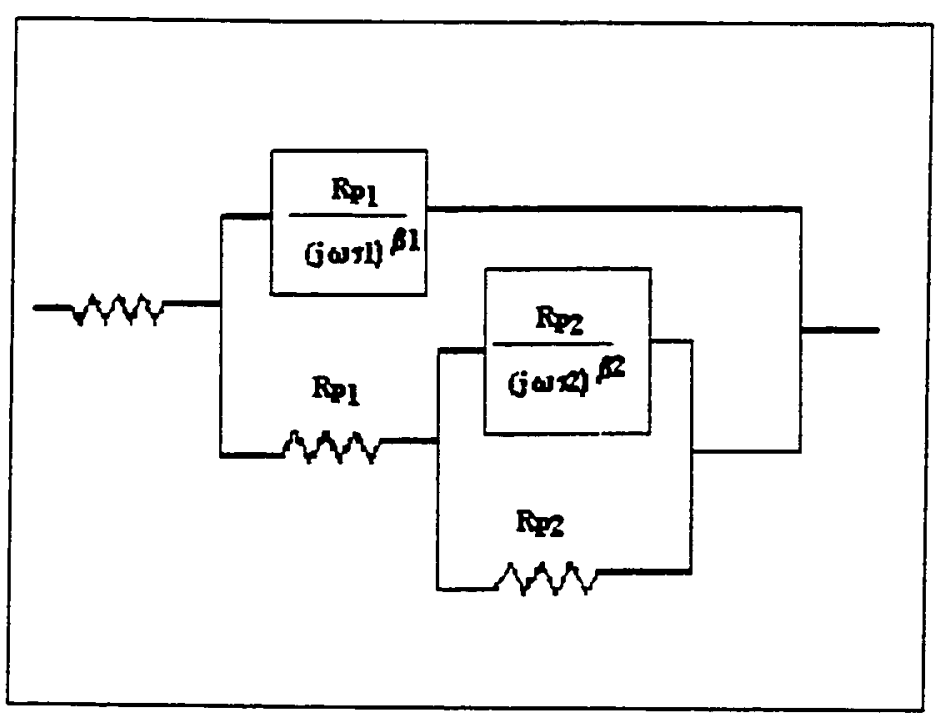

(b)

Figure 2.2. (a) Nyquist plot for a circuit with two constant phase elements in series with a resistor, (b) the corresponding circuit. 


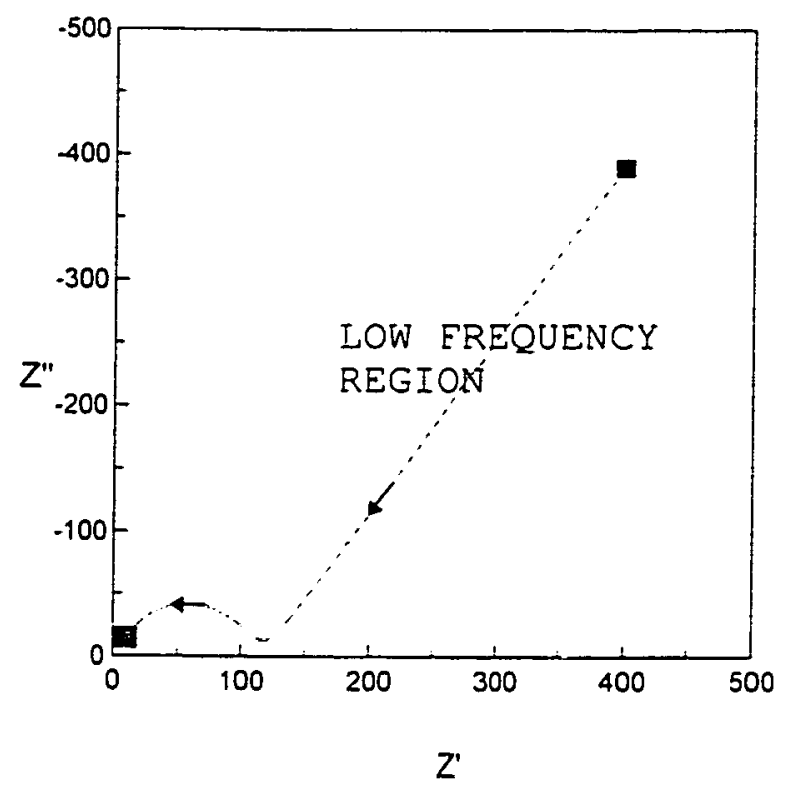

(a)

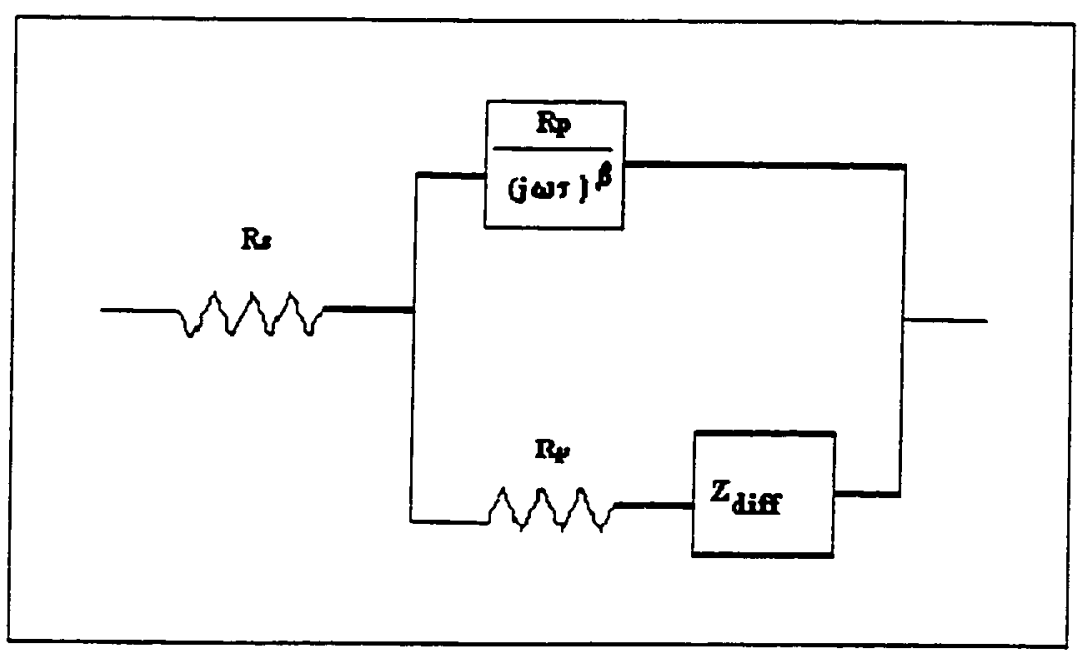

(b)

Figure 2.3. (a) Nyquist plot for a circuit with a constant phase element and a diffusion element. (b) the corresponding circuit. 


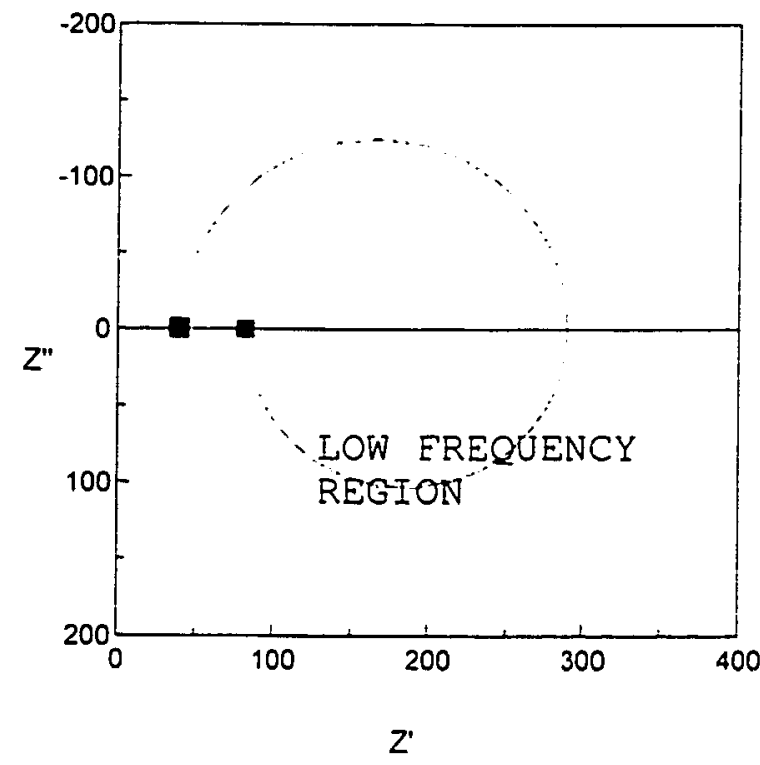

(a)

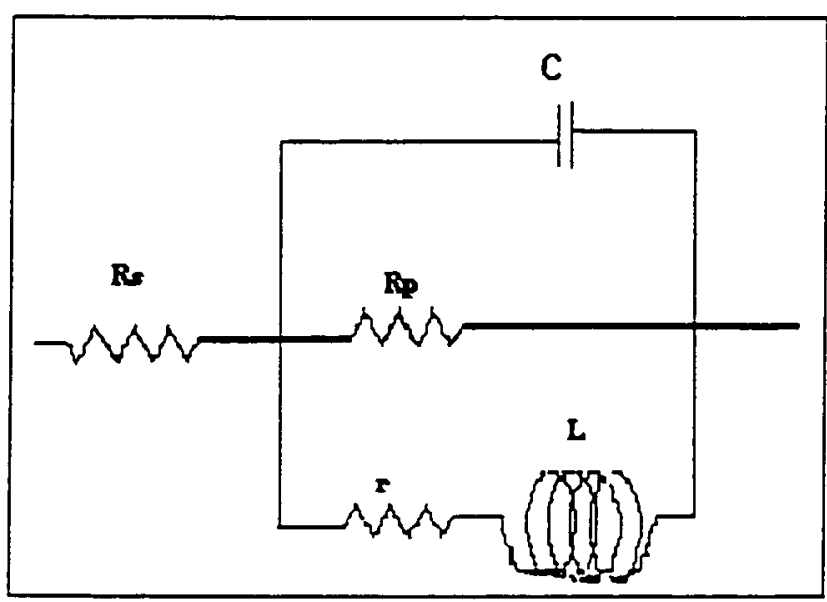

(b)

Figure 2.4.(a) Nyquist plot for a circuit with inductance and capacitance, (b) the corresponding circuit. 
In the article by Silverman et al. (1987) the authors demonstrated applicability of EIS technique to corrosion rate determination. They used a microcomputer to control data acquisition for ac voltage and current response at different frequencies. This response was then analyzed by a frequency response analyzer (FRA) or gain analyzer and translated to impedance data. Based on the nature of the impedance data a circuit model was chosen. The values of the elements of the circuit were estimated using the Nyquist plot and method defined by Kendig et al. (1983) with computer aid. A simulated impedance response was generated for the circuit model on a mainframe computer and this response was compared graphically to the experimental response. The experiments carried out by Silverman et al. mainly fitted the first three circuit models. No pseudoinductance phenomenon as seen in Figure 2.4 was observed.

Silverman et al. (1987) studied passive alloy AISI 316 SS using EIS. Two experiments were conducted to study the passivation phenomenon. The first was a long exposure (24 hour) of the metal in organic acid mixture ( $1 \mathrm{wt} \%$ acetic acid and $0.2 \mathrm{wt} \%$ of maleic acid) at $96^{\circ} \mathrm{C}$ and the second one was a short exposure by dipping the sample in $3 \mathrm{wt} \%$ sodium hydoxide solution for 45 minutes followed by dipping it in 3 wt \% phosphoric acid for 60 minutes.

In the long exposure experiment the Nyquist plot (Fig. 2.5) showed one depressed semicircular behavior. The researchers fitted it to an equivalent circuit of one constant phase element in series with a resistance. Figure 2.5 shows also a Bode plot. A Bode plot 
contains plots of impedance and phase angles versus frequency. When the phase angle goes through a maxima, a constant phase element can be incorporated in the equivalent circuit model. When there are two maxima in the phase angle plot, two constant phase elements can be incorporated in the circuit. These maximas need to be checked with the Nyquist plot to ensure CPE or pseudoinductance behavior. The two CPEs may not always be apparent from the Nyquist plot as seen by Silverman et al. (1987). 
(a)

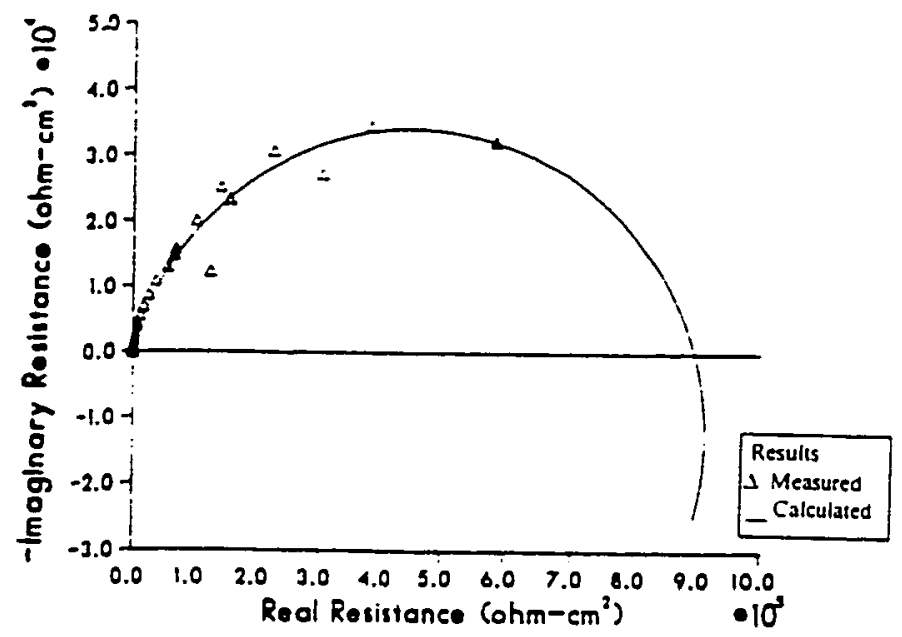

(b)

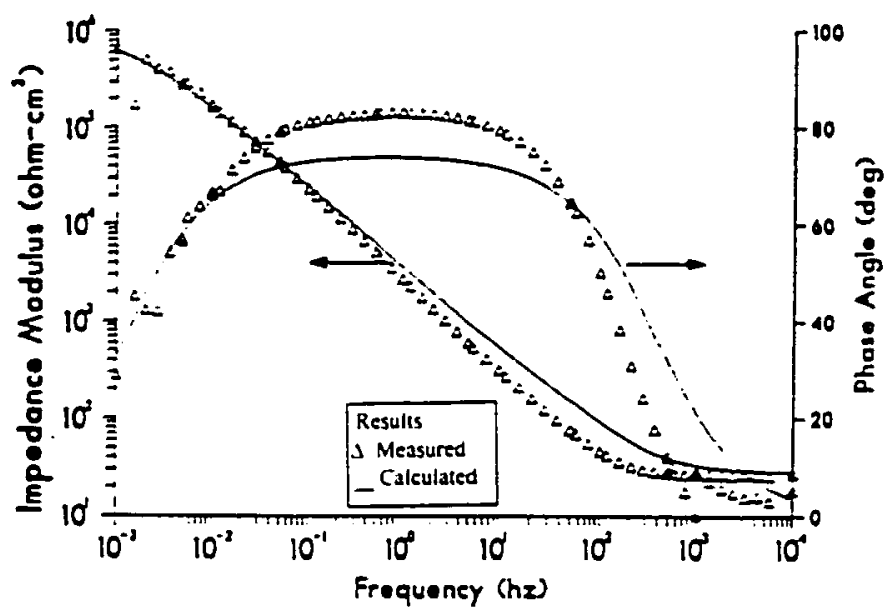

Figure 2.5. (a) Frequency response in the Nyquist plot of SS 316 in dilute organic acid at $96^{\circ} \mathrm{C}$, (b) same frequency response in the Bode plot (Silverman et al., 1987). 
The Nyquist and Bode plots for 15 to 30 minute exposures of SS 316 in $3 w t \%$ caustic at 80 degree $C$ are shown in Figure 2.6. The Nyquist plot shows the beginning of a second semicircle but the authors ignored it for corrosion rate calculations, considering it to be a convection phenomenon.

(a)

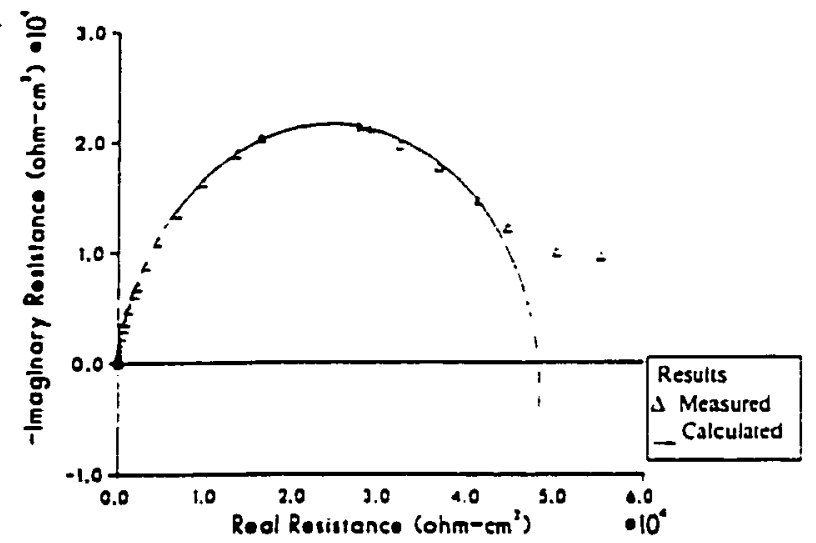

(b)

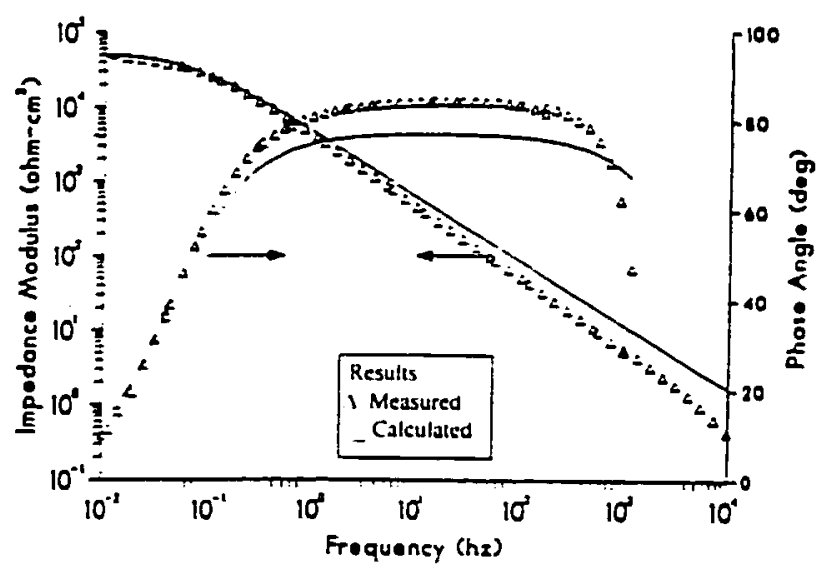

Figure 2.6. (a) Frequency response in the Nyquist format of SS 316 in $3 \mathrm{wt} \%$ sodium hydroxide at $80^{\circ} \mathrm{C}$, (b) same frequency response in the Bode format (Silverman et al., 1987). 
In the inhibitor study Silverman et al. (1987) used carbon steel samples. They detected two types of inhibition, interface and inter-phase. They called the layer at the metal surface, the interface inhibition and the reddish brown layer that partially covered the metal, as the inter-phase inhibition.

Their study for carbon steel in water was carried out at near neutral $\mathrm{pH}$ condition. The experiment was conducted first under no inhibitor condition, then with an inhibitor containing $25 \mathrm{ppm}$ of chromate and $10 \mathrm{ppm}$ of zinc. The Nyquist and Bode plots for the no inhibitor condition in water is shown in Figure 2.7. The Nyquist plot shows a depressed semicircle and the beginning of a second semi-circle. The authors identified this response in the Nyquist plot with the Randles circuit Nyquist plot response (Fig. 2.3). They observed a marked build up of a nearly gelatinous orange brown deposit on the entire electrode of the uninhibited solution and small parts of electrodes in an inhibited solution. Dawson and John as mentioned in the article by Silverman et al. (1987) modeled an assumption for diffusion for this kind of response. A diffusion element is considered along with one capacitor in the equivalent circuit. They used Dawson's model to determine corrosion rate. 
(a)

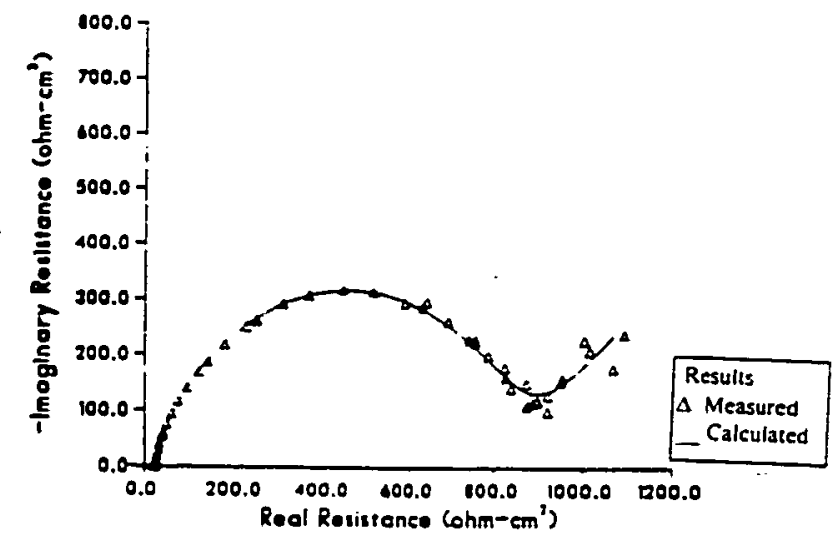

(b)

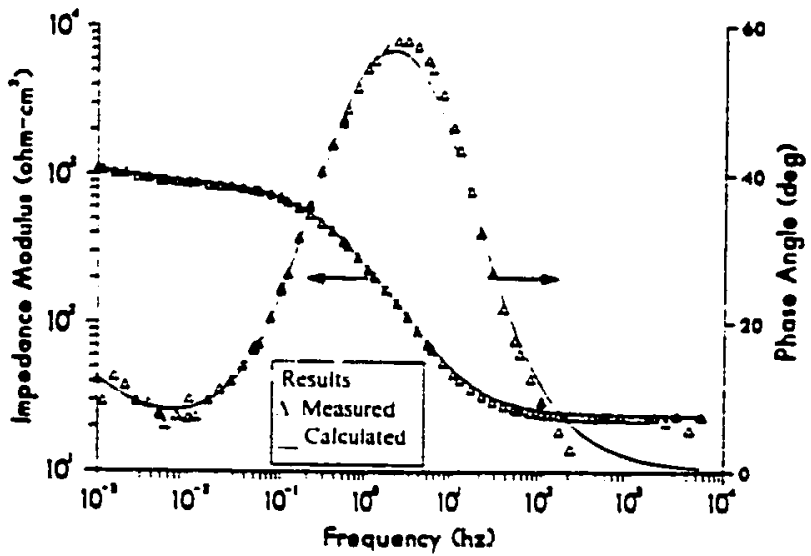

Figure 2.7. (a) Frequency response in the Nyquist format of carbon steel in neutral water at $32{ }^{\circ} \mathrm{C}$ at stagnant condition, (b) same frequency response in the Bode format (Silverman et al., 1987). 
Figure 2.8 shows the Nyquist and Bode plots for a solution with inhibitor zinc and chromate ion. According to the authors a circuit with two CPE was ideal in order to predict this type of response. The two maxima in the phase angle diagram of the Bode plot show the possibility of two CPE. The authors obtained the polarization resistance (Rp) from the low frequency region of the Nyquist plot. They used this Rp along with the Tafel constant to measure the corrosion rate.

(a)

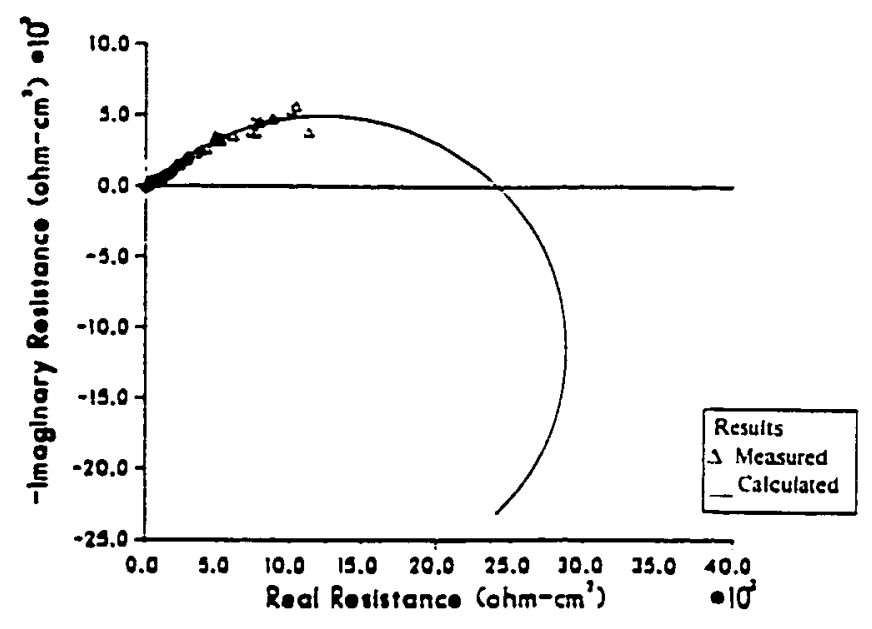

(b)

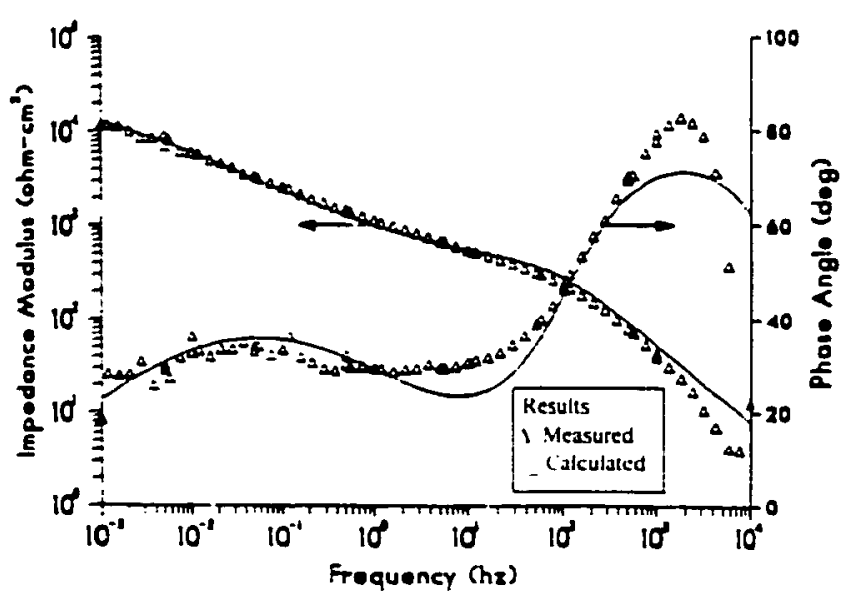

Figure 2.8. (a) Frequency response in the Nyquist format of carbon steel in water at with $25 \mathrm{ppm}$ chromate and $10 \mathrm{ppm}$ zinc ion at $32{ }^{\circ} \mathrm{C}$, (b) same frequency response in the Bode format (Silverman et al., 1987). 
Silverman et al. (1987) found the polarization resistance from the low frequency region of the Nyquist plot and calculated the corrosion current from the polarization resistance. The low frequency region is in the high real resistance side of the Nyquist plot. They used the slopes of the Tafel plot to determine the value of B (Equation 2.3) and polarization resistance (Rp) along with B to determine corrosion current (Equation 2.4). The corrosion rate is determined using Equation 2.5.

$$
\begin{aligned}
& \mathrm{B}=\left(\mathrm{ba}^{*} \mathrm{bc}\right) /(\mathrm{ba}+\mathrm{bc}) \\
& \mathrm{I}=\mathrm{B} /(2.303) \mathrm{Rp} \\
& \rho=\mathrm{i}^{*} \mathrm{a} /\left(\mathrm{n}^{*} \mathrm{~F}\right) \\
& \mathrm{Rp}=\text { Polarization resistance from low frequency side of Nyquist plot } \\
& \text { ba. bc= Anodic and cathodic slope from Tafel plot } \\
& \mathrm{I}=\text { Corrosion current }(\mu \mathrm{A}) . \\
& \mathrm{a}=\text { Atomic weight of electrode material } \\
& \rho=\text { Corrosion rate }\left(\mathrm{mg} / \mathrm{dm}^{2} \text { day }\right) \\
& \mathrm{i}=\text { current density }\left(\mu \mathrm{A} / \mathrm{cm}^{2}\right)=\mathrm{V} / \mathrm{Area} \text { of electrode } \\
& \mathrm{n}=\text { number of equivalent exchanged } \\
& \mathrm{F}=\text { Faradays constant }(96.500 \text { coulombs/equivalent })
\end{aligned}
$$

The anodic and cathodic reactions for iron dissolution are as follows -

$$
\begin{aligned}
& \mathrm{Fe} \longrightarrow \mathrm{Fe}^{2+}+2 \mathrm{e} \text { anodic reaction } \\
& 2 \mathrm{H}^{+}+2 \mathrm{e} \longrightarrow \mathrm{H}_{2} \text { cathodic reaction }
\end{aligned}
$$

The value of $n$ depends on the charge transfer at the anode. 
The values for the constant phase element parameters and the corrosion rate are given in Table 2.1.

Table 2.1. Circuit parameters and corrosion rates from impedance data for SS 316 in dilute organic acid solution (Adapted from Silverman et al., 1987).

\begin{tabular}{|l|l|}
\hline Polarization resistance & $8.9^{*} \mathrm{E} 5\left(\mathrm{ohm}-\mathrm{cm}^{2}\right)$ \\
\hline Time constant & $1.2^{*} \mathrm{E} 2(\mathrm{~s})$ \\
\hline Depression below axis & .82 \\
\hline Pseudocapacitance & $1.3^{*} \mathrm{E}-4\left(\mathrm{farad} / \mathrm{cm}^{2}\right)$ \\
\hline Corrosion from impedance data & $8.0^{*} \mathrm{E}-4(\mathrm{~mm} /$ year $)$ \\
\hline Corrosion from mass loss method & $5.0^{*} \mathrm{E}-3(\mathrm{~mm} /$ year $)$ \\
\hline
\end{tabular}

Calculation of corrosion rate required a $\mathrm{B}$ value from the Tafel plot and polarization resistance from either polarization or EIS. The B value was calculated by polarization method from the Tafel plot. The authors did mention that the DC current measurement was above the reliability limit of the potentiostat and may have resulted in overestimation. In the case of mass loss method the balance was at its lowest limit. The result can be considered a close estimate. 
The polarization resistance values and the corrosion rates for Short exposure are shown in Table 2.2. The higher the $\mathrm{Rp}$ value the lower the corrosion rate. The data in Table 2.2 reflect that.

Table 2.2. Estimates of resistance and corrosion rate for SS 316 and inhibitor (Adapted from Silverman et al., 1987).

\begin{tabular}{|l|c|c|}
\hline $\begin{array}{l}\text { Environment } \\
\text { (exposure in minute) }\end{array}$ & $\begin{array}{l}\text { Resistance } \\
\left(\mathrm{ohm}-\mathrm{cm}^{2}\right)\end{array}$ & $\begin{array}{l}\text { Corrosion rate } \\
\text { (mm/year) }\end{array}$ \\
\hline $\begin{array}{l}3 \text { wt \% caustic } \\
(15 \text { to } 30)\end{array}$ & $4.8 \mathrm{E} 4$ & $3.4 \mathrm{E}-2$ \\
\hline $\begin{array}{l}3 w \mathrm{wt} \text { caustic } \\
(45 \text { to } 60)\end{array}$ & $8.0 \mathrm{E} 4$ & $1.4 \mathrm{E}-2$ \\
\hline $\begin{array}{l}3 \mathrm{wt} \% \text { phosphoric acid } \\
(15 \text { to } 30)\end{array}$ & $1.5 \mathrm{E} 5$ & $8.1 \mathrm{E}-3$ \\
\hline $\begin{array}{l}3 w t \% \text { phosphoric acid } \\
(45 \text { to } 60)\end{array}$ & $1.1 \mathrm{E} 5$ & $1.0 \mathrm{E}-2$ \\
\hline
\end{tabular}

The corrosion rates from the mass loss method and impedance method (i.e. using Rp values) are listed in Table 2.3 for carbon steel in water.

Table 2.3. Corrosion rates of carbon steel and water (Adapted from Silverman et al., 1987).

\begin{tabular}{|l|c|c|}
\hline & \multicolumn{2}{|c|}{ Corrosion rate (mm/year) } \\
\hline Inhibitor & Mass loss method & Impedance method \\
\hline None & 0.25 & 0.46 \\
\hline Zinc ion and chromate ion & 0.010 & 0.0025 \\
\hline
\end{tabular}

From Table 2.3 it can be said that measuring techniques need to be improved to estimate corrosion rate otherwise the impedance calculation can be an order of magnitude off. Again the measurement can be off also if the mass loss method has high measurement error. 
The research by Silverman et al. (1987) was designed to prove that EIS coupled with polarization measurement can give comparable corrosion rate to the weight loss method. They used EIS coupled with polarization curve to determine corrosion rate electrochemically as opposed to weight loss method. In this article the authors mentioned four different circuit models which they considered for simulating to experimental EIS. They could use only two of the models for determining corrosion rate. For the thesis research proposed here, the EIS method will be evaluated for in-situ monitoring. 


\subsection{Study of SS 304 in Pure Water by EIS}

The second article close to the thesis topic is by Mabuchi et al. (1994). The researchers studied the corrosion behavior of type 304 stainless steel with electrochemical impedance spectroscopy in high temperature pure water. Parallel experiments on platinum and carbon steel were also conducted under three levels of dissolved oxygen for comparison. Figure 2.6 shows the Nyquist plot for the three samples over 150 hours under the three conditions.

The Nyquist plot for stainless steel sample under the low dissolved oxygen condition $(<5$ ppb) showed only redox reaction at high temperature. The redox reaction as explained by the researchers is the formation of oxygen and hydrogen molesules from an ionic state. Under this condition the beginning of a second semicircle is observed in the Nyquist plot for both SS304 and carbon steel. No low frequency semicircle was observed. Under low dissolved oxygen concentration, the authors inferred only impedance of $\mathrm{H}_{2} \mathrm{O} / \mathrm{H}_{2}$ redox reaction, and stated that redox reaction is independent of corrosion reaction and has high reversibility. They could not obtain pure charge transfer resistance of the corrosion process of Type 304 stainless steel and carbon steel in high temperature water at a low dissolved oxygen level. 
(a)
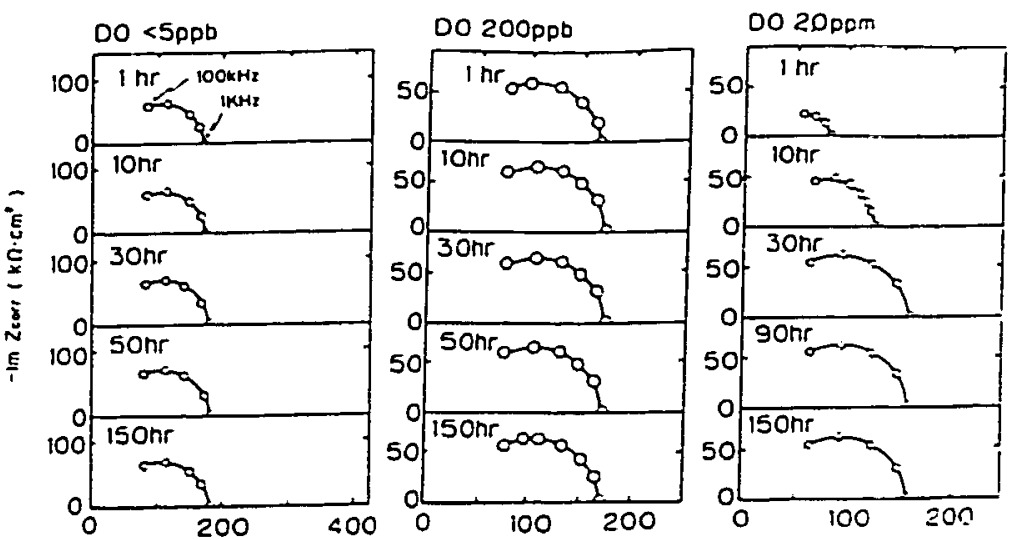

(b)
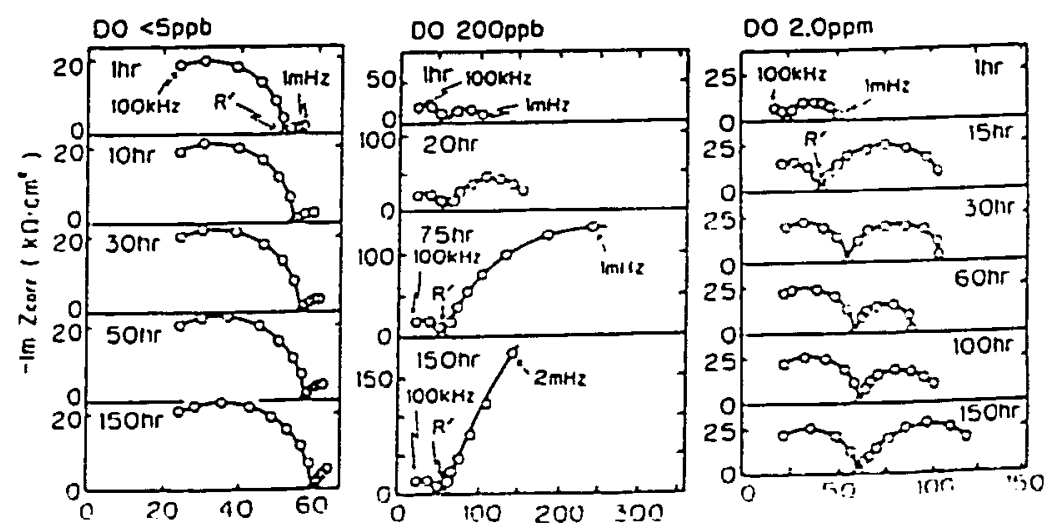

(c)
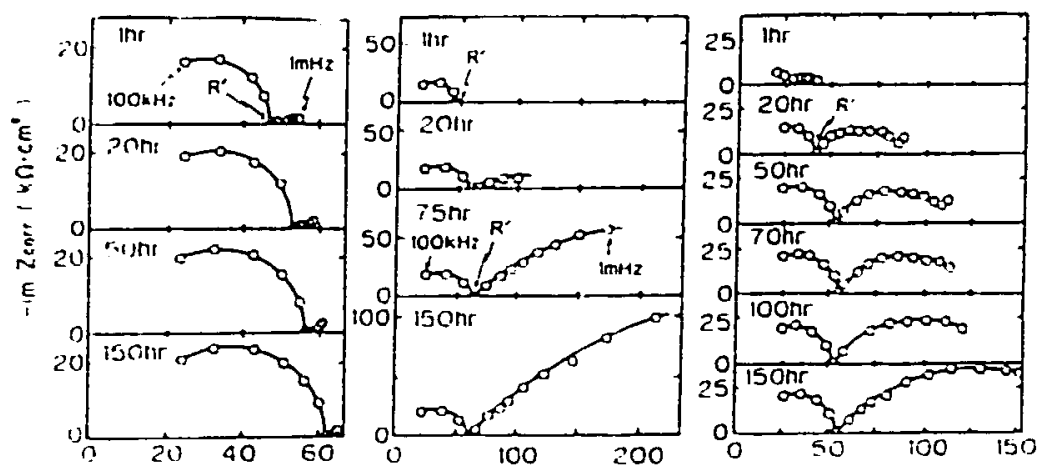

Re Zcorr ( $\left.\mathrm{kn} \cdot \mathrm{cm}^{\prime}\right)$

Figure 2.9. Nyquist plot of measured impedance spectra as function of time for metals exposed to a high temperature water with various concentration of dissolved oxygen(DO), (a) for platinum, (b) for SS 304 and (c) for carbon steel (Mabuchi et al., 1994). 
At $200 \mathrm{ppb}$ oxygen concentration initially the impedance diagram for SS 304 and carbon steel are found to be composed of two semicircles. The low frequency semicircle gradually changes into a Warburg diffusion line. The authors explained that the diffusion impedance is developed due to an oxygen vacuum in the film at the low dissolved oxygen situation.

At a high dissolved oxygen condition the oxygen vacuum is not there and Warburg diffusion line changes back to a semicircle. The depressed semicircle predicts a corrosion reaction control region for both SS304 and carbon steel. Therefore, the carbon steel diffusion control of oxygen sets in when the oxide film grows thicker. The 150 hour high oxygen condition Nyquist plot shows that for the carbon steel sample.

They concluded that the impedance response at high frequency is that of $\mathrm{H}_{2} \mathrm{O} / \mathrm{O}_{2}$ redox reaction and at low frequency is that of a corrosion reaction correlated to oxide film growth. Impedance frequency dispersion of type 304 stainless steel and of carbon steel were divided mainly into redox reactions, diffusion of oxygen bearing ions through oxide films, and dissolution of iron by these researchers. An equivalent circuit shown in Figure 2.10 was proposed as an oxygen diffusion model for film growth. 


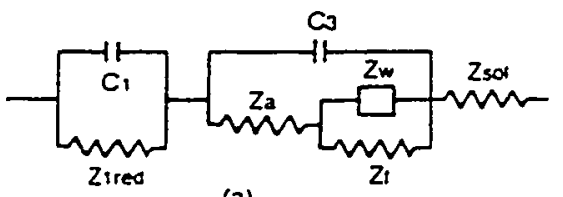

(a)

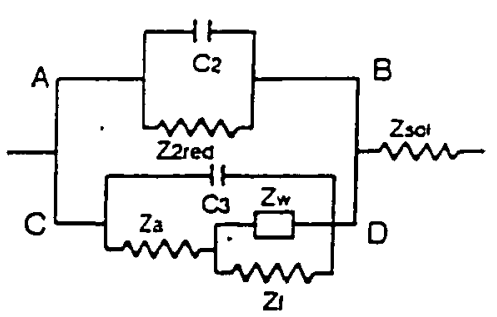

(b)

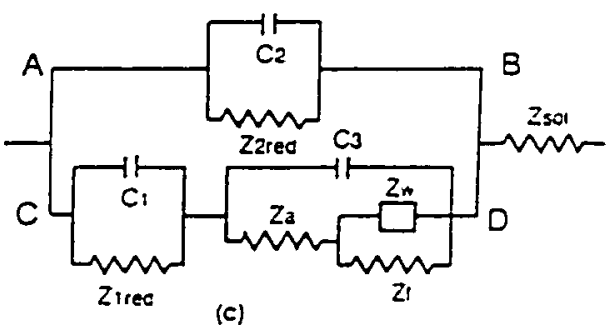

$Z_{1, e d}$ and $Z_{2, e s}$ : Resistanes of redox rene. tion. $\mathrm{H}_{2} \mathrm{O}, \mathrm{O}$, and $11, \mathrm{O} / 1 !$ respectively.

2. : Resistance of irondissolution.

$Z_{1} \quad$ : Resistances of oxide film.

Z. :Warburg impedaner $Z_{-}=Z_{0}(1-j) /(2 \pi)^{\prime} \cdot z$

2. : Warburg impedance coeflicient

$C_{1}$ and $C_{2}$ : Capacitances of the oxide film/ solution interface including dou. ble layer.

C. : Capacitance of the electrode/so. lution interface.

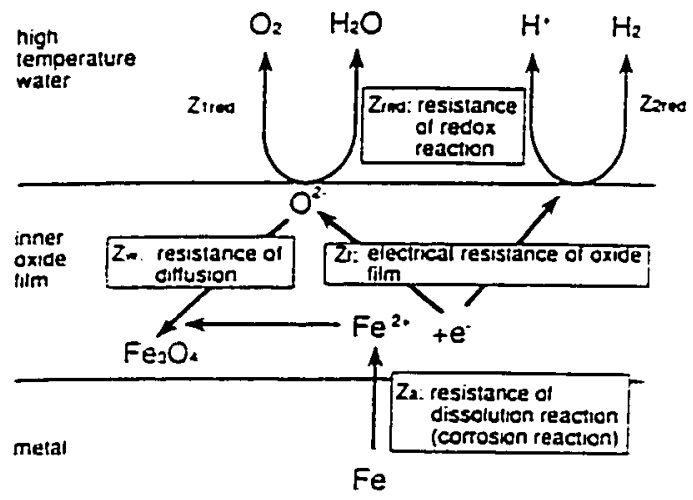

(d)

Figure 2.10. (a) and (b) Components of circuit model for SS304 and carbon steel in high temperature water, (c) complete circuit model and (d) physical corrosion model for SS 304 and carbon steel (Mabuchi et al., 1994). 


\subsection{Study of SS 446 in Borate/boric Acid Buffer by EIS}

In the study of passive film formation by Capobianco et al. (1993), the authors have found that when treated with borate/boric acid buffer the 446 stainless steel forms a two layer passive film, a porous top later and an impervious interfacial layer. They confirmed this by removing the porous top layer by irradiation and measuring impedance of the system before and after using EIS technique. This study was interesting from an equivalent circuit modeling perspective since the researchers investigated by developing equivalent circuit models using EIS. They studied the same sample under four different condition and gave four different models and compared the fit of the data for each sample condition with all models. The sample conditions were (1) bare metal, (2) anodically passivated, (3) galvanostatically reduced and (4) gamma-ray irradiated. Figure 2.11 shows the schematic of the physical models i, ii. iii and iv. The corresponding proposed circuit model and the chi-square value for the different simulated models for the samples are also shown in this figure. Although chi-square value conformed to more than one circuit model, physical condition was considered to develop the final model. 


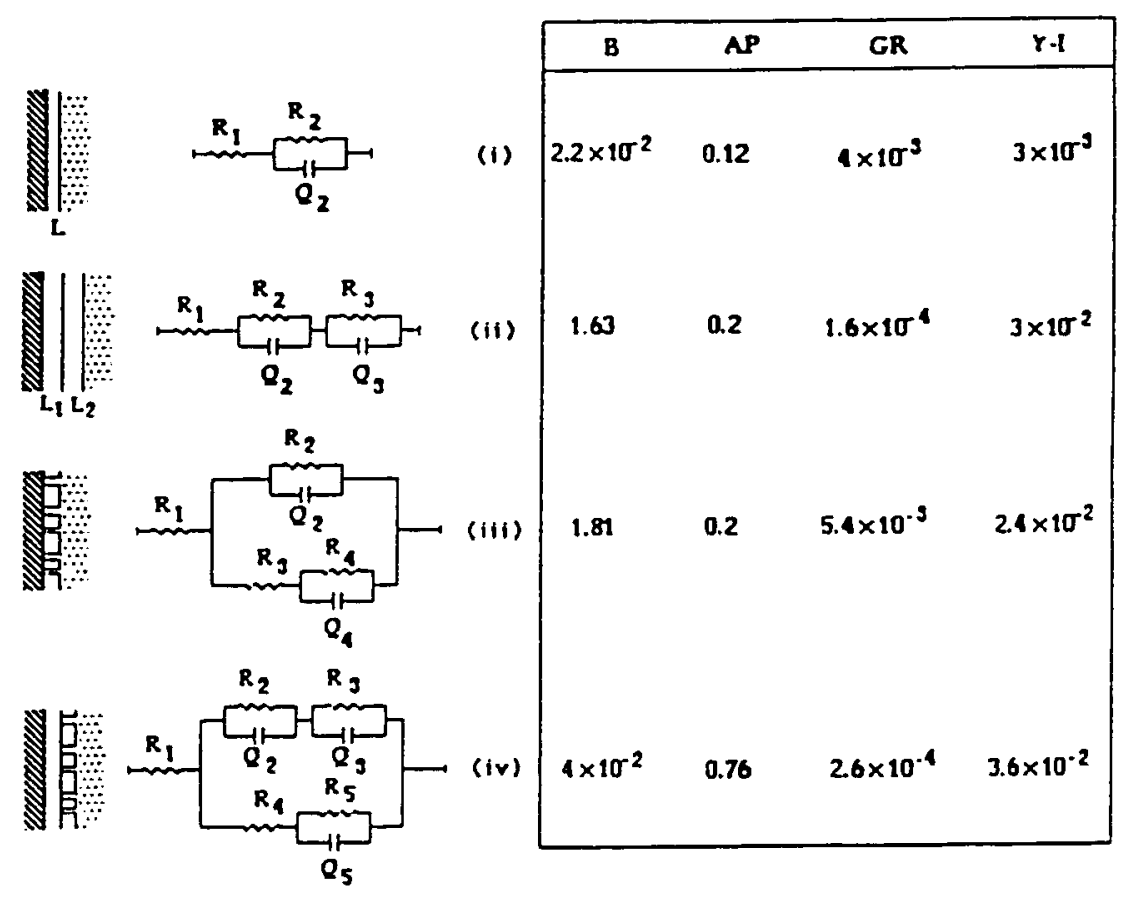

Figure 2.11. Proposed physical models, equivalent circuits and $\chi^{2}$ values for the four types of samples (Capobianco et al., 1993).

The initial condition is the bare sample. The AP sample is the passivated sample. The GR sample and the gamma ray irradiated samples are obtained by stripping some passive film. They found that the AP sample best fits model number (i). The capacitors shown in Figure 2.11 are CPEs. The beta value for the CPE was 0.88 for this sample. The GR sample fitted both model (i) and (ii). The researchers explained that model (i) predicts quasi capacitor structure of the film and model (ii) predicts heterogeneous structure. The authors looked at the phase angle plots in their article for checking the circuit fitting. 
Superimposition of phase angle in Bode plot showed that model (ii) is fits better. For the gamma ray irradiated $(\gamma-\mathrm{I})$ sample optimum fits were obtained for models (i), (ii) and (iii). The authors obtained negative values for beta component for model (iii), hence disregarded this model. From the impedance measurement they came to the conclusion that a compact film is formed by anodically passivating SS 446 in borate/boric solution, a coarse spongy structure when the AP sample is galvanostatically reduced and a thin compact structure when the GR sample is gamma ray irradiated.

\subsection{Copper and Tap Water Interface Investigated by EIS}

The study of corrosion of copper in neutral tap water using polarization and weight loss method was found to be under diffusion control by Feng et al. (1996). The anodic polarization curve was compared with weight loss method and according to the author the results agreed fairly well. Their system showed that polarization resistance increased over time and that anodic diffusion of copper ions in the oxide film controlled the overall corrosion rate. The diffusion phenomenon disappeared when they raised the $\mathrm{pH}$ from 5 to 7.8. Passivation occurred again at $\mathrm{pH}$ of 10 . The XPS result showed that the surface film contained small amount of cuprous oxide and hydroxide.

\subsection{Thesis Study}

Electrochemical impedance spectroscopy was carried out on steel and other metals by several researchers. The extensive study by Silverman et al. (1987) gives an understanding of various outcomes possible for different electrolytes, while that by Mabuchi et 
al. (1994) shows the effect of dissolved oxygen on SS304 in DI water by EIS. The article by Capobianco et al. (1993) depicts two possible layers on stainless steel 446 in DI water system. Feng et al. (1996) explores the DI water and copper system and defines an equivalent circuit model for copper corrosion.

These studies develop different equivalent circuit models to explain various corroding systems. This thesis research will focus on modeling the mechanism of SS 316 passivation in DI water at room temperature. The model will be an electrical circuit similar to the studies discussed in literature. The SS 316 and DI water system will be compared to SS 316 and various electrolyte systems for verification. Another aspect of this research is to evaluate whether this model may be used for monitoring corrosion. 


\section{CHAPTER 3. MATERIALS AND METHODS}

\subsection{Introduction}

The purpose of this study is to model, using an electrical circuit, the behavior of SS 316 in deionized water. The scope of the research is limited to the system at room temperature and atmospheric condition ( 1 atmosphere pressure and $21 \%$ oxygen). A full spectrum of electrical impedance from mega hertz to millihertz is used to help discover the corrosion mechanism between metal (SS 316) and the electrolyte (DI water). The result of this research will help to evaluate whether EIS can be used to monitor SS 316 corrosion in DI water.

\subsection{Hypothesis}

A passivation dissolution of chromium, iron and molybdenum was studied using Electron Spectroscopy for Chemical Analysis (ESCA) and $\gamma$-spectrometry by Hultauist et al. (1984). They found a chromium rich passive layer on the surface and a chromium depleted layer between the surface and the alloy. According to their finding, passive state corrosion occurs due to the selective dissolution of ferrous ions. The cumulative iron, chromium and molybdenum dissolution adapted from their article is shown in Table 3.1. 
Table 3.1. Accumulated amounts of chromium and molybdenum in the surface region measured by $\gamma$-spectrometry. (Adapted from Hultquist $e t$ al., 1984)

\begin{tabular}{|c|c|c|c|}
\hline Time(h) & Chromium $\left(\mu \mathrm{g} / \mathrm{cm}^{2}\right)$ & Iron $\left(\mu \mathrm{g} / \mathrm{cm}^{2}\right)$ & Molybdenum $\left(\mu \mathrm{g} / \mathrm{cm}^{2}\right)$ \\
\hline 24.5 & 0.0168 & 0.474 & 0.0021 \\
\hline 72.5 & 0.0198 & 0.578 & 0.0023 \\
\hline 96.5 & 0.0208 & 0.631 & 0.0027 \\
\hline
\end{tabular}

The iron dissolution between 24.5 hour and 72.5 hour is $.00216 \mu \mathrm{g} / \mathrm{cm}^{2} \mathrm{~h}$ and that between 72.5 hours and 96.5 hours is $0.00221 \mu \mathrm{g} / \mathrm{cm}^{2} \mathrm{~h}$.

From the data in the above table it can be said for the SS 316 and DI water that a maximum two physical layers are expected to be detected by EIS at the interface. the charge transfer layer at the interface for corrosion and a changing passive layer. These layers in electrical analysis may show constant phase element behavior. diffusive behavior, or inductive behavior. The EIS responses for possible four equivalent circuit models are shown in Figure 3.1. to 3.4. A two phase model can be obtained at best if all of the physical layers are detected by the EIS method. The two layers are the passive layer and the salt enriched layer next to the passive layer in the electrolyte. The chromium depleted layer may not be detectable as it is in the metal rich. conducting material. The physical interface can be expressed in an electrical equivalent by the circuit models shown in Figure 3.1(a), 3.2(a). 3.3(a) and 3.4(a). The corresponding expected EIS responses. in the Nyquist plot for these electrical circuits are shown in Figures 3.1(b). 
3.2(b), 3.3(b) and 3.4(b) respectively. The imaginary part of impedance versus the real part is plotted in the Nyquist plot.

The Nyquist plot of an R-C circuit, in which a resistor and a capacitor are connected in parallel, normally exhibits a semicircular behavior but a constant phase element shows a depressed semicircular behavior. The equivalent circuit and the corresponding Nyquist plot are shown in Figure 3.1 for one constant phase element in series with a resistance.

Simply it can be said if a capacitor $(C)$ and a resistor $(R p)$ were connected in parallel, the equivalent impedance $(Z)$ of this circuit would be as shown in Equation 3.1 .

$$
\begin{aligned}
& Z=R p(1 / j \omega C) /\{R p+(1 / j \omega C)\} \quad \text { or } \\
& Z=(R p) /(1+j \omega R p C)
\end{aligned}
$$

where $\omega=2 \pi f$ and $f=$ frequency.

A constant phase element has two parts connected in parallel. A resistive part (Rp) and a capacitive part (C). The modified impedance is as follows where $\tau$ is the time constant and equals to $\mathrm{RpC}$ and $\beta$ is the fudge factor to account for depressed semicircular impedance response. Modification was made to fit the electrochemical phase behavior as opposed to the solid state capacitor behavior, which is a semicircular response. The CPE is modified by raising the $\mathrm{R}-\mathrm{C}$ element of the impedance of the equivalent circuit to a power. The impedance for $\mathrm{CPE}$ in series with a resistor $\mathrm{Rs}$ is, 


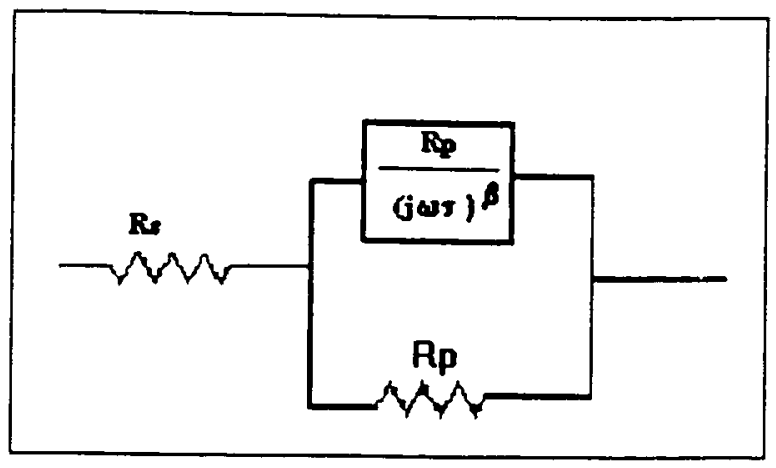

(a)

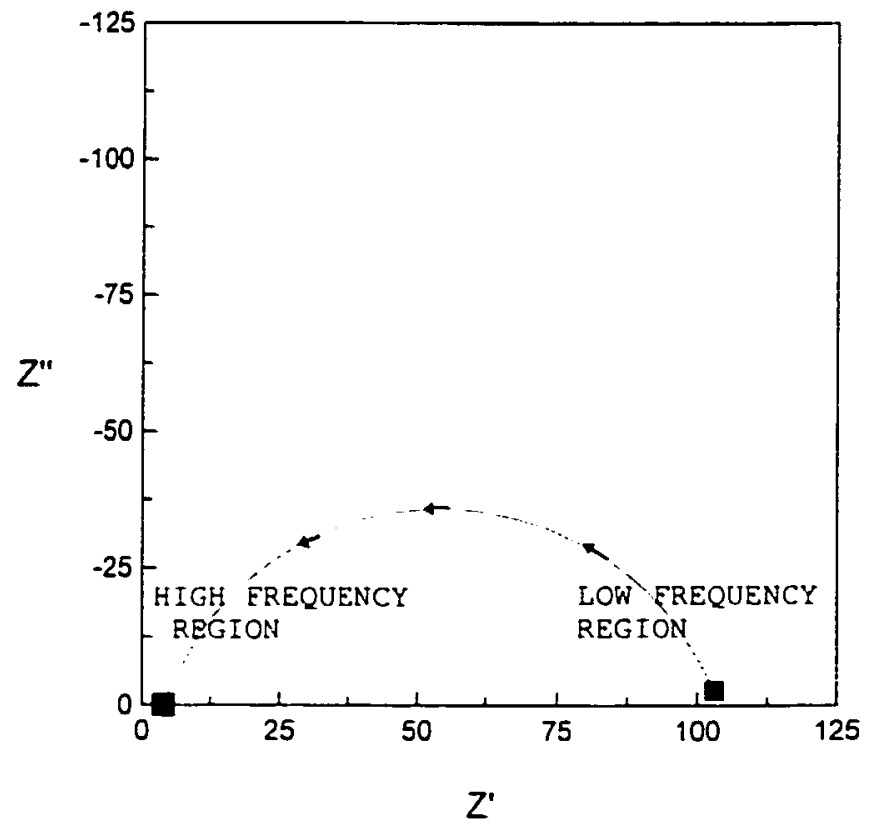

(b)

Figure 3.1. (a) An electrical circuit with one constant phase element in series with a resistor, (b) the corresponding Nyquist plot. 
The impedance response can be analyzed using the method suggested by Kendig $e t$ al., 1983. This method employed fitting impedance response in a complex plane (Nyquist plot) to a semicircular geometrical curve. In their article the authors showed how the impedance expression for a CPE, can be fitted to an Equation of a depressed semicircle. The derivations for the Equations of circles in the Nyquist form from the impedance Equations 3.1 and 3.2 are shown in Appendix A.

The impedance expression for Equation 3.2 when reduced to the Equation of a circle becomes

$$
\left[Z^{\prime}-(2 R s+R p) / 2\right]^{2}+\left[Z^{\prime \prime}+0.5 R p \cot (\pi \beta / 2)\right]^{2}=[0.5 R p / \sin (\pi \beta / 2)]^{2}
$$

In Equation $3.3, Z^{\prime}$ is the real part of the impedance, $Z^{\prime \prime}$ is the imaginary part, $\tau$ is the relaxation time constant, and $\beta$ is the power to which the imaginary component is raised to in order to fit the depressed semicircular curve to a circle. $Z^{\prime}$ versus $Z^{\prime \prime}$ plot is the Nyquist plot in this thesis.

The second circuit model consists of two CPEs, one nested in another. The impedance for this circuit is given in as follows

$$
Z=R s+\left[\left\{R p_{2}+R p_{1} /\left(1+\left(j \omega \tau_{1}\right)^{\beta 2}\right\} /\left\{\left(j \omega \tau_{2}\right)^{\beta 1}\right]\right.\right.
$$

The corresponding Nyquist plot shows two semicircles as shown in Figure 3.2.(b). 


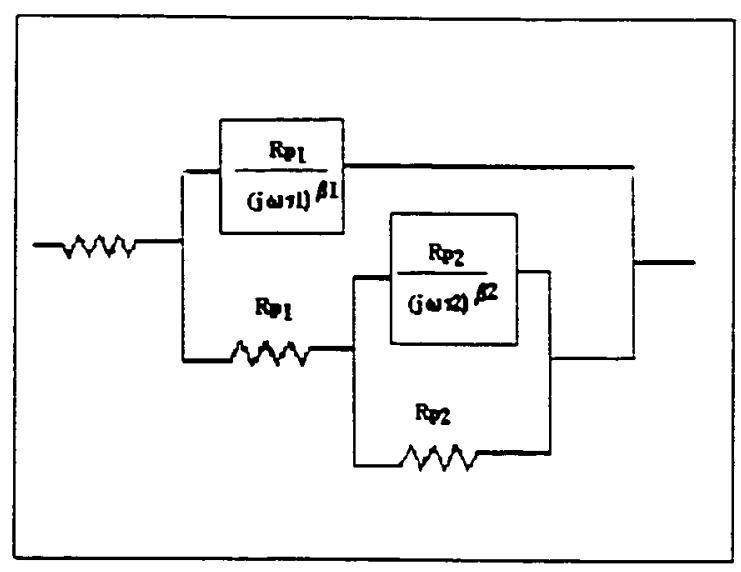

(a)

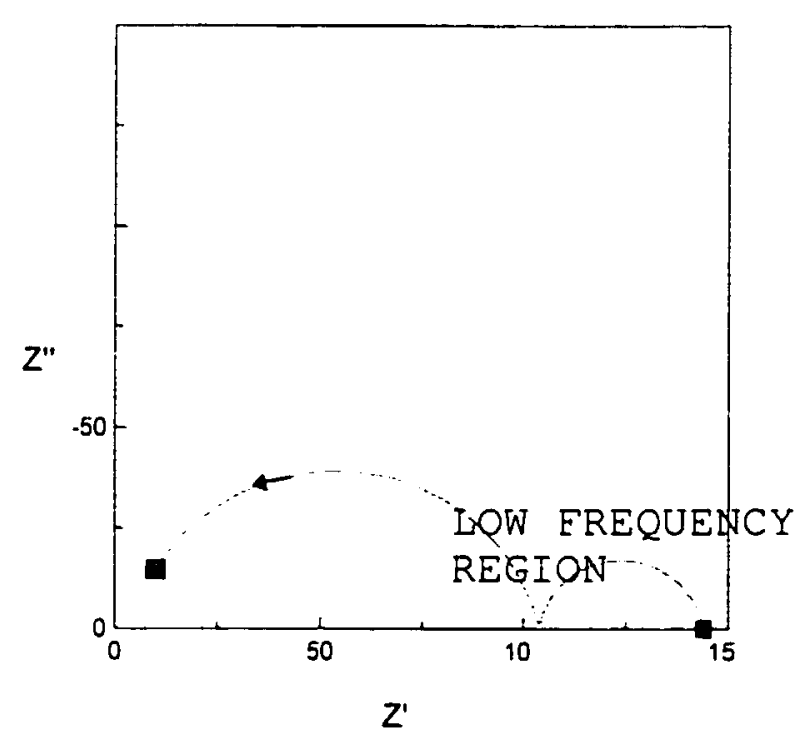

(b)

Figure 3.2. (a) Equivalent circuit with two constant phase elements in series with a resistor, and (b) the corresponding Nyquist plot. 
The third circuit model consists of a CPE in parallel with a diffusion element. This circuit is also called Randles equivalent circuit where Randles circuit has a diffusion element in series with the resistance of a CPE. The impedance for this circuit is given by

$$
Z=R s+\left(R p+Z_{\text {diff }} /\left(1+(j \omega \tau)^{\beta}\right.\right.
$$

The impedance for diffusion by Randle is given in Equation 3.6.

$$
Z_{\text {diff }}=\sigma_{\text {diff }} \omega^{0.5}+j \sigma_{\text {diff }} \omega^{0.5}
$$

where $\sigma_{\text {diff }}=$ Warburg diffusion coefficient

In Figure 3.3, one can see the semicircular plot at high frequency region depicting a CPE and a straight line plot in the lower frequency region depicting a diffusion region.

The fourth circuit model consists of a capacitor in parallel with an inductor and a resistor. This fourth model was developed by D. D. Macdonald (1978) for pseudoinductance behavior in impedance response. The Nyquist plot shows a semicircle in the first quadrant and another in the fourth quadrant (Fig. 3.4), which is typical for a pseudoinductance behavior. The semicircle in the first quadrant is mainly for the capacitor, while that in the fourth quadrant is due to the response of the inductive element at low frequency. The impedance for this circuit is given by

$$
Z=Z^{\prime}+j Z^{\prime \prime}
$$

where.

$$
\begin{aligned}
& Z^{\prime}=R s+\left[\left\{r^{2} R p+R p^{2} r+\omega^{2} L^{2} R p\right\} l^{\prime}\left[\left\{r+R p-\omega^{2} L R p C\right\}^{2}+\omega^{2}\{L+r R p C\}\right]\right. \\
& \left.Z^{\prime \prime}=\omega\left\{R p^{2} r^{2} C-L R p^{2}+\omega^{2} L^{2} R p^{2} C\right\}\right] /\left[\left\{r+R p-\omega^{2} L R p C\right\}^{2}+\omega^{2}\{L+r R p C\}\right]
\end{aligned}
$$


$\mathrm{L}=$ Inductive element and

$r=$ Resistor in series with the inductive element 


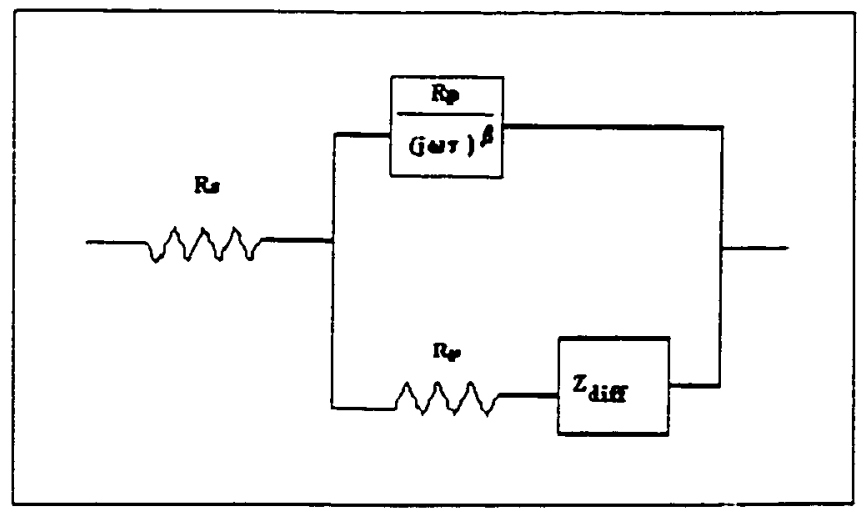

(a)

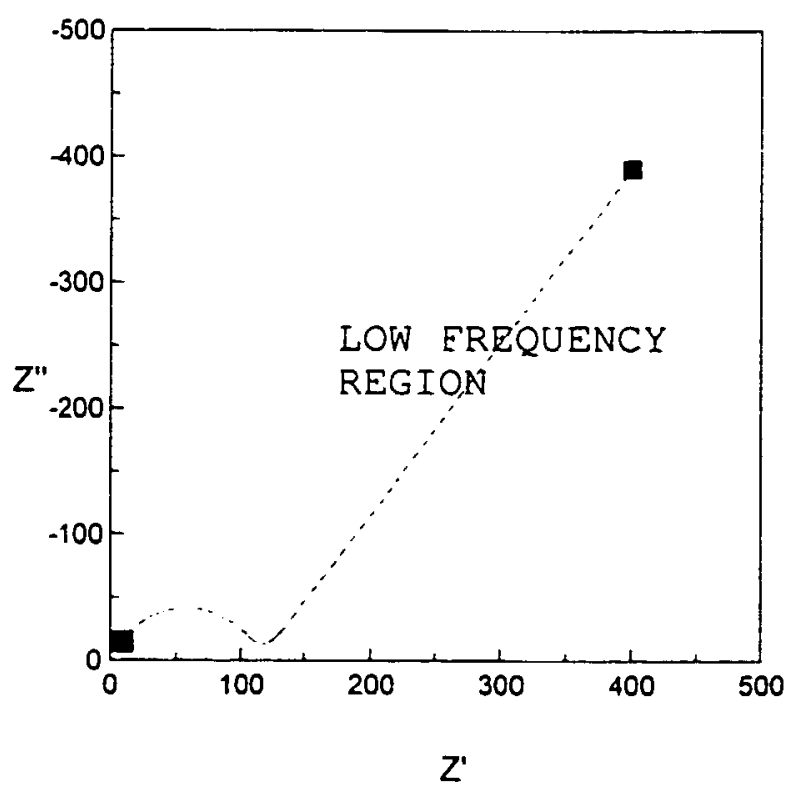

(b)

Figure 3.3. (a) An electrical equivalent circuit with a constant phase element and a diffusion element, (b) the corresponding Nyquist plot. 


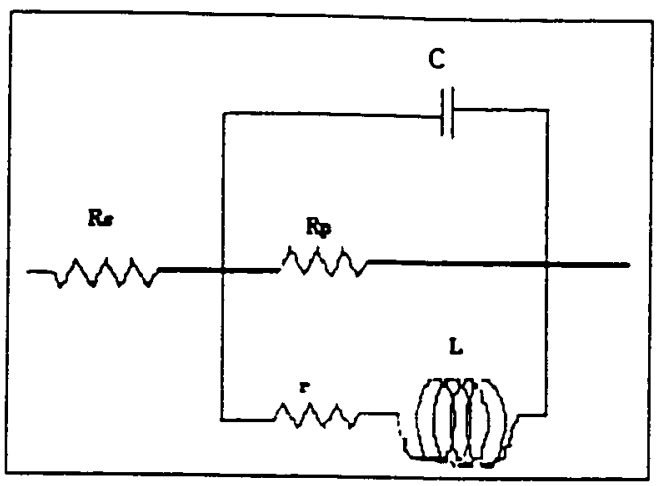

(a)

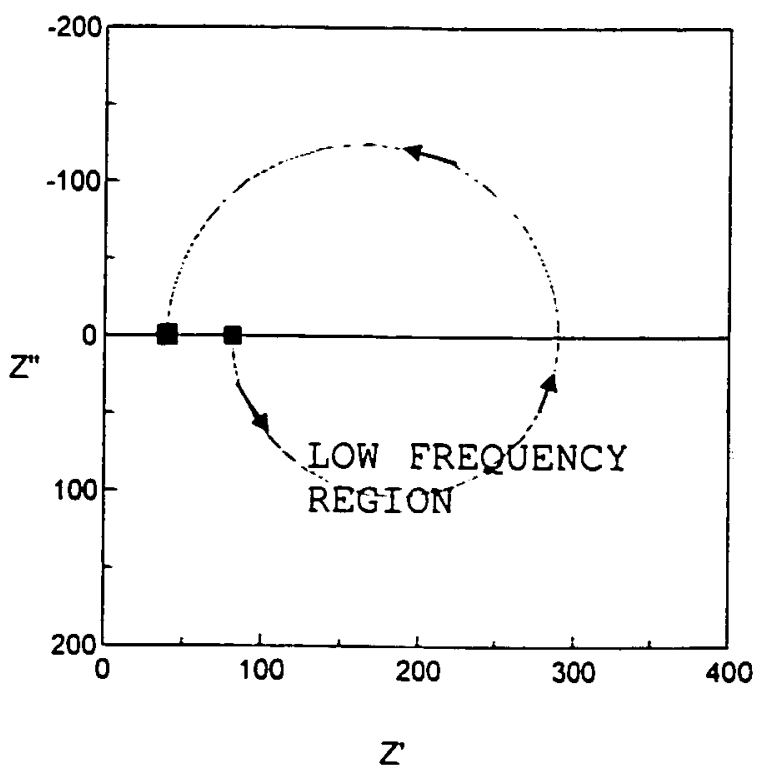

(b)

Figure 3.4. (a) An electrical circuit with inductance and capacitance (b) corresponding Nyquist plot. 


\subsection{Experimental Setup}

In order to obtain the impedance response from an interfacial system, typically a three electrode setup has been used by researchers (Mabuchi et al., 1994, Feng et al., 1996 and Silverman et al., 1987) as discussed in the literature section of this paper. In the three electrode set up measurements are taken with respect to the reference electrode used. For this thesis research a two electrode setup that excludes the reference electrode, which contains some salt solution, was chosen instead of a three electrode setup to avoid the contamination of the electrolyte by the reference electrode. For DI water, which gets contaminated easily, a three electrode setup is not ideal for in situ corrosion monitoring. Perhaps a two electrode setup that is able to evaluate the possibility of using a small steel probe to monitor the relative rate of corrosion can be developed for a corrosion sensor. EIS cannot be used to measure corrosion rate directly without coupling with DC polarization. DC polarization requires the use of a reference electrode. However the low frequency EIS data can be used to determine the polarization resistance and polarization resistance is inversely related to the corrosion rate. Therefore, from EIS, a relative measure of corrosion may be possible.

Both working and auxiliary electrodes were made of SS 316 to eliminate ambiguity. SS 316 plates with an area of $7 \mathrm{~cm} \times 7 \mathrm{~cm}$ were used as electrodes. An experimental cell (Fig. 3.5) was designed to take into consideration the low conductivity of deionized water. The electrode area was increased comparative to the distance between the electrodes. The face of the electrode plates was machined for some experiments and polished for others. The 
plates had a small extension to attach alligator clips. The cell consisted of two electrodes separated by a $U$-shaped Teflon sheet $0.6 \mathrm{~mm}$ thick and $1 \mathrm{~cm}$ wide. The assembly was held together by metal clips. Thick plexiglas separated the metal clip from the electrode plate. The plexiglas with the same dimension as the electrode plate helped in distributing the pressure of the clips evenly on the electrode. Teflon was chosen since it is a nonreacting insulator, which will not effect the assembly electrically or chemically. Electrolyte was pored in between the electrodes and was contained by the Teflon $U$ tube and electrodes. Pieces of Teflon tape were placed between the Teflon sheet and the electrode plate to prevent leakage. The area of the electrodes exposed to the electrolyte was $5 \mathrm{~cm} \times 5 \mathrm{~cm}$.

The cell was connected to a Solartron Electrochemical Interface 1287, which was then connected to a Solartron 1260 Impedance Gain Phase Analyzer (Fig. 3.6). The 1287 Interface controls the applied voltage as set by the computer and measures the current response. The function of the gain phase analyzer (GPA) is to analyze the voltage and current response at each frequency and send the information to the computer for storage. In this experiment the response was stored as real and imaginary parts of impedance (Appendix B). 


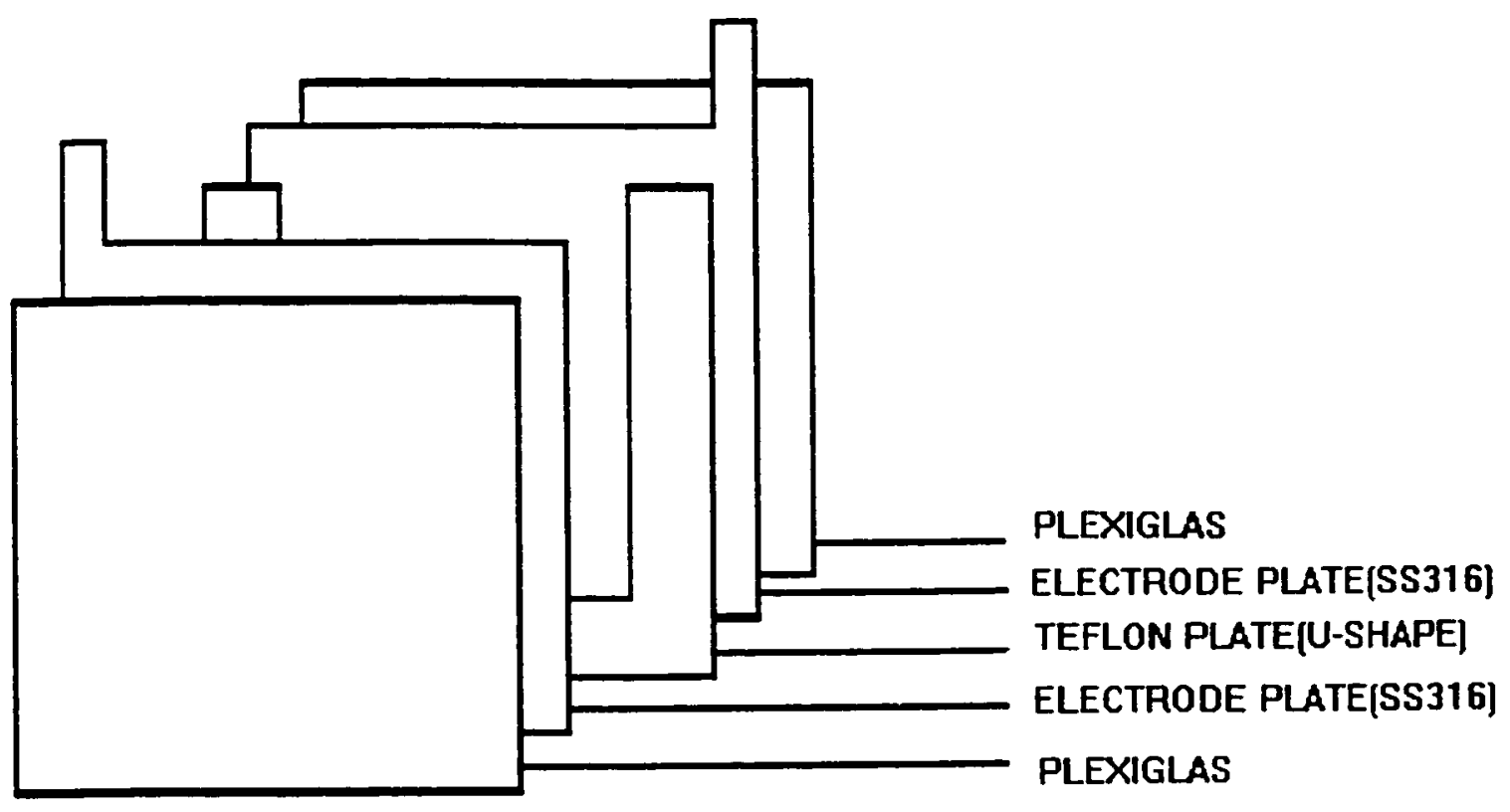

Figure 3.5. Schematic of two electrode cell assembly.

To facilitate the data analysis, the Electrochemistry software by Scribner and Associates was used. The software plotted the Nyquist and Bode plot for the experiments. For the semi-circular impedance plot on the complex plane, a curve fitting tool built in the software was used to determine the value of the charge transfer resistance (Rp) and the capacitor $(\mathrm{Cp})$. The $\mathrm{Rp}$ value was also measured from the graph to check correctness of the value. The depression angle also was obtained from the software. The $C p, \beta$ and $R p$ values were used to simulate the total circuit and the impedance response of this circuit for different frequencies was checked against the experimental response. 


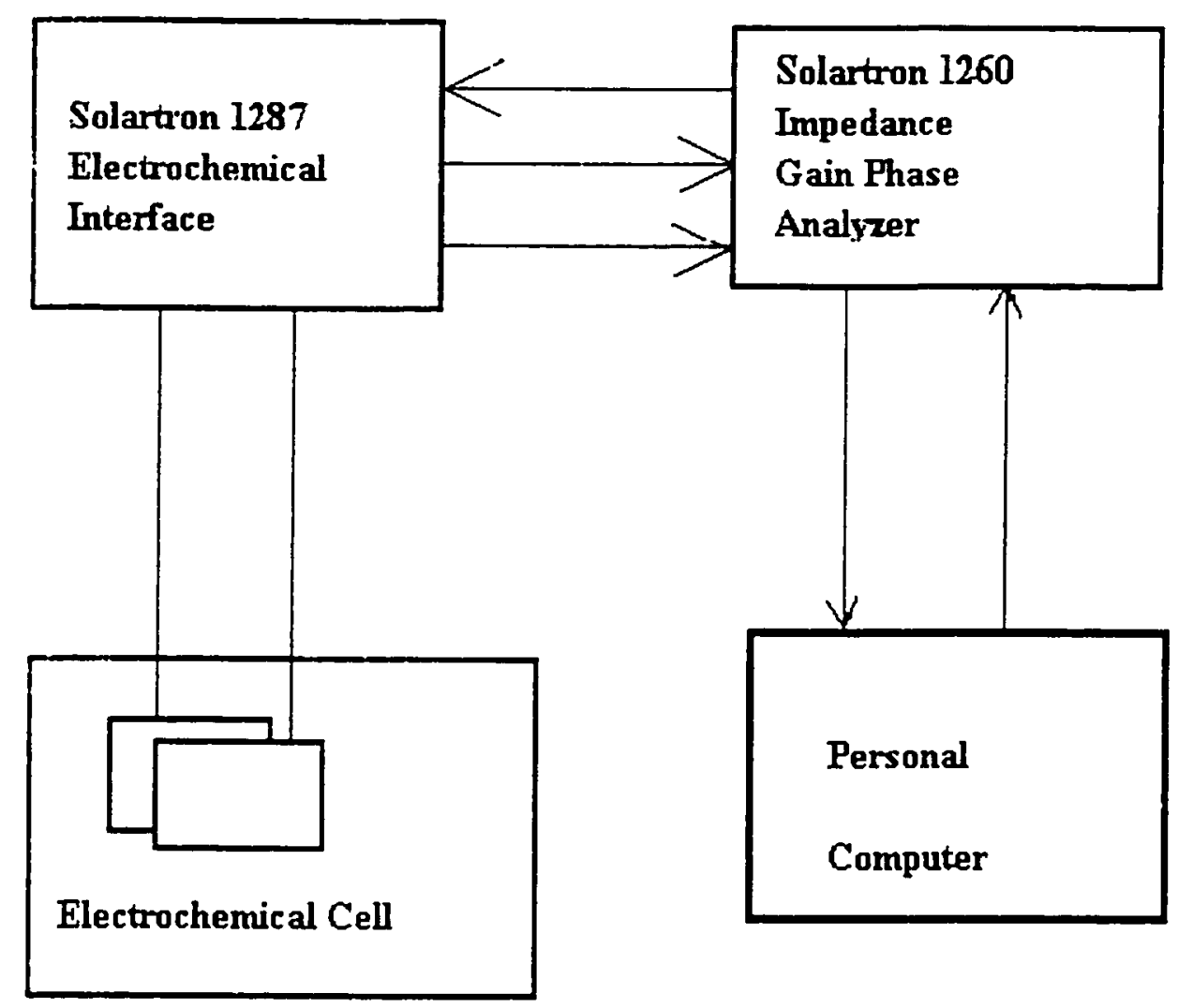

Figure 3.6. Schematic of the experimental setup used in the study.

The function of the GPA is to analyze the applied voltage and current response for each frequency and provide impedance data in the real and imaginary form. The applied voltage was controlled by the Solartron Electrochemical Interface. The PC terminal can talk to the control panel of the Interface, which allows the PC to control applied voltage through the Solartron Interface. 


\subsection{Experimental Procedure}

First an experiment was conducted to choose a suitable ac rms potential by applying different rms potentials using deionized water as electrolyte. Later experiments were conducted with two different sets of electrolytes, tap water and sodium chloride solution under this rms potential for comparison.

Potential determination: Impedance measurements were taken at 10,20 and $50 \mathrm{mV} \mathrm{rms}$ values for frequency range $3 \mathrm{mHz}-1.0 \mathrm{MHz}$. From this data a suitable potential was chosen to run further experiments. Equipment limitation was considered in choosing a suitable rms value. The lowest $\mathrm{rms}$ value that provided a reliable current measurement at low frequency was chosen as the working rms value for the experiment.

When the impedance response plot of DI water and SS 316 were not varying much, three sets of plate electrodes were prepared with three different electrolytes to test the relative difference of impedance plots. The electrolytes chosen were DI water, tap water and evaporated tap water. The evaporated tap water was obtained by reducing the volume of tap water to one tenth by evaporation and taking the residue. The experiment with these three electrolytes, was carried out for three days. Since the tap water composition was not known, impedance data was analyzed qualitatively based on the Nyquist and Bode plots.

It was decided then to prepare three sodium chloride solutions using reagent grade sodium chloride and DI water. Three chloride solutions with concentrations $1.0 \mathrm{~N} .0 .1 \mathrm{~N}$, 
$0.01 \mathrm{~N}$ and DI water were used as electrolytes for this experiment. Four electrode sets were prepared for these four electrolytes. This time the electrodes were polished with a series of graded sand paper, from coarse to fine, with the finest being 600 grit. After polishing, the electrodes were degreased by wiping with acetone. The impedance measurements were taken after two hours for the first set of electrodes. The cells were measured sequentially since impedance for only one cell could be measured at a time and each measurement took about an hour. The subsequent cells were measured at about an hour interval. Data from these measurements showed a trend in change.

The last experiment was conducted with DI water and $0.1 \mathrm{~N}$ sodium chloride solution. In this experiment the electrodes were polished at the experimental site and the experiments were run right after polishing. After polishing it took about 10 minutes to assemble the cell and the time for measuring was about five minutes. Fewer number of data were taken over a wide range during this experiment and several runs were made back to back. These data were used to model the SS 316-DI water passivation mechanism. Since DI water was the electrolyte of investigation, DI water and one of the three salt solutions were used in the short run. 


\subsection{Determining the Components of the Equivalent Circuits}

When the Nyquist plot fits a depressed semicircle, it is assumed that the depressed semicircle fits a CPE. The equation of a plot for the equivalent circuit with one CPE (Fig. 3.1) in series with a resistor is

$$
\left[Z^{\prime}-(2 R s+R p) / 2\right]^{2}+\left[Z^{\prime \prime}+0.5 R p \cot (\pi \beta / 2)\right]^{2}=[0.5 \mathrm{Rp} / \sin (\pi \beta / 2)]^{2}
$$

From the Equation 3.3 we can say that it is an equation of the circle with Xo, Yo as coordinates for the center of the circle and Ro, its radius. These are given as

$$
\begin{aligned}
& X_{0}=(2 R s+R p) / 2 \\
& Y_{0}=-0.5 R p \cot (\pi \beta / 2) \\
& R_{0}=0.5 \mathrm{Rp} / \sin (\pi \beta / 2)
\end{aligned}
$$

In order to fit the experimental data to the above equation, a least square fit is used. The sum of the residual square of error over $\mathrm{n}$ data point can be calculated by

$$
\Delta Z=\sum_{i=1}^{n}\left(\Delta Z_{i}^{\prime 2}+\Delta Z_{i}^{\prime 2}\right)
$$

where each point has the real and imaginary components. Subscript $i$ is used to indicate impedance for a frequency (Kendig et al., 1983). These components are given by

$$
\begin{aligned}
& \Delta Z_{i}^{\prime}=Z_{i}^{\prime}-X o-\operatorname{Ro}\left(Z_{i}^{\prime}-X o\right) /\left[\left(Z_{i}^{\prime}-X o\right)^{2}+\left(Z_{i}^{\prime \prime}-Y_{0}\right)^{2}\right]^{1 / 2} \\
& \Delta Z_{i}^{\prime \prime}=Z_{i}^{\prime \prime}-Y o-\operatorname{Ro}\left(Z_{i}^{\prime \prime}-Y o\right) /\left[\left(Z_{i}^{\prime}-X o\right)^{2}+\left(Z_{i}^{\prime \prime}-Y o\right)^{2}\right]^{1 / 2}
\end{aligned}
$$

In order to find the values of Xo, Yo and Ro, the sum of the residual error $\Delta Z$ must be minimized. i.e.

$$
\partial \Delta Z / \partial X_{0}=\partial \Delta Z / \partial Y_{0}=\partial \Delta Z / \partial R_{0}=0
$$


The set of equations developed from Equation 3.14 have summation terms and cannot be solved algebraically. An iterative method like Newton-Raphson method is employed to solve these equations for the values of Xo, Yo and Ro.

After finding $X_{o}$, Yo and Ro, Rp can be found. $R p$ is the chord lying on the $Z_{i}^{\prime}$-axis of the Nyquist plot. Two values for $Z_{i}^{\prime}$ will be found when $Z_{i}^{\prime \prime}$ is substituted by zero in a Equation of the circle represented by Xo, Yo and Ro. The difference between these two values of $Z_{i}^{\prime}$ will give the value of $R p$. Equations 3.15 and 3.16 result from Equations 3.10 and 3.12. Using Equations 3.15 and 3.16, the value of Rs and $\beta$ can be calculated as

$$
\begin{aligned}
& R s=(2 X o-R p) / 2 \\
& \beta=\left[2 \sin ^{-1}(0.5 \mathrm{Rp} / \mathrm{Ro})\right] / \pi
\end{aligned}
$$

Once the curve is fitted, the relaxation time constant $\tau$ value can be found from any point by using the equation (see Appendix $\mathrm{A}$ for derivation)

$$
\omega \tau=Z^{\prime} /\left(Z^{\prime \prime}-R s\right)
$$

The geometrical fit of the impedance data to a semicircle obtained using Electrochemistry software by Scribner Associates is shown in Figure 3.7. The curve fit gives the value of the diameter (Ro), the length of the chord on $Z^{\prime}$-axis (Rp) and the center coordinates (Xo.Yo). 


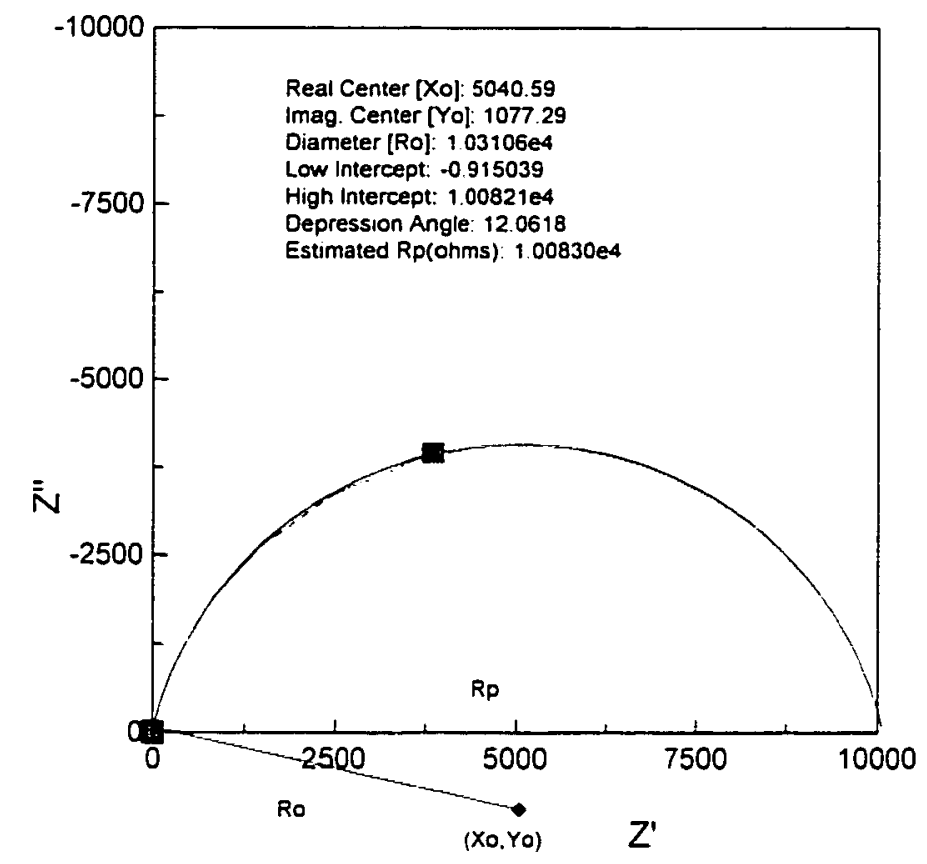

Figure 3.7. A geometrically fitted impedance curve in the complex plane showing the parameters Rp, Ro, Xo and Yo.

Once the radius (Ro) and the center $(\mathrm{Xo}, \mathrm{Yo})$ is determined from the geometrical fit the Rs, Rp, the two intercepts and the depression angle are calculated by the software. The left intercept gives the Rs value. From the depression angle. the value of $\beta$ can be calculated using Equation 3.18. The value of $\beta$ is 1.0 when the depression angle is zero.

$$
\beta=\sin (\pi / 2-\text { depression angle })
$$

The first circuit model has a resistor in series with a constant phase element. The Nyquist plot response is semicircular. The circuit parameters can be obtained by the method described in this section. 
For the second circuit model (Fig. 3.2), the Nyquist plot has two semicircles. Each of the semicircle can be separately fitted to a curve and the respective parameters can be estimated. These estimated parameter values are combined according to a suggested equivalent circuit model and further fitted to the model by applying Newton-Raphson method.

For the third circuit model (Fig. 3.3), the plot is semicircular at the high frequency region and fits a straight line of 45 degrees in the low frequency region. The CPE components can be measured from the semicircular part of the curve as described in this section. The Warburg diffusion coefficient can be measured from the slope of the plot of the imaginary part of impedance, $Z^{\prime \prime}$ versus $1 / \omega^{1 / 2}$, where $\omega=2^{*} \pi^{*}$ f. All the estimated components can be better fitted to the circuit model by applying Newton-Raphson method over the whole response curve.

For the fourth model similarly parameters can be estimated by fitting sections of the curve first, then all the parameters are fitted to the total response by using the model response.

\subsection{Validation of the Models}

The model is validated by checking the sensitivity of each component. The sensitivity is checked by the percent error. The percent error of a component is the percentage change 
of the impedance with a small change in the component value. The percent error value should be near zero for the component to obtain a good fit to the model.

The chi-square value was also considered for testing the relationship of the values to the impedance response curve. The chi-square in the calculations was used to check the total fit of the curve.

$$
\text { chi- square }=\Sigma\left\{\left(\Delta \mathrm{Zi}^{2}\right) / \mathrm{Zi}^{\prime}+\left(\Delta \mathrm{Zi}^{\prime \prime}{ }^{2}\right) / \mathrm{Zi}^{\prime \prime}\right\}
$$

The smaller the value of chi-square, the better is the fitness of the curve.

\subsection{Bode Plot}

Bode plot is another form of presenting the impedance data. In this plot the log of the absolute impedance and the log of the phase angle between the voltage and current are shown in the $y$-axis and the frequency on the $x$-axis. Sometimes the semicircles in the high frequency range for Nyquist plot are not apparent due to scaling. The advantage of using a Bode plot is that the phase angle plot shows a maxima for each semicircle. So even if the semicircle is not apparent in the Nyquist plot, the phase angle maxima in the Bode plot will show up to indicate the presence of a semicircle at that frequency range. The impedance response for the circuit model in Figure 3.2 is shown in Figure 3.8. $|\mathrm{z}|$ is the magnitude of the impedance and theta is the phase angle of the impedance. 

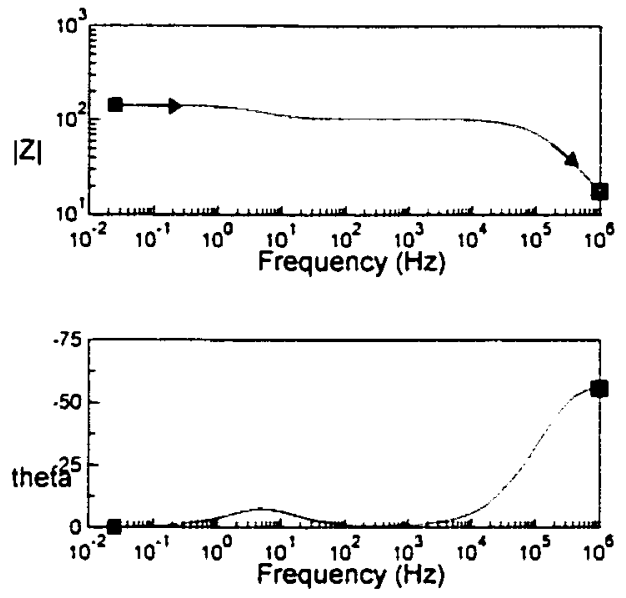

Figure 3.8. The impedance response in Bode plot for the circuit in Figure 3.2.

The experimental setup and method of analysis leads us to the experimental results. which are discussed in Chapter 4. 


\section{CHAPTER 4. EXPERIMENTAL RESULTS AND DISCUSSION}

\subsection{Introduction}

SS 316 is a common material for vessel or piping construction and DI water is a common solvent carried through these pipings and contained in such vessels. Over a period of time these vessels and piping materials corrode. The hypothesis of this thesis is that the corrosion mechanism of SS 316 and DI water at the interface may be determined by EIS method. An electrical equivalent circuit can represent the physical system of SS 316 and DI water interface. Thus, EIS method can be extended to design sensors for monitoring such an interface.

Once the hypothesis was established and the cell designed to carry out the test experiments, the next step was to build the cell and begin experiments. It took some time to get familiar with the instruments, purchase materials and build the cell. Four experiments were run. Experiment \#1 took place between October 15 and November 11 , 1997 to choose a suitable AC rms value. Experiment \#2 was carried out for three consecutive days from November 12, 1997 to November 14, 1997. In this run parallel experiments were carried out with DI water, tap water and concentrated tap water as an electrolyte. Experiment \#3 was carried out for 21 days starting on November 21, 1997. Data were collected on days $1,4,7,14$ and 21 . In this run parallel tests were carried out on DI water and sodium chloride solutions of three different concentrations, $0.01 \mathrm{~N}, 0.1 \mathrm{~N}$, $1.0 \mathrm{~N}$. A short experiment was carried out with $\mathrm{DI}$ water and $0.1 \mathrm{~N} \mathrm{NaCl}$ in experiment $\# 4$ 
on December 15, 1997. The system parameters studied were the polarization resistance, time constant and the overall impedance change of the system. The results are grouped by experimental runs. All the impedance values $\left(Z, Z^{\prime}, Z^{\prime \prime}\right.$ and $\left.|Z|\right)$ are in Ohms in the Nyquist and Bode plots.

\subsection{AC RMS Value Determination}

An AC perturbation needed to be chosen to obtain good sensitivity and low noise. In order to do this four AC ms values, 10,20,50 and $100 \mathrm{mV}$ were applied to a cell and compared. For each experiment, an rms value was applied and the impedance spectrum obtained. The electrodes were not polished in order to check the perturbation at passive state. The Nyquist plot for the four $\mathrm{AC}$ rms values are shown in Figure 4.1. It is interesting, that at very low frequency, the real value of the impedance for $10 \mathrm{mV}$ takes a plunge at around 800,000 . Possibly the instrument cannot handle the low current response at that potential. This rms value was rejected for the experiment. There was no significant difference observed for 20,50 and $100 \mathrm{mV}$ rms potential. For corrosion measurement a minimum voltage is desirable, because perturbation voltage should be such that the system does not move away from equilibrium. In this case $20 \mathrm{mV}$ rms value was chosen as the standard for the rest of the research experiment as it was the lowest perturbation with reliable current measurement. 


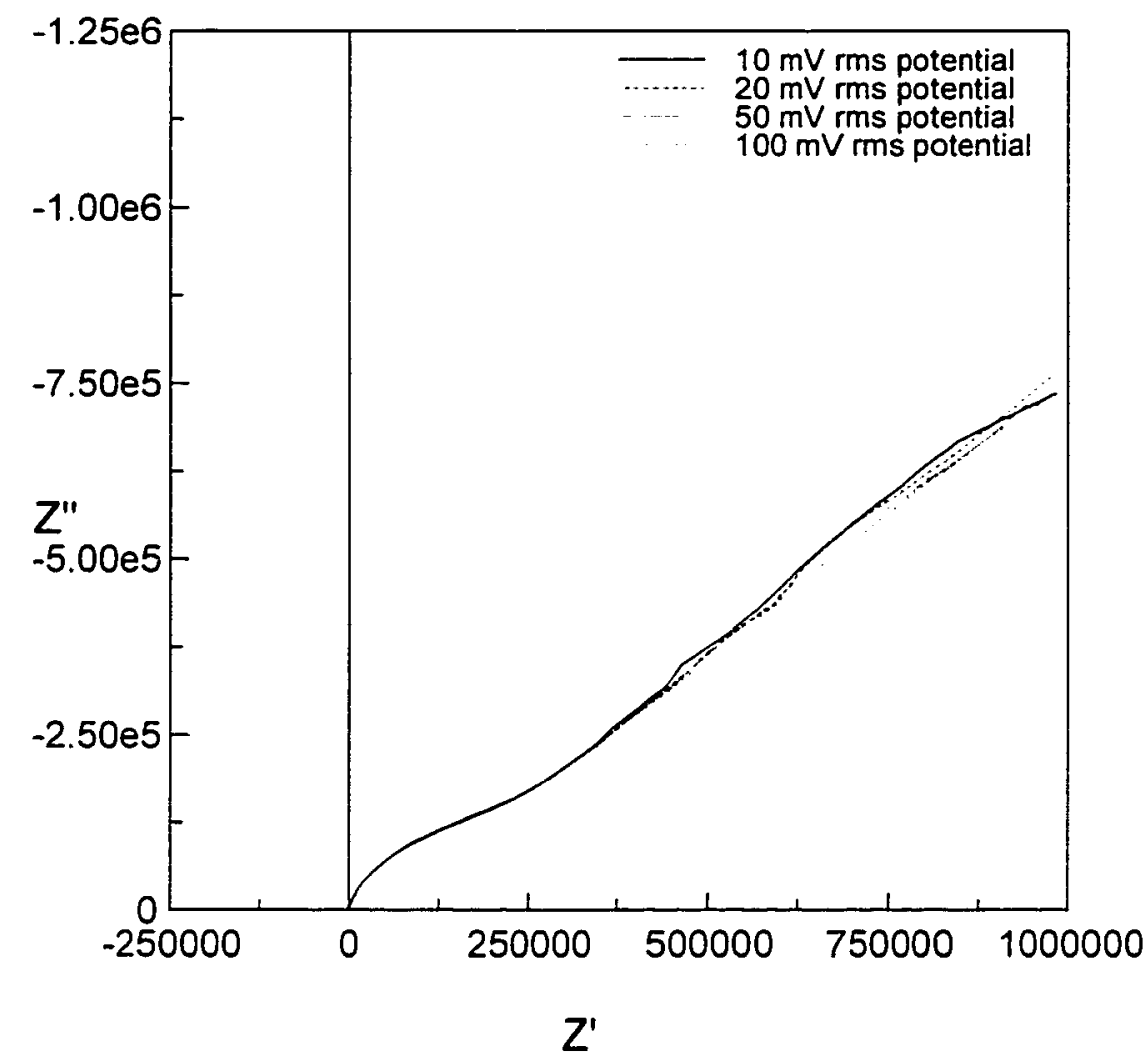

Figure 4.1. Nyquist plot for various voltages applied to the DI water and SS 316 system.

\subsection{The Passive Impedance Spectrum}

The impedance spectrum obtained at $20 \mathrm{mV}$ rms for SS 316 and DI water system is shown in Nyquist plot in Figure 4.2. Investigation of the response shows that the plot is semicircular at the high frequency region and fits a straight line of 45 degrees in the low frequency region. This response can be compared with Randles equivalent circuit response (Rubinstein et al.). The semicircular shape suggests reaction control corrosion 
and the straight line suggests diffusion control corrosion. As discussed in the previous chapter the parameters on the reaction control region can be represented by a CPE and those on the diffusion control region by a diffusion element. Warburg's diffusion coefficient is used to define the diffusion impedance (Rubinstein et al., 1995).

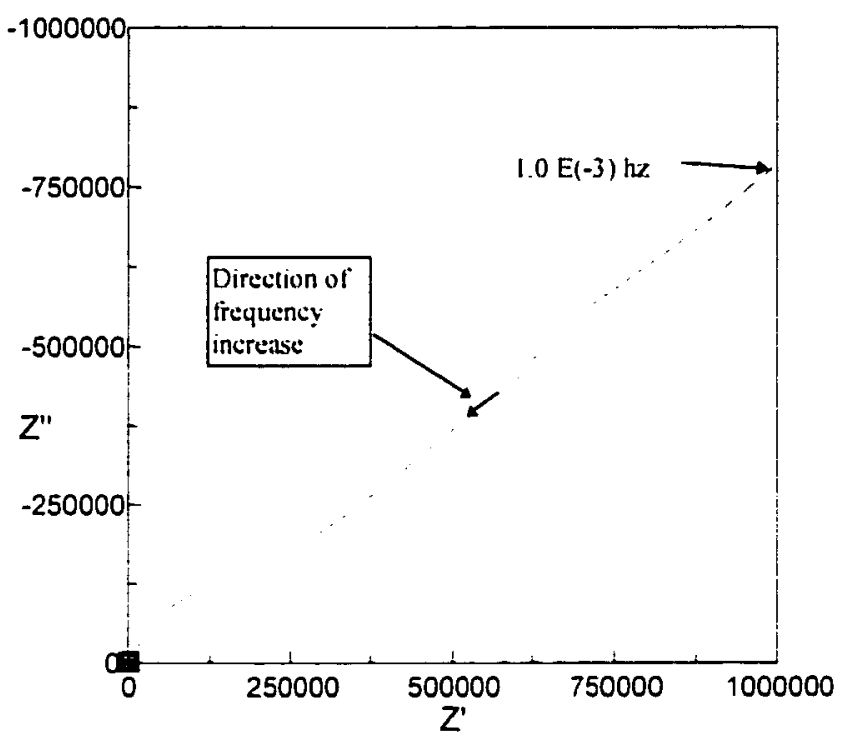

Figure 4.2. Impedance response in Nyquist plot for SS 316 and DI water system where SS 316 sample was not polished. 


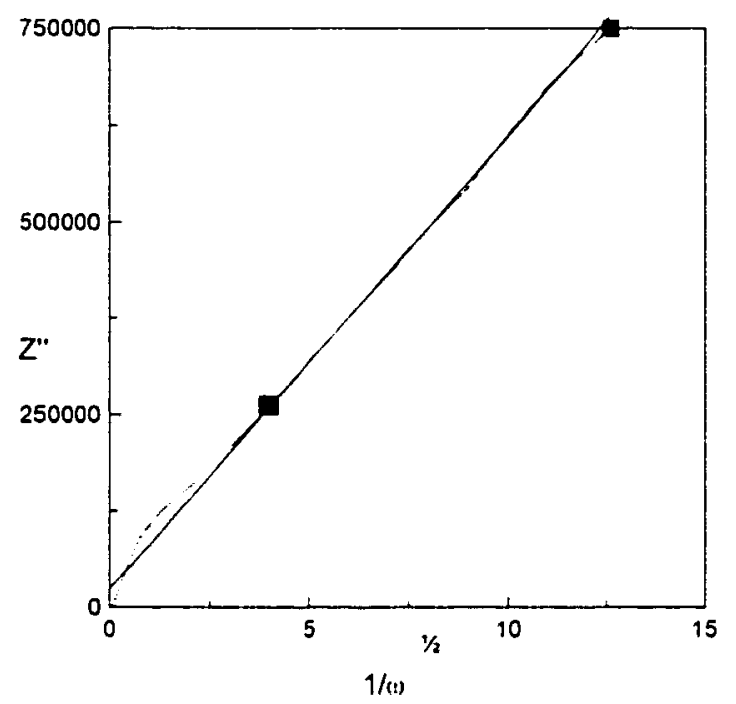

Figure 4.3. Plot of imaginary part of impedance versus $1 / \omega^{1 / 2}$ for SS 316 and DI water system.

The $Z^{\prime \prime}$ versus $\omega^{1 / 2}$ plot for this response is shown in Figure 4.3. The slope of this plot gives the Warburg diffusion coefficient. The Warburg diffusion coefficient can be used in conjunction with the thickness of the diffusion layer and diffusion factor to determine mobile ions. Ferreira et al.(1985) had calculated thickness of the diffusion layer, assuming the dielectric property of the film and thickness are inversely proportional to the capacitor value found from the impedance response. They considered a dielectric constant of iron oxide for their thickness measurement. from which eventually they calculated the corrosion rate. For SS 316 the oxide film is not strictly of iron but a combination of iron oxide and chromium oxide. The film composition on SS 316 is complex as reported by Hultquist et al. (1984) based on electron spectroscopy for chemical analysis (ESCA). 
Even though other researchers used this technique to measure corrosion rate for their systems, in this research the same cannot be done as the dielectric constant of the complex oxide film is not known. However the Warburg diffusion co-efficient is reported for the diffusion region.

A second semicircle is present at the high frequency zone that is not visible in Figure 4.2 due to scale. Since the second semicircle is very small, a blow up section of that part of the impedance plot is shown in Figure 4.4. This semicircie resulted from the parallel plate arrangement of the electrodes, a conclusion, which will be proven later. Figure 4.4 shows the semicircular plot at low impedance and high frequency zone. 


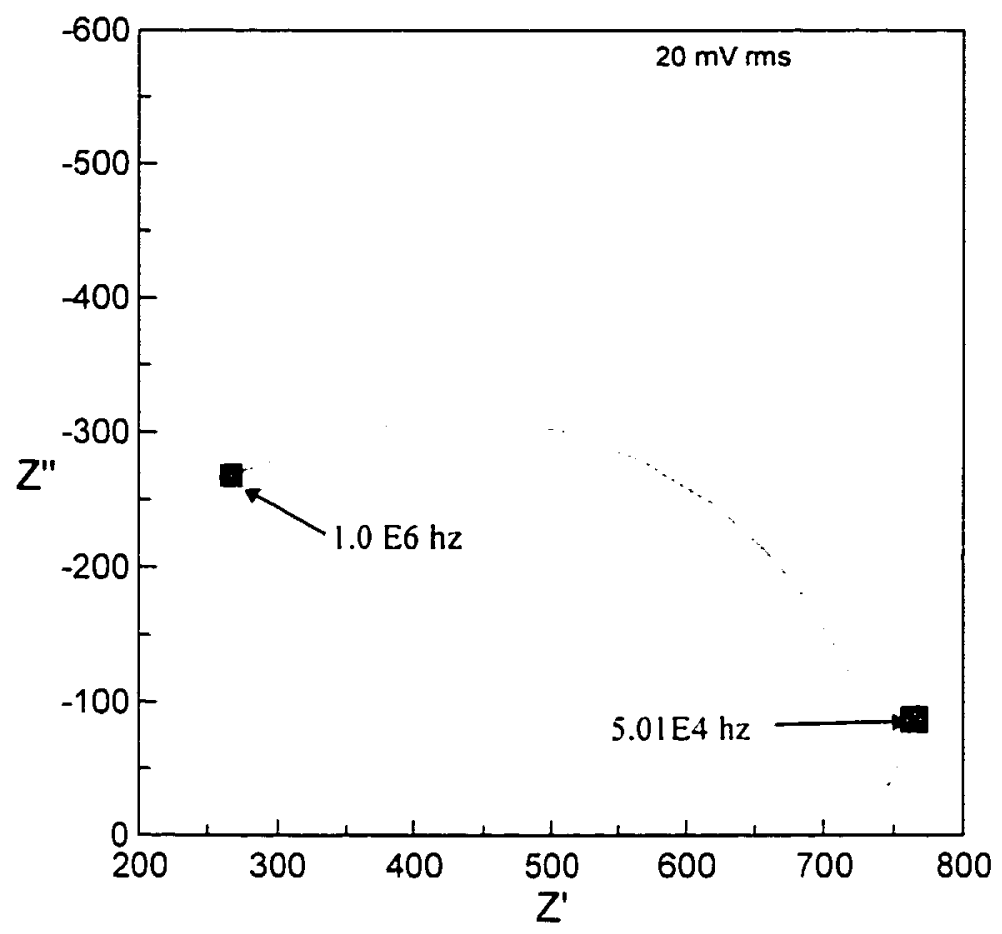

Figure 4.4. Section of Nyquist plot at high frequency region for SS 316 and DI water system.

The second semicircle at the high frequency zone is not considered in this circuit since this is not a phase behavior. The passive alloy and DI water interface mechanism can be represented by Randle's circuit. which is shown in Figure 4.5. Parameters for Randle's circuit given in Table 4.1 were obtained using the curve fitting method as described in the previous chapter. 
Table 4.1. Randle's circuit parameters.

\begin{tabular}{|l|l|}
\hline Parameters & Values \\
\hline Series resistance $(\mathrm{Rs})$ & $743.3 \mathrm{ohm}$ \\
\hline Time constant of CPE( $\tau)$ & $.063 \mathrm{~s}$ \\
\hline Polarization resistance $(\mathrm{Rp})$ & $182600 \mathrm{ohm}$ \\
\hline Beta & 0.477 \\
\hline Warburg diffusion coefficient & $-5.887^{*} \mathrm{E} 4$ \\
\hline
\end{tabular}

To evaluate the quality of the curve fit the chi-square value was calculated. The chisquare value for the curve fit was 0.0224 , which validates the estimated parameters.

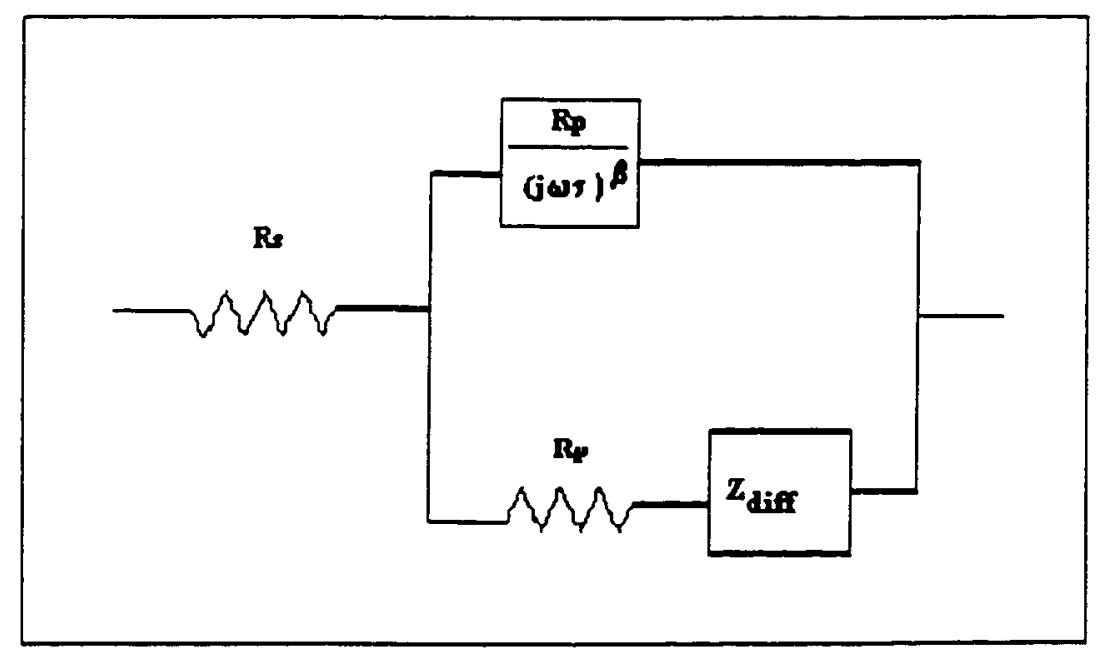

Figure 4.5. Randles Equivalent Circuit. 


\subsection{Comparison of DI Water with Tap Water and Evaporated Tap Water}

When no change was found in the EIS of the SS 316 and DI water system, a different electrolyte was chosen with an expectation to see some change in the impedance response during the time period of the previous experiment. Another experiment was conducted with DI water, tap water and evaporated tap water in three different cells. The electrodes were not polished. Three sets of electrodes were used and the experiment was run for three days. The Bode plots for the first day are shown in Figure 4.6 to compare the resistances of the electrolytes. The electrolyte resistances are clearly different as can be seen from the horizontal part of the impedance plots in the high frequency zone. On the first day of the 21 day run, the resistances were found to be $842 \mathrm{ohm} .9 .5 \mathrm{ohm}$ and 2.3 ohm for DI water, tap water and evaporated tap water, respectively. This difference in electrolytic resistance shifts the impedance spectrum in the Nyquist plot to the left for low resistance and to the right for high resistance. The shift is accompanied by a small semicircle. The small semicircle resulted from the parallel plate arrangement. Figure 4.7 shows the Nyquist plot for the same data as in the Bode plot of Figure 4.6. The DI water plot is slightly shifted to the right at high frequency region over time. The samples were not polished for this experiment. 

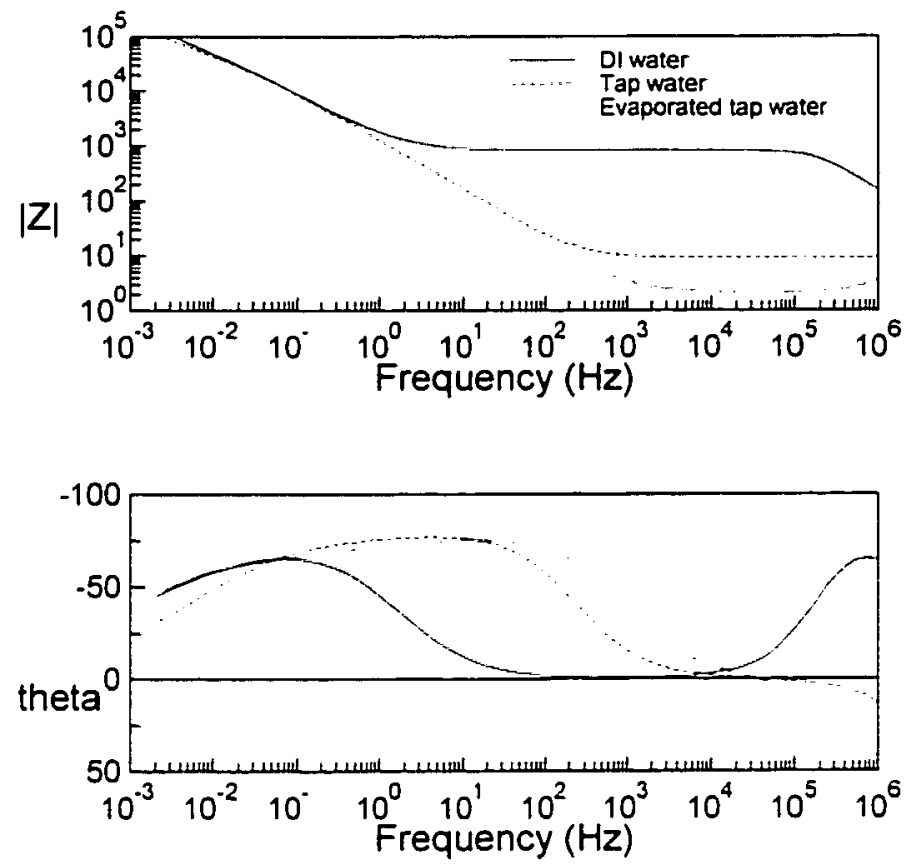

Figure 4.6. Impedance data plotted in Bode format for DI water. tap water and evaporated tap water. 


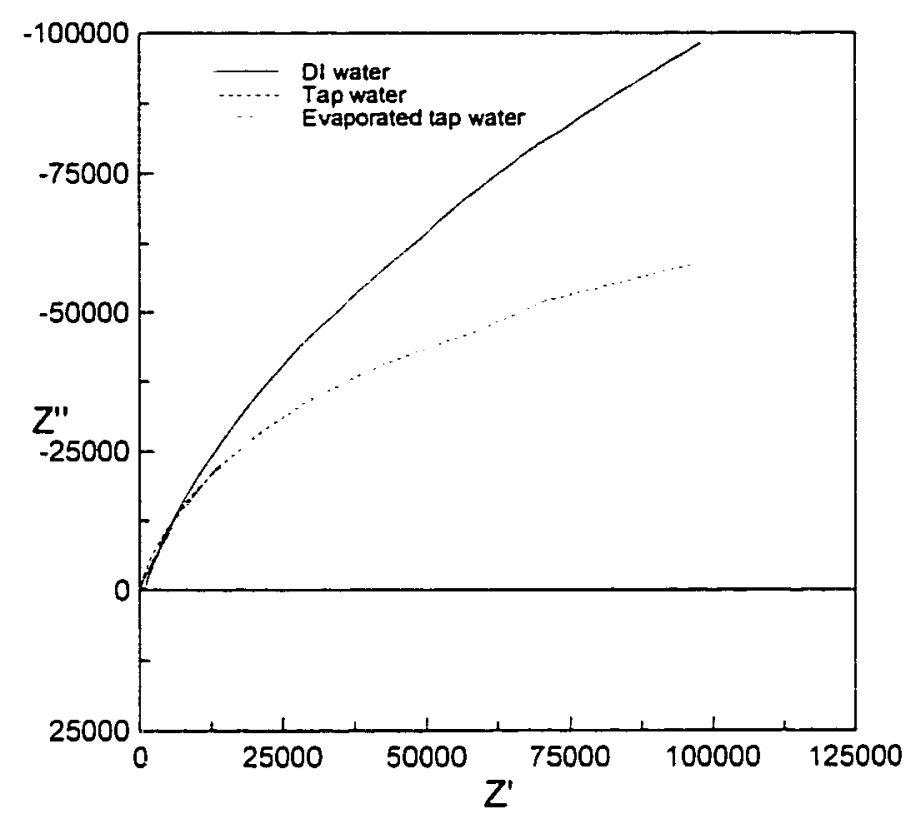

Figure 4.7. Nyquist plot for SS 316 in three different electrolytes.

The electrode for DI water was not changed because the same electrode, which had passivated in the last experiment, was being used. It can be inferred that the DI water was already in the passivated region whereas the tap water and the evaporated tap water systems were almost at the passive state. The radius of the arc in the Nyquist plot for DI water was so large that it appears to be a straight line (Fig. 4.7). The Nyquist plot for tap water and evaporated tap water show depressed semicircles. This semicircle shape of the Nyquist plot for tap water and evaporated tap water suggests that corrosion in these electrolytes may still be in the reaction control region. 


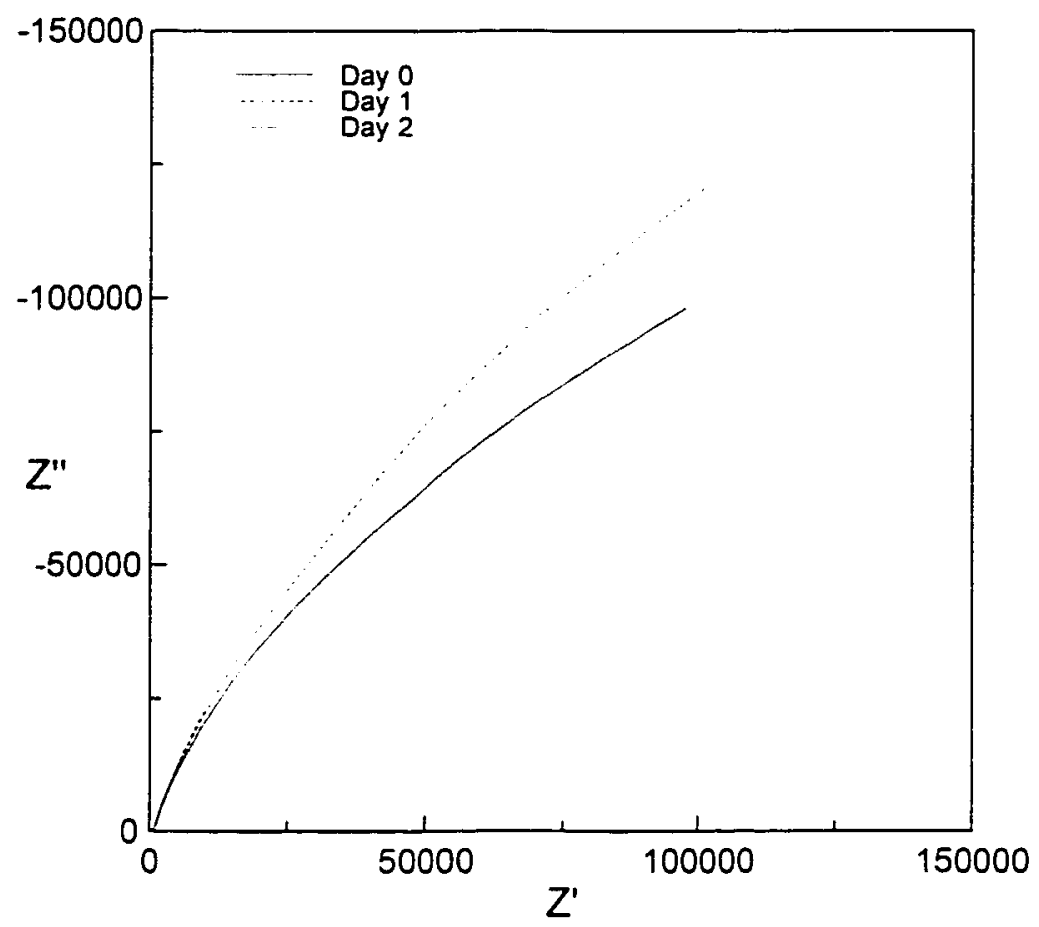

Figure 4.8. Nyquist plot for SS 316 and DI water.

In Figure 4.8, a three day change of the Nyquist plot is shown for DI water. The trend in the increase in the radius of the semicircle suggests that the DI water is passivating further. However this is not found to be true. When the high frequency region in Figure 4.8 is blown up for closer scrutiny, it becomes evident that there is only a change in the electrolyte resistance. DI water tends to become contaminated easily. especially when transported to the experimental site. 
The low frequency change in impedance as seen in Figure 4.8 is actually the shift of the curve at high frequency (Figure 4.9) due to the DI water contamination. It can be inferred no change at the interface is detected during these three days.

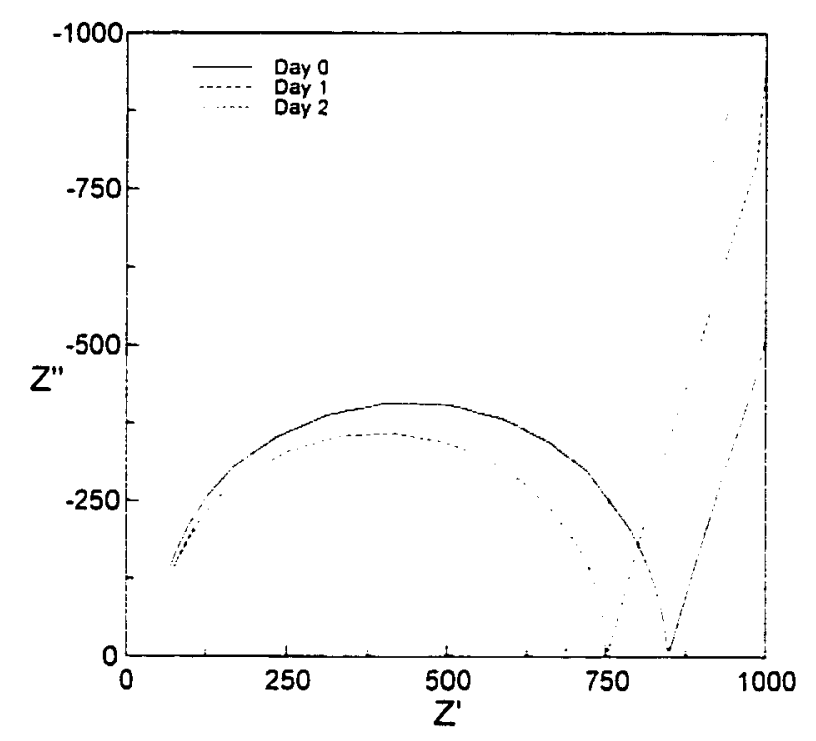

Figure 4.9. Nyquist plot for SS 316 in DI water (high frequency region).

The three day trends for tap water and evaporated tap water are shown in Figure 4.10 (a) and (b) respectively in the complex plane plot of $Z^{\prime \prime}$ versus $1 / \omega^{1 / 2}$. 


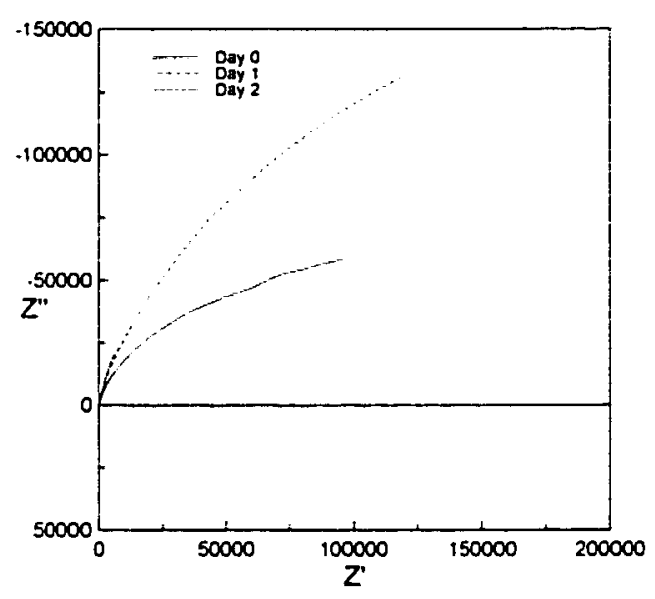

(a)

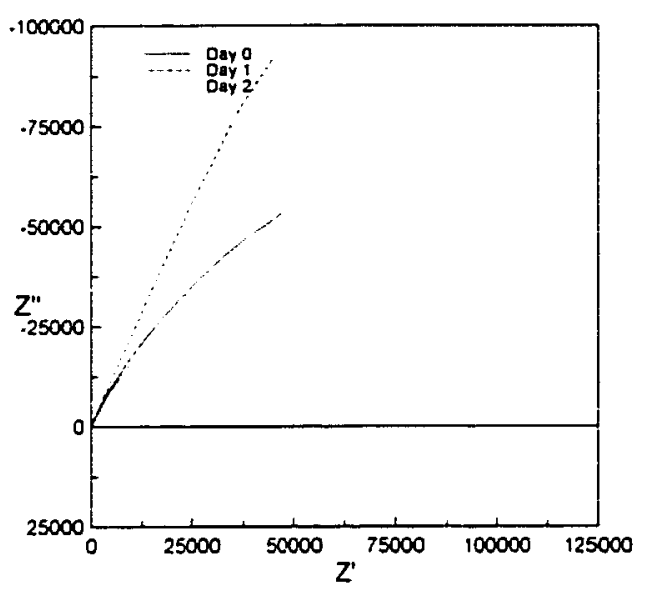

(b)

Figure 4.10. Nyquist plot for SS 316 and (a) tap water. (b) evaporated tap water.

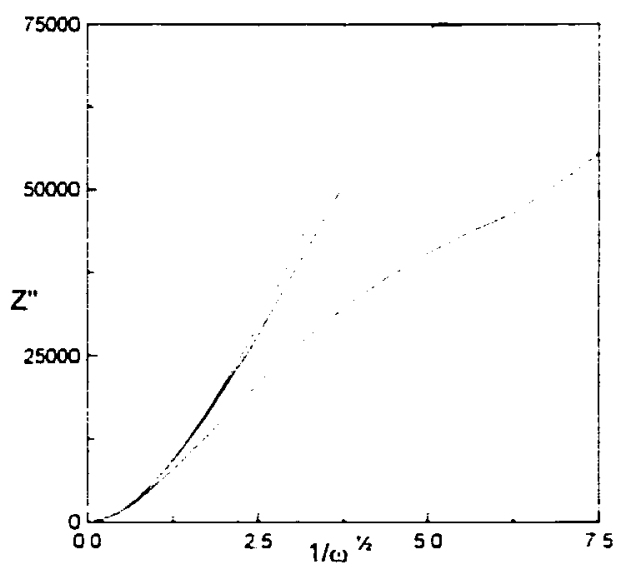

(a)

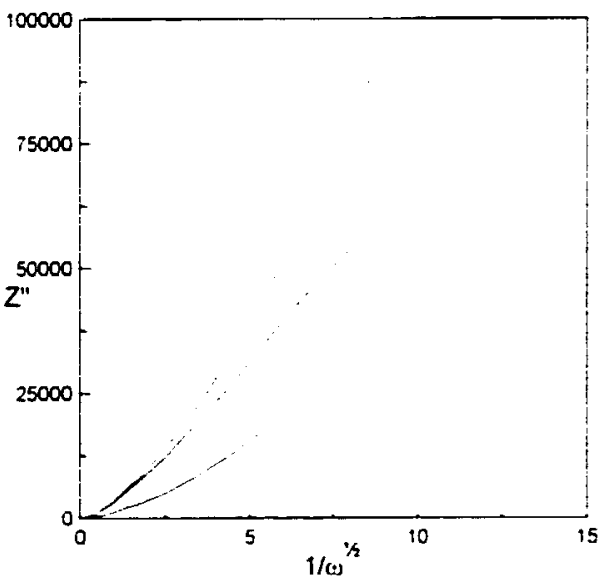

(b)

Figure 4.11. Z" versus $1 / \omega^{1 / 2}$ plot for SS 316 in (a) tap water. (b) evaporated tap water. The legends in Figure 4.11 are same as in Fig. 4.10.

The $Z^{\prime \prime}$ versus $1 / \omega^{1 / 2}$ plot for the tap water shows that during day 0 the reaction was not fully diffusion controlled. However. in Figure 4.11 (b) it is evident that the plots are all 
straight lines at low frequency. This shows that the diffusion control phenomenon sets in very fast for evaporated tap water. All the plots in Figure 4.11(a) show a trend towards a straight line except that of tap water for Day 0.

From the three day change in the systems, it can be inferred that it takes some time before passivation sets in as seen in the case of tap water. The change towards passivation can be detected by EIS. If this change towards passivation can be detected, possibly the EIS method can be used for monitoring. It is evident further investigation is required to confirm this. Since the composition of tap water is unknown, an experiment was conducted to compare this passivation phenomenon of DI water with known solutions of sodium chloride using this method as discussed in the following section. 


\subsection{A Comparative Analysis of SS 316 in DI Water and Sodium Chloride Solution}

\section{Over 21 Days}

Three sodium chloride solutions and DI water were used as electrolyte to compare the SS 316 interface effect. First a twenty one day run was conducted with each of the electrolytes. The electrodes were polished with 600 grit emery paper and wiped with acetone before being used. On day 0 , two readings were taken for DI water. In Figure 4.14 the plots for the two readings show marked difference in terms of the semicircle phenomenon at low frequency range. The second reading was taken with fresh DI water from a squeeze bottle. This reading suggests that the DI water was contaminated. Since the experiment was in progress, the DI water was not changed nor were any of the solutions. From day four no marked change is observed other than a decrease in electrolytic resistance due to contamination that can be seen in high frequency region in Figure 4.12. 


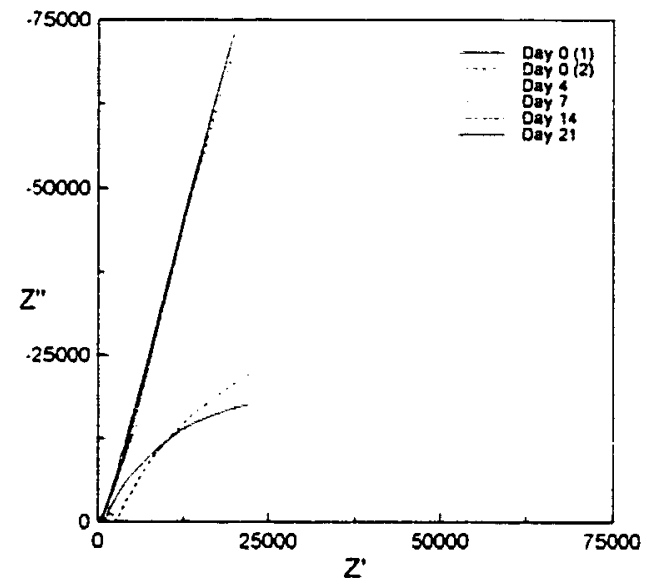

(a)
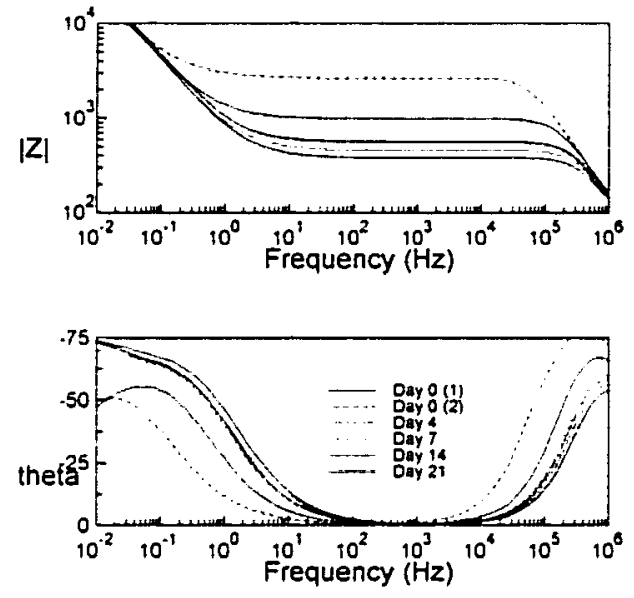

(b)

Figure 4.12. SS 316 and DI water system observed over 21 days. (a) Nyquist plot and. (b) Bode plot.

This contamination problem detected by the reduction of resistance may be attributed to the increase in ions or particles. The presence of ferrous ions could not be confirmed by chemical analysis due to the limitation of the analytical method which does not allow iron ion measurement below $10 \mathrm{ppm}$ in a solution.

The horizontal section of the impedance in the Bode plot is read as the resistance of the electrolyte. Figure 4.12(b) shows both the impedance and phase angle plot. Two semicircular response can also be verified by the two maxima in the phase angle from the Bode plot in Figure 4.12(b) as discussed in Chapter 3. 


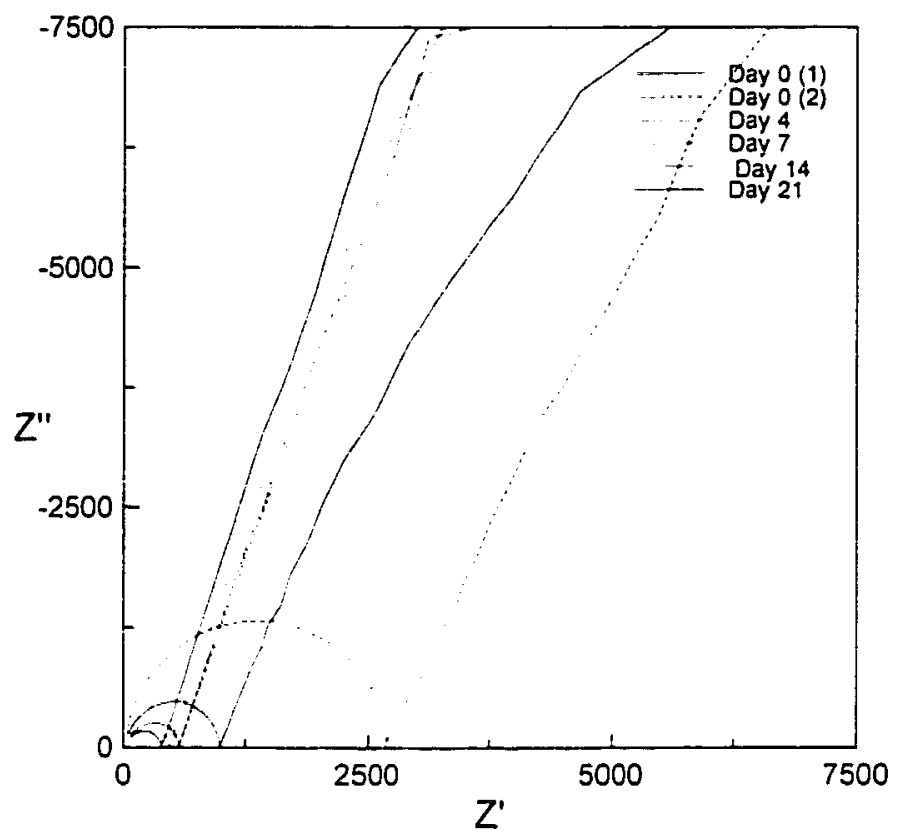

Figure 4.13. Nyquist plot for SS 316 in DI water with high frequency region magnified. 
Figure 4.13 shows the small semicircle at high frequency region in the Nyquist plot. The radius of the semicircle corresponds to the resistance in the Bode plot. The EIS for 0.01 $\mathrm{N}$ sodium chloride solution is shown in Figure 4.14(a) and (b). The day 0 impedance spectrum in the Nyquist plot in Figure 4.14(a) shows a semicircular curvature whereas in days $4,7,14$ and 21 the spectrum is more like a straight line indicating diffusion limited regime. The corresponding Bode plot shows phase angle maxima for day 0 . For the other days no maxima is observed in the phase angle plot. The phase angle does not show a maxima for days $4,7,14$ and 21 . This indicates that by day 4 passivation had set in and no further changes could be evaluated by EIS.

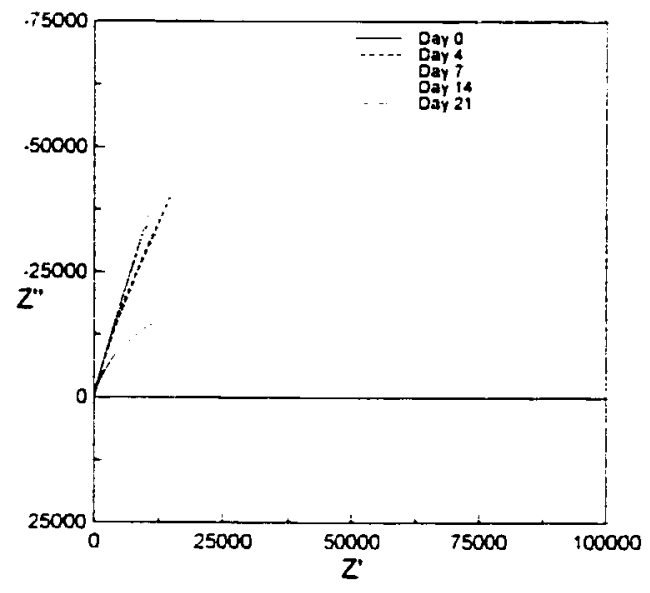

(a)
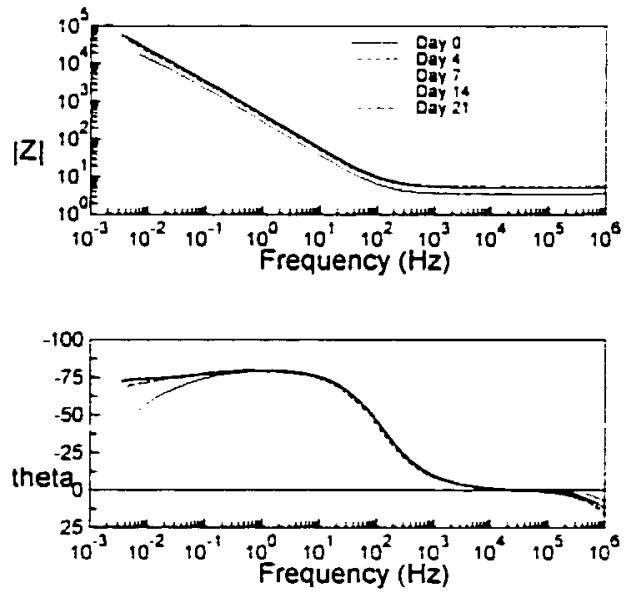

(b)

Figure 4.14. Impedance response for SS 316 in $.01 \mathrm{~N}$ sodium chloride solution in (a) Nyquist plot and (b) Bode plot.

Similar phenomenon is observed from the electrochemical impedance spectrum for $0.1 \mathrm{~N}$ sodium chloride solution and $1.0 \mathrm{~N}$ sodium chloride solution. The Nyquist plot for $0.1 \mathrm{~N}$ 
sodium chloride solution and 1.0 N sodium chloride solution are shown in Figure 4.15(a) and 4.16(a) respectively. The corresponding Bode plots are shown in 4.15(b) and 4.16(b).

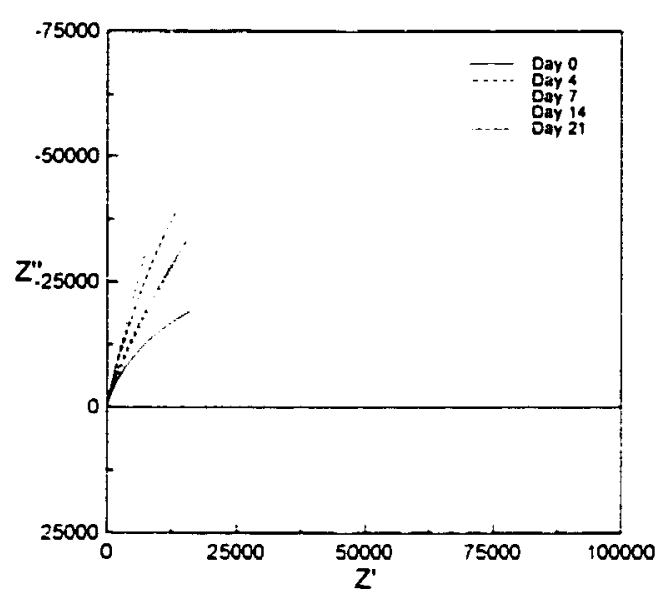

(a)
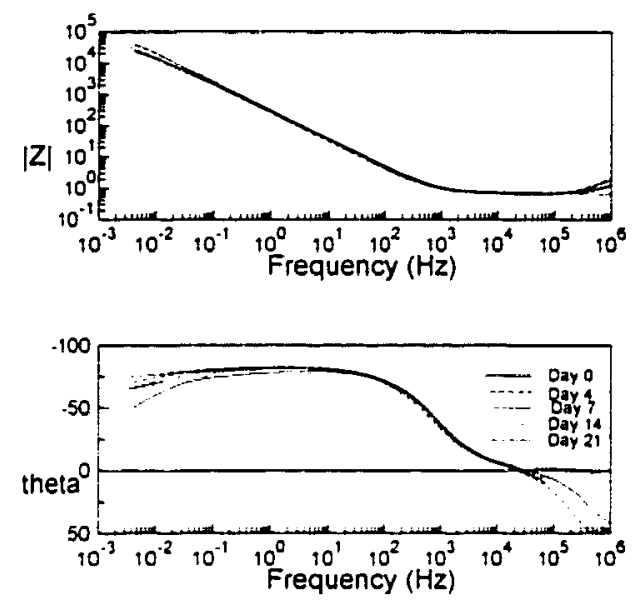

(b)

Figure 4.15. Impedance response for SS 316 in $0.1 \mathrm{~N}$ sodium chloride solution in (a) Nyquist plot and (b) Bode plot.

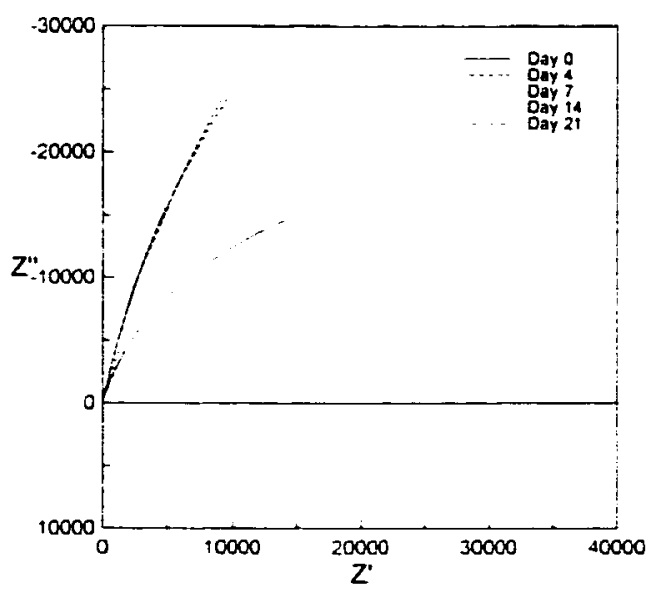

(a)
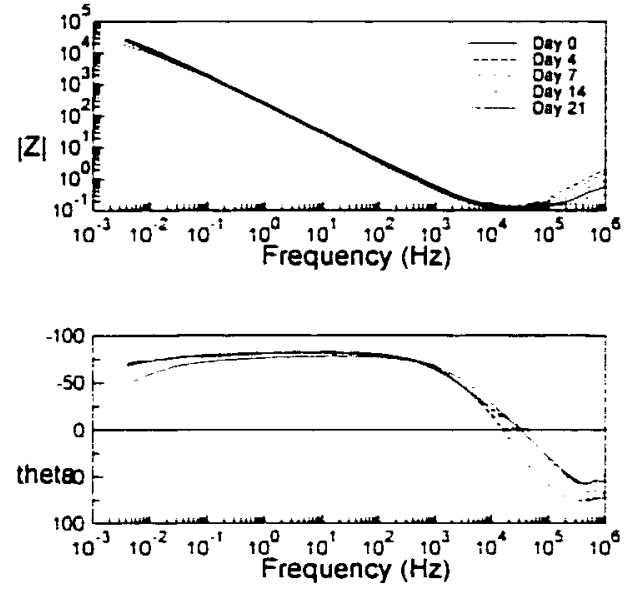

(b)

Figure 4.16. Impedance response for SS 316 in $1.0 \mathrm{~N}$ sodium chloride solution in (a) Nyquist plot and (b) Bode plot. 
The salt solutions show only one phase angle maximum in the Bode plot whereas the DI water plot shows two maxima. It is clear from this behavior that, the high frequency maxima in the DI water case is a parallel plate capacitor. This will be confirmed by the value of beta as discussed in the next section.

From the 21 day experiment it is apparent that once passivation sets in, EIS method cannot be used to measure major change. The low frequency polarization curve could be observed during day 0 only as passivation sets in very fast. A short interval EIS measurement was taken to confirm the change.

\section{Short Interval Experiment}

A set of runs was conducted with $0.1 \mathrm{~N}$ sodium chloride solution and DI water as electrolyte at an interval of five minutes. The impedance plots for DI water and SS 316 in Figure 4.23 show two semicircles, one at high frequency region and the other at low frequency region. The low frequency semicircle radius increases over time, indicating decrease in corrosion rate. This proves that if the corrosion rate is in the reaction control region it can be detected by the impedance spectroscopy. The high frequency semicircle is for the parallel plate construction of the cell. 


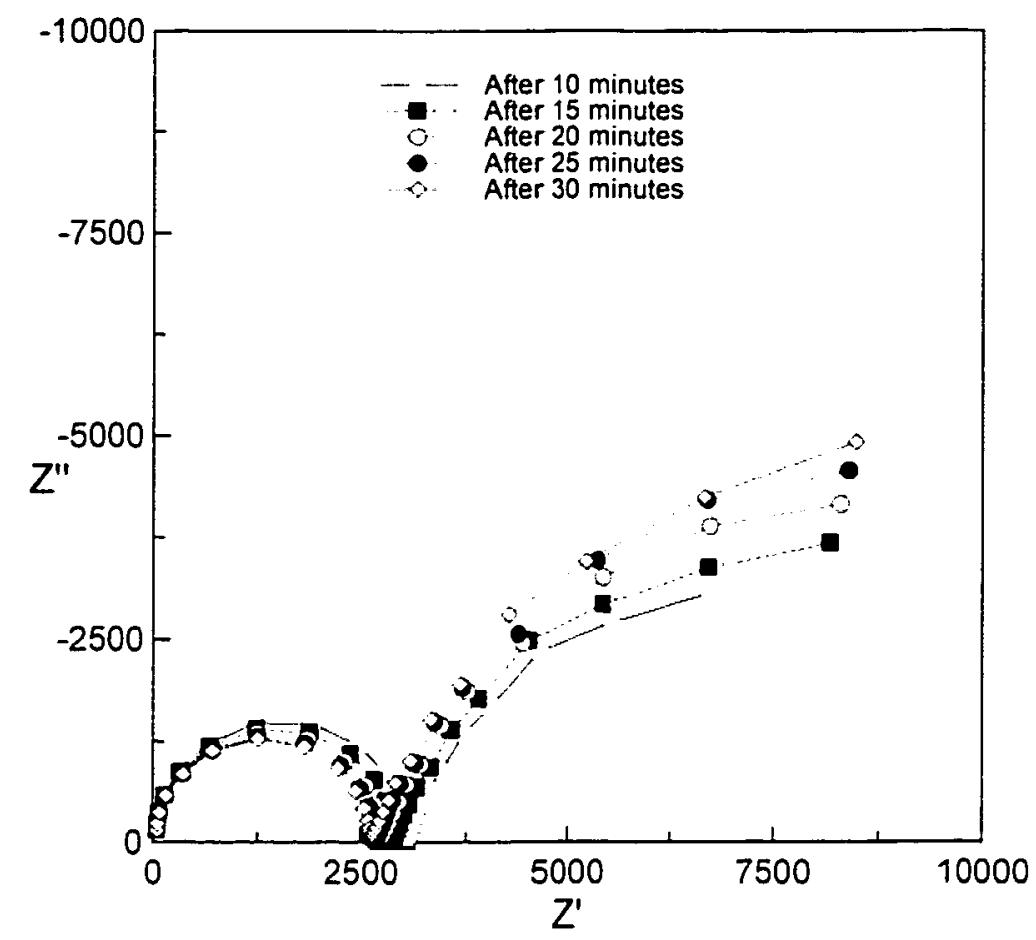

Figure 4.17. Nyquist plot for SS 316 and DI water system for short run.

The short interval experiment on $0.1 \mathrm{~N}$ sodium chloride showed EIS response similar to DI water. The Nyquist plot for this response is shown in Figure 4.18. The sodium chloride typically did not show the high frequency semicircle because the electrolyte is conducting and the parallel electrodes did not behave like capacitors in this case. The radius of the low frequency semicircle for this system also increased over time. 


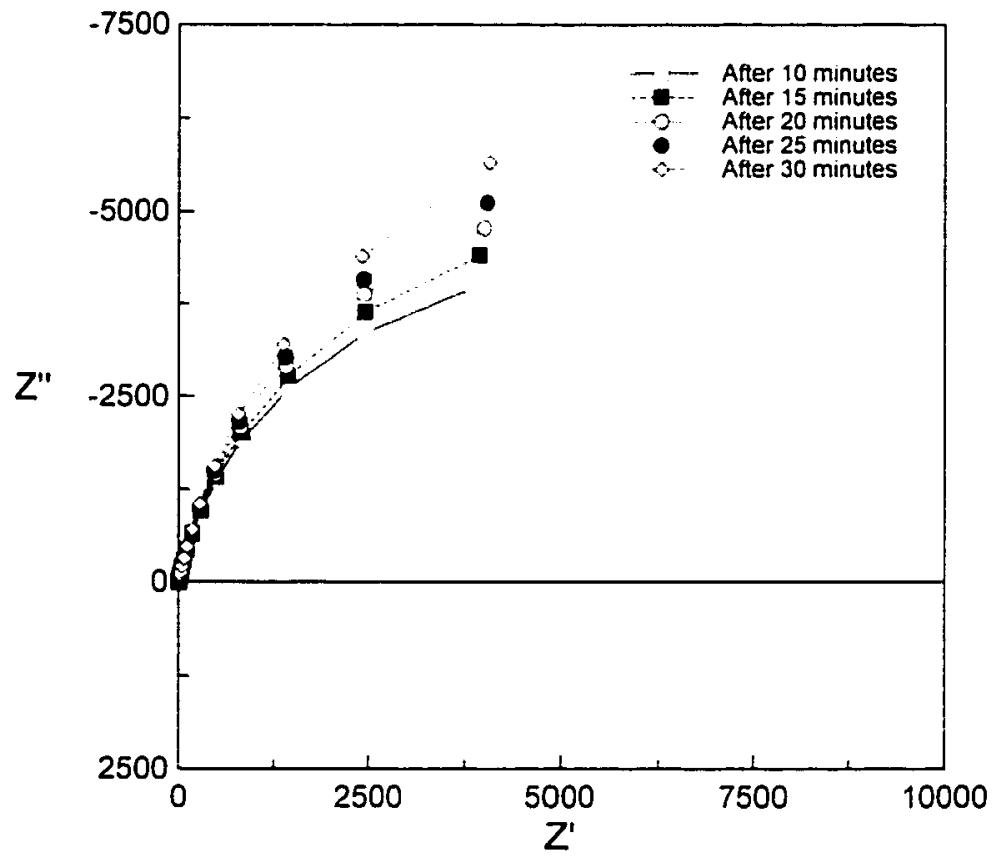

Figure 4.18. Nyquist plot for SS 316 and $0.1 \mathrm{~N}$ sodium chloride system in short run.

From this it can be said that EIS can fingerprint the status of the interface. Therefore the change from one state to another can be compared using this method. Now the question is how to estimate this change. The equivalent circuit development is a good way of separating the different points of change. This way. the state to state change can be monitored. 


\subsection{Equivalent Circuit Model for SS 316 and DI Water System}

The Nyquist plots for SS 316 system have been studied qualitatively in the previous chapter. The circuit model that has the same response as the system can be developed using the method described in Chapter 3. Equivalent circuit model will be developed for the DI water and SS 316 system. The superimposed Nyquist plot of the 21 day run and short run is shown in Figure 4.19. The Bode plot for the same is shown in Figure 4.20.

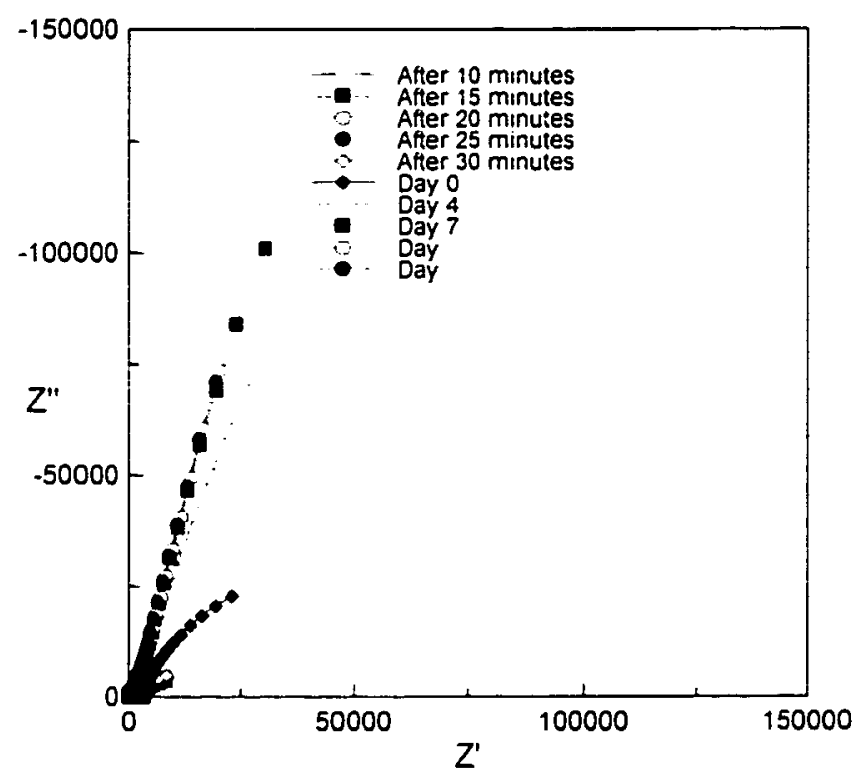

Figure 4.19. Nyquist plot for SS 316 and DI water system. 21 day run and short run superimposed.

The circuit with two CPE was considered for the DI water and SS 316 system because in the previous section it is evident that the system showed a second circle at high frequency range in the Nyquist plot. 

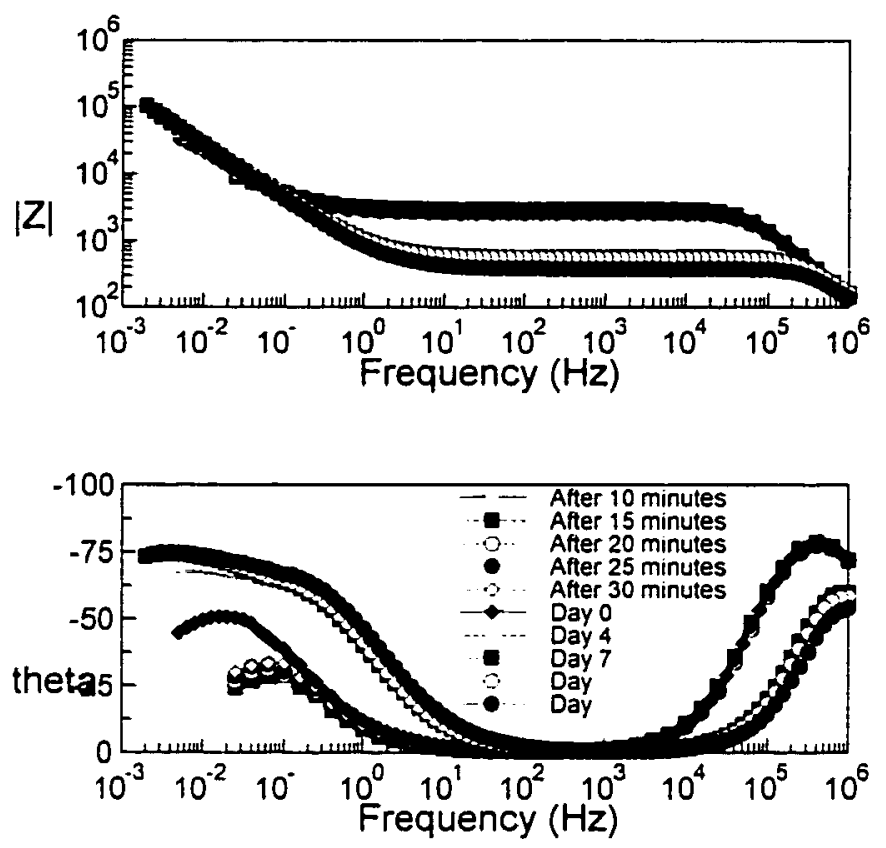

Figure 4.20. Bode plot for SS 316 and DI water system. 21 day run and short run superimposed.

In the Bode plot the phase angle shows two maxima indicating the possibility of two CPE in the circuit model. The beta value for the semicircle can show whether these semicircles are representative of capacitor or CPE. For capacitor the beta value will be very close to 1.0. Two possible circuits were considered for the two CPE circuit. The circuits are shown in Figure 4.21(a) and 4.21(b). 

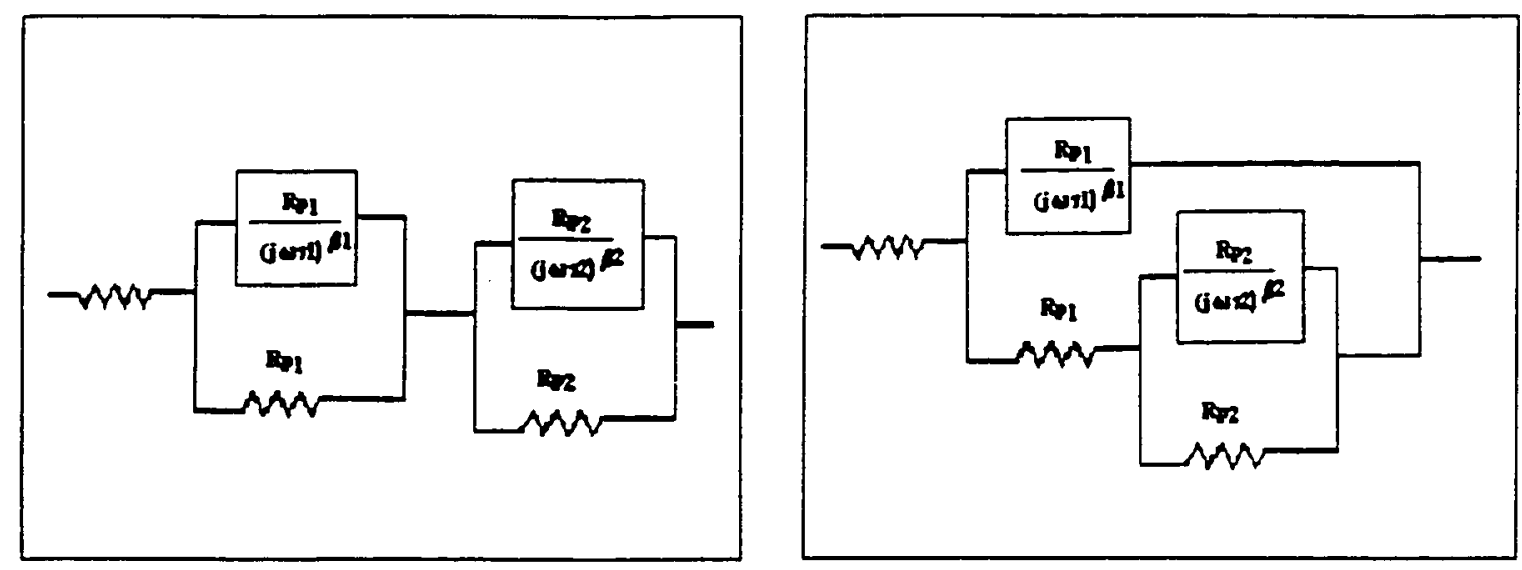

(a)

(b)

Figure 4.21. Circuit with two CPE (a) in series and (b) in nested connection.

Both circuits showed good fitting for the first few hours of the experiment for the 20 minute run. The circuit in Figure 4.21(b) is the model in the hypothesis and response from this model was curve fitted to the EIS response from DI water and SS 316 system. The parameter values for circuit in Figure 4.21(b) and corresponding error percents and chi square values are shown in Table 4.2(a) and 4.2(b) for all the DI water data. 
Table 4.2(a) Circuit element $R s, R p_{1}, \tau_{1} / R p_{1}$, and $B_{1}$ values and their error percents for circuit in Figure 4.21.(b).

\begin{tabular}{|l|r|r|r|r|r|r|r|r|}
\hline Time & \multicolumn{2}{|c|}{ Rs } & \multicolumn{2}{c|}{ Rp $_{1}$} & \multicolumn{2}{c|}{$\tau_{1} / R_{1}$} & \multicolumn{2}{c|}{$\beta_{1}$} \\
\hline & Value & Error \% & Value & Error \% & Value & Error \% & Value & Error \% \\
\hline Day 21 & 36.85 & 6.777 & 349.5 & 0.78856 & $1.2870 \mathrm{E}-09$ & 1.469 & 0.99519 & 0.75652 \\
\hline Day 14 & 41.95 & 6.237 & 520.2 & 0.58731 & $1.1038 \mathrm{E}-09$ & 1.035 & 1.00000 & 0.64213 \\
\hline Day 7 & 39.91 & 6.576 & 530 & 0.59666 & $1.1990 \mathrm{E}-09$ & 1.034 & 1.00300 & 0.68339 \\
\hline Day 4 & 41.42 & 3.392 & 419.8 & 0.38011 & $1.2215 \mathrm{E}-09$ & 0.67878 & 1.00500 & 0.39164 \\
\hline Day 0 & 39 & 2.453 & 2648 & 0.13284 & $1.0627 \mathrm{E}-09$ & 0.28465 & 1.01000 & 0.15684 \\
\hline 30 minute & 40.56 & 3.282 & 2578 & 0.20085 & $1.0400 \mathrm{E}-09$ & 0.42713 & 1.00800 & 0.23174 \\
\hline 25 minute & 40.51 & 3.382 & 2632 & 0.20693 & $1.0395 \mathrm{E}-09$ & 0.4407 & 1.00800 & 0.23736 \\
\hline 20 minute & 40.45 & 3.275 & 2714 & 0.20005 & $1.0388 \mathrm{E}-09$ & 0.42757 & 1.00800 & 0.22788 \\
\hline 15 minute & 40.42 & 3.011 & 2847 & 0.18388 & $1.0376 \mathrm{E}-09$ & 0.39501 & 1.00800 & 0.20712 \\
\hline 10 minute & 40.3 & 2.722 & 3013 & 0.16718 & $1.0362 \mathrm{E}-09$ & 0.35806 & 1.00800 & 0.18426 \\
\hline
\end{tabular}

Table 4.2(b) Circuit elements $R s . R p_{2,}, \tau_{2} / R p_{2}$, and $B_{2}$ values and their error percents for circuit in Figure 4.21.(b) and the chi-square value of curve fit.

\begin{tabular}{|c|c|c|c|c|c|c|c|}
\hline Time & \multicolumn{2}{|c|}{$R p_{2}$} & \multicolumn{2}{|c|}{$\tau_{2} / R p_{2}$} & \multicolumn{2}{|c|}{$\beta_{2}$} & Chi-square \\
\hline & Value & Error \% & Value & Error \% & Value & Error \% & \\
\hline Day 21 & $4.08 E+11$ & $5.73 E+06$ & 0.027894 & $1.34 \mathrm{E}+06$ & 0.81045 & 0.16587 & 0.001712 \\
\hline Day 14 & $1.03 E+11$ & $1.41 \mathrm{E}+06$ & 0.022957 & 351035 & 0.80155 & 0.18376 & 0.001758 \\
\hline Day 7 & $2.20 E+10$ & 240710 & 0.017206 & 61002 & 0.79994 & 0.1924 & 0.002209 \\
\hline Day 4 & $6.58 \mathrm{E}+06$ & 50.19 & 0.002799 & 13.9 & 0.78993 & 0.098866 & 0.000547 \\
\hline Day 0 & 87571 & 2.02 & 0.001167 & 1.467 & 0.75266 & 0.2401 & 0.000578 \\
\hline 30 minute & 13652 & 2.366 & 0.000622 & 2.044 & 0.79435 & 0.6767 & 0.00079 \\
\hline 25 minute & 12740 & 2.382 & 0.000616 & 2.09 & 0.79533 & 0.71907 & 0.000851 \\
\hline 20 minute & 11368 & 2.216 & 0.000608 & 1.984 & 0.79932 & 0.73047 & 0.000819 \\
\hline 15 minute & 9835 & 1.973 & 0.000603 & 1.804 & 0.80506 & 0.72383 & 0.000723 \\
\hline 10 minute & 8393 & 2.53 & 0.000598 & 2.113 & 0.81181 & 0.83715 & 0.000641 \\
\hline
\end{tabular}

The values with subscript $I$ are for the high frequency semicircle. The $\%$ error for these values is nominal except for Rs. The value of Rs is small and 6-7\% error is about 1 to 2 ohms. This error can be attributed to instrument measurement discrepancy at high frequency. One thing noticeable here is that the beta value is almost equal to 1.0 which indicates that the high frequency phenomenon is that of a pure capacitor and has resulted from the parallel plate arrangement of the electrodes. The error percent is also very low 


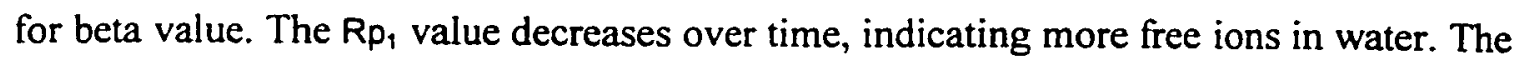
chi-square value in Table 4.2.(b) looks reasonable for short run, day 0 and day 4 . This value increases for later days. The $13.9 \%$ error in $\tau_{2} / R p_{2}$ value and $50 \%$ error in the $R p_{2}$ value in day 4 is a sure sign of the misfit of this model. It is apparent from the increasing $\%$ error of these elements for days $4,7,14$ and 21 that the same model cannot be used for these days. The experimental and simulated curves are shown in Appendix $C$ and the raw data is tabulated in Appendix B.

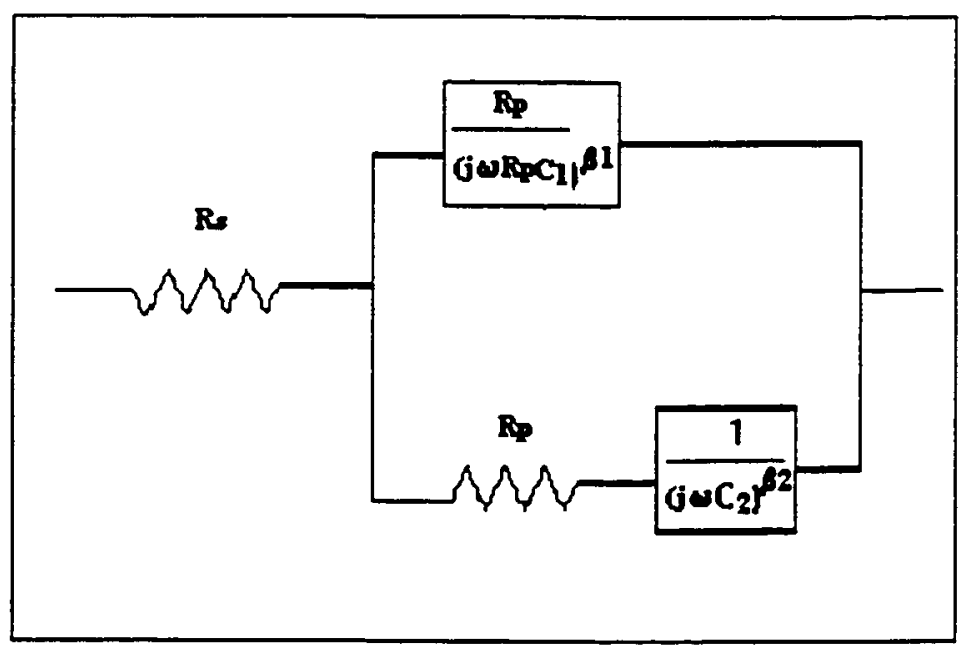

Figure 4.22. Circuit with one CPE and a modified capacitor. 
A second model was considered for days $4,7,14$ and 21 . Since passivation sets in on days $4,7,14$ and 21 , a passivation model was considered. Figure 4.22 shows the circuit diagram for this simulation. This circuit does not have the $\mathrm{Rp}_{2}$ circuit element and the circuit is open at that point. The circuit component values, error percent and chi square values are shown in Table 4.3(a) and (b).

Table 4.3(a) Circuit element $R s, R p_{1}, C_{1}$ and $B_{1}$ values and their error percents for circuit in Figure 4.22.

\begin{tabular}{|l|r|r|r|r|r|r|r|r|}
\hline Time & \multicolumn{2}{|c|}{ Rs } & \multicolumn{2}{c|}{ Rp $_{1}$} & \multicolumn{2}{c|}{$\mathrm{C}_{1}$} & \multicolumn{2}{|c|}{$\beta_{1}$} \\
\hline & Value & Error \% & Value & Error \% & \multicolumn{1}{c|}{ Value } & Error \% & Value & Error \% \\
\hline Day 21 & 36.85 & 6.754 & 349.5 & 0.78498 & $1.0287 \mathrm{E}-09$ & 1.464 & 0.99519 & 0.75382 \\
\hline Day 14 & 39.91 & 6.218 & 520.2 & 0.58454 & $1.1038 \mathrm{E}-09$ & 1.031 & 1 & 0.63981 \\
\hline Day 7 & 41.47 & 6.556 & 530 & 0.59391 & $1.1990 \mathrm{E}-09$ & 1.031 & 1.003 & 0.68103 \\
\hline Day 4 & 39.89 & 3.417 & 419.7 & 0.38301 & $1.2216 \mathrm{E}-09$ & 0.68481 & 1.005 & 0.39508 \\
\hline Day 0 & 41.81 & 9.275 & 2608 & 0.51867 & $1.0603 \mathrm{E}-09$ & 1.105 & 1.014 & 0.60944 \\
\hline 30 minute & 41.78 & 14.41 & 2518 & 0.955 & $1.0362 \mathrm{E}-09$ & 1.944 & 1.014 & 1.059 \\
\hline 25 minute & 41.75 & 14.65 & 2569 & 0.97555 & $1.0357 \mathrm{E}-09$ & 1.979 & 1.014 & 1.071 \\
\hline 20 minute & 41.72 & 14.99 & 2646 & 1.006 & $1.0350 \mathrm{E}-09$ & 2.031 & 1.014 & 1.088 \\
\hline 15 minute & 41.71 & 15.13 & 2773 & 1.026 & $1.0338 \mathrm{E}-09$ & 2.06 & 1.014 & 1.087 \\
\hline 10 minute & 41.26 & 11.12 & 2958 & 0.74104 & $1.0327 \mathrm{E}-09$ & 1.504 & 1.013 & 0.77664 \\
\hline
\end{tabular}

Table 4.3.(b) Circuit elements $C_{2}$, and $B_{2}$ values and their error percents for circuit in Figure 4.22 and the chi-square value of curve fit.

\begin{tabular}{|l|r|r|r|r|r|}
\hline Time & \multicolumn{2}{|c|}{$\mathrm{C}_{2}$} & \multicolumn{2}{|c|}{$\beta_{2}$} & Chi Square \\
\hline & \multicolumn{1}{|c|}{ Value } & Error \% & \multicolumn{1}{|c|}{ Value } & Error \% & \\
\hline Day 21 & 0.000346 & 0.30101 & 0.81045 & 0.13776 & 0.001702 \\
\hline Day 14 & 0.000317 & 0.32173 & 0.80155 & 0.14996 & 0.001747 \\
\hline Day 7 & 0.000331 & 0.36771 & 0.79994 & 0.15939 & 0.002196 \\
\hline Day 4 & 0.000356 & 0.18064 & 0.78905 & 0.083391 & 0.000557 \\
\hline Day 0 & 0.000354 & 1.18 & 0.68458 & 0.67196 & 0.008087 \\
\hline 30 minute & 0.00042 & 2.466 & 0.61167 & 2.139 & 0.013568 \\
\hline 25 minute & 0.000425 & 2.564 & 0.60243 & 2.256 & 0.014094 \\
\hline 20 minute & 0.000437 & 2.729 & 0.58877 & 2.452 & 0.014947 \\
\hline 15 minute & 0.000457 & 2.939 & 0.57150 & 2.706 & 0.01562 \\
\hline 10 minute & 0.000491 & 2.474 & 0.59578 & 2.348 & 0.009218 \\
\hline
\end{tabular}


The \% error of circuit parameters for the CPE agrees with the experimental results. The chi square values for time 10 minute to 30 minute using this model are high compared to that for Day $0,4,7,14$ and 21 . That means this model predicts interface phenomenon for day 0 to 21 better than for time 10 minute to 30 minute. The behavior of the system in days 4 to 21 is not purely diffusive since the beta value for this element is not 0.5 as is usual in most diffusion cases. The chi-square values are higher or the same for the curve fits indicating that this circuit is not a better representative equivalent circuit.

From the results it can be inferred that for the first few hours the two CPE model can represent the interface and bulk behavior. The interface behavior is corrosion controlled when the surface of SS 316 is polished and this control does not last very long indicating rapid reaction towards passivation.

For days 4 to 21 the second circuit (Fig. 4.22) can also represent the bulk and interface behavior. The interface behavior for polished electrodes is not as defined as in Randles circuit. Alternate circuit model is developed to represent the response in the passive region. No model fitted the response obtained for days 4, 7.14 and 21 .

For an unpolished sample the circuit model was found to be similar to the Randle's circuit model. Therefore, it can be inferred that the behavior of the interface is different when SS 316 is passivated in air in comparison to SS 316 passivated in DI water. 


\section{CHAPTER 5: CONCLUSIONS AND RECOMMENDATIONS}

The equivalent circuit that represented SS 316 DI water system best was a circuit with two constant phase elements. One of these constant phase elements was found to be a pure capacitor. This capacitor resulted from the parallel plate arrangement of the electrodes and having DI water in between the electrodes. The second constant phase element resulted from the resistance of charge transfer at the interface. This resistance of the constant phase element kept increasing over time. It can be inferred that one compact interfacial layer formed during the experiment. As this interface layer kept growing the charge transfer resistance kept increasing which resulted in the passivation of the metal.

It can also be concluded from this research that electrochemical impedance spectroscopy can be used to detect the interfacial change in the SS 316 and deionized water system in the reaction control regime where the equivalent circuit represented the system very well. The reaction control regime was represented by the constant phase element detected at low frequency region.

At diffusion control regime the change was very slow and the responses did not follow any pattern. A modified capacitance model was developed to represent the diffusion control regime. Normally Warburg diffusion coefficients are used to model such system. The modified capacitance model response also did not fit the system response any better than the circuit with two constant phase element. The thesis model was limited to the four 
models in the hypothesis. Therefore it is recommended that more models be investigated to predict the diffusion control corrosion regime and incorporate the change from corrosion control to diffusion control.

The thesis study was conducted with electrodes having the same area. Investigation of the effect of change in electrode area on the components was not necessary to develop the electrical models. However to apply this model to other systems such an investigation is recommended.

One of the most important factors that influence corrosion highly is the oxygen level. A study by EIS method at different oxygen level will reveal the effect of it on the interface. The thesis study was conducted at atmospheric pressure and an oxygen level of $9 \mathrm{ppm}$.

A closer look at the interface simultaneously with the investigation of the interfacial film by electron spectroscopy is also recommended. Surface study can be conducted using Scanning Electron Microscope (SEM) and X-ray Diffraction method. These methods will provide information on morphology and the composition at the interface. 


\section{REFERENCES}

Capobianco, G., G. Sandona, T. Monetta and F. Belluci, 1993, Corrosion Science, Passive Films on Stainless Steel after Gamma Ray Irradiation, as Studied by Electrochemical Impedance Spectroscopy, Vol. 35, Nos. 1-4, 35-41.

Feng, Y., W. K. Teo, K. S. Siow, K. L. Tan and A. K. Hsieh, 1996, Corrosion Science, The Corrosion Behavior of Copper in Neutral Tap Water. Part I: Corrosion Mechanism, Vol. 38, No. 3, 369-385.

Ferreira, M. G. S. and J. L. Dawson, 1985, Journal of Electrochemical Society, Electrochemical Studies of the Passive Film on 316 Stainless Steel in Chloride Media, Vol. 132, No. 4, 760-765.

Hultquist, G., C. Leygraf and D. Brune, 1984, Journal of Electrochemical Society, Quantitative measurement of Chromium, Iron, and Molybdenum from Stainless Steel, Vol. 131, No. 8. 1773-1776.

Jones. D. A., 1996, Principles and Prevention of Corrosion, Prentice Hall, Upper Saddle River, NJ, p75-79.

Kendig, M. W., E. M. Meyer, G. Lindberg and F. Mansfield, 1983, Corrosion Science, $A$ Computer Analysis of Electrochemical Impedance Data, Vol. 23, No. 9, $1007-$ 1015.

Lula, R. A., 1986, Stainless Steel, American Society of Metals, Metals Park, Ohio, 64-65.

Mabuchi, K., M. Sakai, N. Ohnaka, 1994, Zairyo-to-Kankyo, A Study on Corrosion Behavior of Type 304 Stainless Steel with Electrochemical Impedance Spectroscopy in High Temperature Pure Water, 43, No. 1, 2-10.

Macdonald, D. D., 1978, Journal of Electrochemical Society, A Method for Estimating Impedance Parameters for Electrochemical Systems That Exhibits Pseudoinductance, Vol. 125, No. 12. 2062-2064.

Macdonald. D. D.. 1990. Corrosion Science. Some Advantages and Pitfalls of Electrochemical Impedance Spectroscopy, Vol. 46. No. 3, 229-241.

Moore T., J. Carey and M. Lapides, 1991, EPRI JOURNAL, The Long View for Nuclear Plant Maintenance, October/November, 24-31.

Rubinstein Israel, 1995, Physical Electrochemistry - Principles. Methods, and Applications, Mercel Dekker, Inc., NY, p-243-298. 
Silverman, D.C. and J.E. Carrico, 1987, Corrosion Science, Electrochemical Impedance Technique-A Practical Tool for Corrosion Prediction. Vol. 44, No. 5, 280-287.

Taylor, S. R, J.R. Scully, D. A. Johnson, L.L. Scribner, W.L. Eggers, N.J. Evans, U. Bertocci, 1992, A Short Course on Electrochemical Impedance Spectroscopy, Theory, Applications and Laboratory Instructions, The Center for Electrochemical Science and Engineering, University of Virginia, Charlottesville, Virginia 22903, $2-1,4-5,6-2$.

Scribner Associate, Electrochemistry Software Ver. 2.0, 1997, www.scribner.com. 


\section{APPENDICES}

Page

Appendix A: Derivation of Nyquist Equations from Impedance

Equations

Appendix B: Raw EIS Data as Obtained from Gain Phase Analyzer

Appendix C: Experimental and Simulated (Using Equivalent Circuit with Two CPEs) Nyquist and Bode Plot Response of SS 316 and DI Water System 


\section{Appendix A: Derivation of Nyquist Equations from Impedance Equations}

The impedance for an R-C parallel circuit in series with a resistor can be written as

$Z=R_{S}+R_{p} /(1+j \omega \tau)$

where $Z=$ impedance

$\mathrm{R}_{\mathrm{S}}=$ resistor in series

$R_{P}=$ resistor in parallel with the capacitor $C$

$C=$ is the resistor in parallel with $R_{P}$

$\tau=R_{P} * C$

It is shown here that Equation 3.1 can be written as an equation of a circle.

$Z$ has a real part $Z^{\prime}$ and an imaginary part $Z^{\prime \prime}$ so that

$Z=Z^{\prime}-\mathrm{j} Z^{\prime \prime}$

Substituting component values we get

$Z=R_{S}+R_{P}(1-j \omega \tau) /\{(1+j \omega \tau)(1-j \omega \tau)\}$

or $Z=R_{S}+R_{P} /\left\{1+(\omega \tau)^{2}\right\}-j \omega \tau R_{p} /\left\{1+(\omega \tau)^{2}\right\}$

or, $Z^{\prime}=R_{s}+R_{p} /\left\{1+(\omega \tau)^{2}\right\}$

and $Z^{\prime \prime}=\omega \tau R_{p} /\left\{1+(\omega \tau)^{2}\right\}$

From (A.1)

$1 /\left(1+(\omega \tau)^{2}\right)=\left(Z^{\prime}-R_{S}\right) / R_{P}$

From (A.2)

$1 /\left(1+(\omega \tau)^{2}\right)=Z^{\prime \prime} / \omega \tau R_{P}$

Equating (A.4) and (A.5)

$\left(Z^{\prime}-R_{S}\right) / R_{p}=Z^{\prime \prime} / \omega \tau R_{p}$

or, $\omega \tau=Z^{\prime \prime} /\left(Z^{\prime}-R_{S}\right)$

Substituting $\omega \tau$ in Equation (A.2) yields

$Z^{\prime \prime}=\left(R_{p} Z^{\prime \prime} /\left(Z^{\prime}-R_{S}\right)\right) /\left(1+\left[Z^{\prime \prime} /\left(Z^{\prime}-R_{S}\right)\right]^{2}\right)$

or $Z^{\prime 2}-2 R_{S} Z^{\prime}+R_{S}{ }^{2}+Z^{\prime \prime 2}=R_{P}\left(Z^{\prime}-R_{S}\right)$ 
or $Z^{\prime 2}-2 R_{S} Z^{\prime}-R_{P} Z^{\prime}+R_{P} R_{S}+R_{S}^{2}+\left(0.5 R_{P}\right)^{2}+Z^{\prime \prime 2}=\left(0.5 R_{P}\right)^{2}$

or $\left[Z^{\prime}-\left(2 R_{S}+R_{P}\right) / 2\right]^{2}+Z^{\prime \prime 2}=\left(R_{P} / 2\right)^{2}$

Equation (A.7) is an equation of a circle where $Z^{\prime}$ and $Z^{\prime \prime}$ are variables.

Equation (3.2) is an expression for impedance of a constant phase element connected in series with a resistor. Equation (A.8) is the general impedance equation. It will be shown that Equation (3.2) can be written as an equation of a circle.

$$
\begin{aligned}
Z= & Z^{\prime}-j Z^{\prime \prime} \\
Z= & R_{S}+R_{P} /\left(1+(j \omega \tau)^{\beta}\right) \\
= & R_{S}+R_{P} /\left(1+(\omega \tau)^{\beta} j^{\beta}\right) \\
= & R_{S}+R_{P} /\left[1+(\omega \tau)^{\beta}\{\cos (\pi \beta) / 2+j \sin (\pi \beta) / 2\}\right] \\
= & R_{S}+\left[R_{P}^{*}\left\{1+(\omega \tau)^{\beta} \cos (\pi \beta / 2)-j(\omega \tau)^{\beta} \sin (\pi \beta / 2)\right\}\right] / \\
& \quad\left[\left\{1+(\omega \tau)^{\beta} \cos (\pi \beta / 2)+j(\omega \tau)^{\beta} \sin (\pi \beta / 2)\right\}\left\{1+(\omega \tau)^{\beta} \cos (\pi \beta / 2)-j(\omega \tau)^{\beta} \sin (\pi \beta / 2)\right\}\right] \\
= & R_{S}+\left[R_{P}+R_{P}(\omega \tau)^{\beta} \cos (\pi \beta / 2)\right. \\
& \left.\quad-j R_{P}(\omega \tau)^{\beta} \sin (\pi \beta / 2)\right] /\left[\left\{1+(\omega \tau)^{\beta} \cos (\pi \beta / 2)\right\}^{2}+(\omega \tau)^{2 \beta} \sin ^{2}(\pi \beta / 2)\right]
\end{aligned}
$$

Separating the real and imaginary parts we get,

$$
\left.Z^{\prime}=R_{S}+R_{P}\left[1+(\omega \tau)^{\beta} \cos (\pi \beta / 2)\right]\right) /\left[\left\{1+(\omega \tau)^{\beta} \cos (\pi \beta / 2)\right\}^{2}+(\omega \tau)^{2 \beta} \sin ^{2}(\pi \beta / 2)\right]
$$

$Z^{\prime \prime}=R_{P}(\omega \tau)^{\beta} \sin (\pi \beta / 2) /\left[\left\{1+(\omega \tau)^{\beta} \cos (\pi \beta / 2)\right\}^{2}+(\omega \tau)^{2 \beta} \sin ^{2}(\pi \beta / 2)\right]$

From Equation (A.9)

$$
\left[\left\{1+(\omega \tau)^{\beta} \cos (\pi \beta / 2)\right\}^{2}+(\omega \tau)^{2 \beta} \sin ^{2}(\pi \beta / 2)\right]=\left(Z^{\prime}-R_{S}\right) / R_{P}\left[1+(\omega \tau)^{\beta} \cos (\pi \beta / 2)\right]
$$

From Equation (A.10)

$$
\left[\left\{1+(\omega \tau)^{\beta} \cos (\pi \beta / 2)\right\}^{2}+(\omega \tau)^{2 \beta} \sin ^{2}(\pi \beta / 2)\right]=Z^{\prime \prime} / R_{P}\left[1+(\omega \tau)^{\beta} \sin (\pi \beta / 2)\right]
$$


Equation the value of $\left[\left\{1+(\omega \tau)^{\beta} \cos (\pi \beta / 2)\right\}^{2}+(\omega \tau)^{2 \beta} \sin ^{2}(\pi \beta / 2)\right]$ from Equations (A.11) and (A.12) we get,

$\left(Z^{\prime}-R_{S}\right)\left((\omega \tau)^{\beta} \sin (\pi \beta / 2)=Z^{\prime \prime}+Z^{\prime \prime}\left((\omega \tau)^{\beta} \cos (\pi \beta / 2)\right.\right.$

or $(\omega \tau)^{\beta}=Z^{\prime \prime} /\left\{\left(Z^{\prime}-R_{S}\right) \sin (\pi \beta / 2)-\left(Z^{\prime \prime} \cos (\pi \beta / 2)\right\}\right.$

Subsituting the value of $(\omega \tau)^{\beta}$ in Equation (A.10) we get,

or $Z^{\prime \prime}=\left[\left\{R_{p} \sin (\pi \beta / 2) Z^{\prime \prime}\right\} /\left\{\left(Z^{\prime}-R_{S}\right) \sin (\pi \beta / 2)-Z^{\prime \prime} \cos (\pi \beta / 2)\right\}\right] /$

$\left[1+\left\{\left(2 \cos \left(\pi \beta / 2 Z^{\prime \prime}\right\} /\left\{\left(Z^{\prime}-R_{S}\right) \sin (\pi \beta / 2)-Z^{\prime \prime} \cos (\pi \beta / 2)\right\}\right.\right.\right.$

$\left.+Z^{\prime \prime 2} /\left\{\left(Z^{\prime}-R_{S}\right) \sin (\pi \beta / 2)-Z^{\prime \prime} \cos (\pi \beta / 2)\right\}^{2}\right]$

or $1+\left\{\left(2 \cos \left(\pi \beta / 2 Z^{\prime \prime}\right\} /\left\{\left(Z^{\prime}-R_{S}\right) \sin (\pi \beta / 2)-Z^{\prime \prime} \cos (\pi \beta / 2)\right\}+Z^{\prime \prime 2} /\left\{\left(Z^{\prime}-R_{S}\right) \sin (\pi \beta / 2)-\right.\right.\right.$ $\left.Z^{\prime \prime} \cos (\pi \beta / 2)\right\}^{2}=\left\{R_{P} \sin (\pi \beta / 2)\right\} /\left\{\left(Z^{\prime}-R_{S}\right) \sin (\pi \beta / 2)-Z^{\prime \prime} \cos (\pi \beta / 2)\right\}$

or $\left\{\left(Z^{\prime}-R_{S}\right) \sin (\pi \beta / 2)-Z^{\prime \prime} \cos (\pi \beta / 2)\right\}^{2}+2 \cos (\pi \beta / 2)\left\{\left(Z^{\prime}-R_{S}\right)\right.$

$\left.\sin (\pi \beta / 2)-Z^{\prime \prime} \cos (\pi \beta / 2)\right\}+Z^{\prime \prime 2}$

$=\left\{R_{p} \sin (\pi \beta / 2)\right\}\left\{\left(Z^{\prime}-R_{S}\right) \sin (\pi \beta / 2)-Z^{\prime \prime} \cos (\pi \beta / 2)\right\}$

From Equation (A.13)

$$
\begin{aligned}
\text { LHS }= & \left\{\left(Z^{\prime}-R_{S}\right) \sin (\pi \beta / 2)-Z^{\prime \prime} \cos (\pi \beta / 2)\right\}^{2}+2 \cos (\pi \beta / 2)\left\{\left(Z^{\prime}-R_{S}\right) \sin (\pi \beta / 2)-\right. \\
& \left.Z^{\prime \prime} \cos (\pi \beta / 2)\right\}+Z^{\prime \prime 2} \\
= & \left(Z^{\prime}-R_{S}\right)^{2} \sin ^{2}(\pi \beta / 2)-2\left(Z^{\prime}-R_{S}\right) Z^{\prime \prime} \sin (\pi \beta / 2) \cos (\pi \beta / 2)+Z^{\prime \prime} \cos ^{2}(\pi \beta / 2) \\
\quad+2\left(Z^{\prime}-R_{S}\right) Z^{\prime \prime} \sin (\pi \beta / 2) \cos (\pi \beta / 2)-2 Z^{\prime \prime 2} \cos ^{2}(\pi \beta / 2)+Z^{\prime \prime 2} & \\
= & \left(Z^{\prime}-R_{S}\right)^{2} \sin ^{2}(\pi \beta / 2)+Z^{\prime \prime} \cos ^{2}(\pi \beta / 2)-2 Z^{\prime \prime 2} \cos ^{2}(\pi \beta / 2)+Z^{\prime \prime 2}
\end{aligned}
$$

From Equation (A.13)

$$
\begin{aligned}
\text { RHS } & =\left\{R_{P} \sin (\pi \beta / 2)\right\}\left\{\left(Z^{\prime}-R_{S}\right) \sin (\pi \beta / 2)-Z^{\prime \prime} \cos (\pi \beta / 2)\right\} \\
& =R_{P}\left(Z^{\prime}-R_{S}\right) \sin ^{2}(\pi \beta / 2)-R_{P} Z^{\prime \prime} \sin (\pi \beta / 2) \cos (\pi \beta / 2)
\end{aligned}
$$

Equating final expressions of LHS and RHS yields

$$
\begin{aligned}
&\left(Z^{\prime}-R_{S}\right)^{2} \sin ^{2}(\pi \beta / 2)-R_{P}\left(Z^{\prime}-R_{S}\right) \sin ^{2}(\pi \beta / 2)+ \\
& Z^{\prime \prime 2}\left\{1-\cos ^{2}(\pi \beta / 2)\right\}+R_{P} Z^{\prime \prime} \sin (\pi \beta / 2) \cos (\pi \beta / 2)=0
\end{aligned}
$$




$$
\begin{aligned}
& \text { or } \sin ^{2}(\pi \beta / 2)\left[\left(Z^{\prime}-R_{S}\right)^{2}-R_{P}\left(Z^{\prime}-R_{S}\right)\right]+Z^{\prime \prime 2} \sin ^{2}(\pi \beta / 2)+R_{P} Z^{\prime \prime} \sin (\pi \beta / 2) \cos (\pi \beta / 2)=0 \\
& \text { or } \sin ^{2}(\pi \beta) / 2\left[\left(Z^{\prime 2}-2 R_{S} Z^{\prime}-R_{P} Z^{\prime}+R_{P} R_{S}+\left(0.5 R_{P}\right)^{2}+R_{s}^{2}\right]+\right. \\
& {\left[\left(Z^{\prime \prime} \sin ^{2}(\pi \beta / 2)+2 Z^{\prime} \sin (\pi \beta / 2) * 0.5 R_{P} \cos (\pi \beta / 2)+\left\{0.5 R_{P} \cos (\pi \beta / 2)\right\}^{2]}=\right.\right.} \\
& 0.25 R_{p}^{2} \sin ^{2}(\pi \beta / 2)+0.25 R_{p}^{2} \cos ^{2}(\pi \beta / 2) \\
& \text { or } \sin ^{2}(\pi \beta) / 2\left[\left(Z^{\prime 2}-2 R_{S} Z^{\prime}-R_{P} Z^{\prime}+R_{P} R_{S}+\left(0.5 R_{P}\right)^{2}+R_{S}{ }^{2}\right]+\right. \\
& {\left[\left(Z^{\prime \prime 2} \sin ^{2}(\pi \beta / 2)+2 Z^{\prime} \sin (\pi \beta / 2)^{*} 0.5 R_{P} \cos (\pi \beta / 2)+\left\{0.5 R_{P} \cos (\pi \beta / 2)\right\}^{2]}=\left(0.5 R_{P}\right)^{2}\right.\right.} \\
& \text { or }\left[Z^{\prime}-\left(2 R_{S}+R_{P}\right) / 2\right]^{2}+\left[Z^{\prime \prime}+0.5 R_{P} \cot (\pi \beta / 2)\right]^{2}=\left[\left(0.5 R_{P}\right) / \sin (\pi \beta / 2)\right]^{2}(A .14)
\end{aligned}
$$

If $Z^{\prime}$ and $Z^{\prime \prime}$ are variables, Equation (A.14) is an equation of a circle.

Equations (A.7) and (A.14) are the Nyquist equations for the two impedances given in Equations (3.1) and (3.2) respectively. 
Appendix B: Raw EIS Data as obtained from Gain Phase Analyzer

ZPlotW Data File: Version 2.0

Raw Data $10 \mathrm{~min}$

Sweep Frequency: Control Voltage

Open Circuit Potential (V): -0.0065

\begin{tabular}{|c|c|c|c|c|c|}
\hline Dbs. & Freq(Hz) & Ampl & Time(Sec) & $Z^{\prime}(a)$ & $Z^{\prime \prime}(\mathrm{b})$ \\
\hline 1 & $1.00 \mathrm{E}+06$ & $2.00 \mathrm{E}-02$ & $8.07 E+00$ & $4.90 \mathrm{E}+01$ & $2 E+02$ \\
\hline 2 & $.31 \mathrm{E}+05$ & $2.00 \mathrm{E}-02$ & $.24 \mathrm{E}+0 \mathrm{I}$ & $5.30 \mathrm{E}+01$ & $-2.34 E+02$ \\
\hline 3 & $98 \mathrm{E}+05$ & $2.00 \mathrm{E}-02$ & $.50 \mathrm{E}+0 \mathrm{I}$ & $7.34 E+01$ & $-3.73 E+02$ \\
\hline 4 & $5 ! E+05$ & $2.00 \mathrm{E}-02$ & $.76 \mathrm{E}+0 \mathrm{I}$ & $1.40 \mathrm{E}+02$ & $-5.87 E+02$ \\
\hline 5 & $58 \mathrm{E}+05$ & $2.00 \mathrm{E}-02$ & & $3.18 E+02$ & $-8.80 E+02$ \\
\hline 6 & $00 \mathrm{E}+05$ & $2.00 \mathrm{E}-02$ & & $6.60 E+02$ & $-1.22 E+03$ \\
\hline 7 & $31 E+04$ & 2.00 & & & $-1.48 E+03$ \\
\hline 8 & +04 & 2.00 & & & -1.471 \\
\hline 9 & 4 & & & & -1.2 \\
\hline 10 & & & & & \\
\hline 11 & & & & & \\
\hline 12 & 3 & & & & 02 \\
\hline 13 & +03 & 2.00 & & & 02 \\
\hline 14 & +03 & 2.0 & & & $-1.53 E+02$ \\
\hline 15 & +03 & 2.0 & & & $-9.94 E+0 I$ \\
\hline 16 & +03 & 2.0 & & & $-6.49 E+01$ \\
\hline 17 & +02 & & & & $-4.32 \mathrm{E}+01$ \\
\hline 18 & +02 & & & & $-3.05 E \div 01$ \\
\hline 19 & +02 & & & 03 & $-2.37 \mathrm{E}+01$ \\
\hline 20 & +02 & & 01 & 03 & $-2.13 \mathrm{E}+01$ \\
\hline 21 & +02 & & & +03 & $-2.2|E+0|$ \\
\hline 22 & +01 & 2.0 & & 03 & $-2.60 \mathrm{E}+0 \mathrm{I}$ \\
\hline 23 & +01 & 2.0 & & 03 & $-3.34 E+01$ \\
\hline 24 & 01 & & & 03 & $-4.49 \mathrm{E}+0 \mathrm{I}$ \\
\hline 25 & +01 & 2.0 & 01 & & $-6.19 E+01$ \\
\hline 26 & +01 & & & 03 & $-8.64 E+01$ \\
\hline 27 & $E+00$ & 2.0 & & +03 & $-1.2 \mathrm{IE}+02$ \\
\hline 28 & $98 \mathrm{E}+00$ & 2.00 & +01 & +03 & $-1.70 \mathrm{E}+02$ \\
\hline 29 & $2.51 \mathrm{E}+00$ & $2.00 \mathrm{E}-02$ & & & $-2.39 E+02$ \\
\hline 30 & $1.58 \mathrm{E}+00$ & $2.00 \mathrm{E}-02$ & $9.51 \mathrm{E}+01$ & $3.17 \mathrm{E}+03$ & $-3.41 E \div 02$ \\
\hline 31 & $1.00 \mathrm{E}+00$ & $2.00 \mathrm{E}-02$ & $9.78 \mathrm{E}+0 \mathrm{I}$ & $3.24 \mathrm{E} \div 03$ & $-4.71 E+02$ \\
\hline 32 & $6.31 \mathrm{E}-01$ & $2.00 \mathrm{E}-02$ & $1.02 E+02$ & $3.31 E+03$ & $-6.68 E+02$ \\
\hline 33 & -01 & 2.00 & $1.05 \mathrm{E}+02$ & $3.47 \mathrm{E} \div 03$ & $-9.04 E+02$ \\
\hline 34 & -01 & 2.00 & $E+02$ & $3.72 \mathrm{E}+03$ & $-1.35 E+03$ \\
\hline 35 & 0 & 2.0 & $:+02$ & $4.06 E+03$ & $-1.69 \mathrm{E}+03$ \\
\hline 36 & & & & $4.67 E+03$ & $-2.36 \mathrm{E}+03$ \\
\hline 37 & & & & $5.54 \mathrm{E} \div 03$ & $-2.7 I E+03$ \\
\hline 38 & $4.00 \mathrm{E}-02$ & $2.00 \mathrm{E}-02$ & $1.74 \mathrm{E}+02$ & $6.72 E+03$ & $-3.07 E+03$ \\
\hline
\end{tabular}


Appendix B continued

ZPlotW Data File: Version 2.0

Raw Data: $15 \mathrm{~min}$

Sweep Frequency: Contro! Yoltage

Open Circuit Potential (V): -0.0065

\begin{tabular}{|c|c|c|c|c|c|}
\hline Obs. & Freq(Hz) & Ampl & Time(Sec) & $Z^{\prime}(a)$ & $Z^{\prime \prime}(b)$ \\
\hline 1 & $1.00 E+06$ & $2.00 \mathrm{E}-02$ & $8.18 \mathrm{E}+00$ & $5 \mathrm{E}+01$ & $52 \mathrm{E}+02$ \\
\hline 2 & $6.31 E+05$ & $2.00 \mathrm{E}-02$ & $1.25 E+01$ & $5.41 E+01$ & $-2.34 \mathrm{E}+02$ \\
\hline 3 & $3.98 E+05$ & $2.00 \mathrm{E}-02$ & $.51 E+01$ & $7.62 \mathrm{E}+0 \mathrm{I}$ & $-3.72 \mathrm{E}+02$ \\
\hline 4 & $2.51 E+05$ & $2.00 \mathrm{E}-02$ & & $47 E+02$ & $-5.84 E+02$ \\
\hline 5 & $1.58 E+05$ & $2.00 \mathrm{E}-02$ & & $3.32 \mathrm{E}+02$ & $-8.70 E+02$ \\
\hline 6 & $E+05$ & $2.00 E-02$ & & $81 E+02$ & $-1.19 E+03$ \\
\hline 7 & +04 & $2.00 \mathrm{E}-02$ & & 03 & \\
\hline 8 & & $2.00 \mathrm{E}$ & & & \\
\hline 9 & & & & & \\
\hline 10 & & & & & \\
\hline 11 & & 2.0 & & 3 & \\
\hline 12 & +03 & $2.00 \mathrm{E}-02$ & & $E+03$ & \\
\hline 13 & +03 & 2.00 & -01 & $E+03$ & $E+02$ \\
\hline 14 & +03 & 2.00 & & $E+03$ & $E+02$ \\
\hline 15 & 03 & 2.0 & & $E+03$ & $E+01$ \\
\hline 16 & & 2.0 & & $E+03$ & $-5.79 E+01$ \\
\hline 17 & 02 & 2.0 & & $E+03$ & $E+0 \mid$ \\
\hline 18 & +02 & 2.0 & & $E+03$ & $-2.82 \mathrm{E}+0 \mathrm{I}$ \\
\hline 19 & & 2.0 & & $E+03$ & $-2.22 \mathrm{E}+0 \mathrm{I}$ \\
\hline 20 & & 2.0 & & $E+03$ & $-2.05 E+01$ \\
\hline 21 & & 2.0 & & $E+03$ & $-2.18 \mathrm{E}+0 \mathrm{I}$ \\
\hline 22 & & 2.0 & & $E+03$ & $-2.62 \mathrm{E}+0 \mathrm{I}$ \\
\hline 23 & & & & $E+03$ & $-3.39 E+01$ \\
\hline 24 & 01 & 2.0 & & 03 & $-4.59 \mathrm{E}+01$ \\
\hline 25 & +01 & 2.0 & & 03 & $E+01$ \\
\hline 26 & +01 & 2.00 & & $E+03$ & $E+01$ \\
\hline 27 & +00 & $2.00 \mathrm{E}-02$ & & 2. & $E+02$ \\
\hline 28 & +00 & $2.00 \mathrm{E}-02$ & $E+01$ & $2.95 \mathrm{E}+03$ & $-1.75 E+02$ \\
\hline 29 & $2.51 E+00$ & $2.00 \mathrm{E}-02$ & 9.2 & $2.97 \mathrm{E}+03$ & $E+02$ \\
\hline 30 & +00 & 2.001 & & $3.02 E+03$ & $E+02$ \\
\hline 31 & +00 & $2.00 \mathrm{E}$ & $E+01$ & $3.08 E+03$ & $-4.87 E+02$ \\
\hline 32 & & 2.0 & +02 & $3.17 \mathrm{E}+03$ & $-6.89 E+02$ \\
\hline 33 & & & +02 & $3.34 E+03$ & $-9.33 E+02$ \\
\hline 34 & & & & $3.57 E+03$ & $-1.40 \mathrm{E}+03$ \\
\hline 2 & & & & $3.91 E+03$ & $-1.77 \mathrm{E}+03$ \\
\hline 3 & & 2.0 & & $4.52 E+03$ & $-2.49 \mathrm{E}+03$ \\
\hline 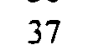 & & & & $5.43 E+03$ & $-2.93 E+03$ \\
\hline 2 & & & $=02$ & $6.72 E+03$ & $-3.39 E+03$ \\
\hline 30 & 0.0252 & 0.02 & 257.48 & 8179.8 & -3687.6 \\
\hline
\end{tabular}


Appendix B continued

ZPlotW Data File: Version 2.0

Raw Data 20 min

Sweep Frequency: Control Voltage

Open Circuit Potential (V): -0.0065

\begin{tabular}{|c|c|c|c|c|c|}
\hline Obs. & $\mathrm{Hz}$ ) & pl & c) & $Z^{\prime}(a)$ & $Z^{\prime \prime}(b)$ \\
\hline l & $1.00 \mathrm{E}+06$ & $2.00 \mathrm{E}-02$ & $8.07 E+00$ & $E+01$ & $2 E+02$ \\
\hline 2 & $6.31 \mathrm{IE}+05$ & $2.00 \mathrm{E}-02$ & $.24 E+01$ & $5.52 \mathrm{E}+0 \mathrm{I}$ & +02 \\
\hline 3 & $3.98 \mathrm{E}+05$ & $2.00 \mathrm{E}-02$ & $.49 E+01$ & $7.87 E+01$ & $-3.71 E+02$ \\
\hline 4 & $2.51 E+05$ & $2.00 \mathrm{E}-02$ & $.76 E+01$ & $1.52 \mathrm{E}+02$ & $-5.81 E+02$ \\
\hline 5 & $1.58 \mathrm{E}+05$ & $2.00 \mathrm{E}-02$ & $2.48 \mathrm{E}+0 \mathrm{I}$ & $3.43 \mathrm{E}+02$ & $-8.60 E+02$ \\
\hline 6 & $1.00 \mathrm{E}+05$ & $2.00 \mathrm{E}-02$ & $2.74 \mathrm{E}+0 \mathrm{I}$ & $6.98 \mathrm{E}+02$ & $-1.17 \mathrm{E}+03$ \\
\hline 7 & $6.31 E+04$ & $2.00 \mathrm{E}-02$ & $3.28 \mathrm{E}+01$ & $1.25 \mathrm{E}+03$ & $-1.35 E+03$ \\
\hline 8 & $3.98 \mathrm{E}+04$ & $2.00 \mathrm{E}-02$ & .54 & $1.85 \mathrm{E}+03$ & $-1.28 \mathrm{E}+03$ \\
\hline 9 & 2.51 & $2.00 \mathrm{E}-02$ & 3.79 & $2.31 E+03$ & $-1.01 E+03$ \\
\hline 10 & & $2.00 \mathrm{E}-02$ & $4.05 \mathrm{E}$ & $.56 \mathrm{E}+03$ & $-7.07 \mathrm{E} \div 02$ \\
\hline 11 & 1.00 & $2.00 \mathrm{E}-02$ & 4.31 & $2.67 \mathrm{E}+03$ & $-4.68 \mathrm{E}+02$ \\
\hline 12 & & $2.00 \mathrm{E}-02$ & & & $-3.03 E+02$ \\
\hline 13 & & & & & $-1.93 E+02$ \\
\hline 14 & & & & & 02 \\
\hline 15 & & & & & $3 E+0 l$ \\
\hline 16 & & 2.0 & & 03 & $-5.33 E+01$ \\
\hline 17 & & 2.0 & & & $-3.60 \mathrm{E}+0$ \\
\hline 18 & & 2.00 & & & $-2.60 \mathrm{E}+0$ \\
\hline 19 & & 2.00 & & +03 & $-2.11 E \div 01$ \\
\hline 20 & & 2.0 & & +03 & $-2.00 \mathrm{E}+0 \mathrm{I}$ \\
\hline 21 & & 2.0 & & $:+03$ & $-2.17 \mathrm{E}+0 \mathrm{I}$ \\
\hline 22 & & 2.0 & & $E+03$ & $-2.65 \mathrm{E}+0 \mathrm{l}$ \\
\hline 23 & & 2.0 & & +03 & $-3.45 E+0 l$ \\
\hline 24 & & 2.0 & & +03 & $-4.69 E+01$ \\
\hline 25 & & 2.0 & & +03 & $-6.52 E+0 !$ \\
\hline 26 & & 2.0 & & +03 & $-9.15 E+01$ \\
\hline 27 & & 2.00 & & +03 & $-1.28 E+02$ \\
\hline 28 & & 2.00 & & $\div 03$ & $-1.80 E+02$ \\
\hline 29 & & 2.00 & & $:+03$ & $-2.54 E+02$ \\
\hline 30 & & & & $E+03$ & $-3.63 E+02$ \\
\hline 31 & $1.00 E+00$ & 2.00 & & $2.97 E+03$ & $-5.04 E+02$ \\
\hline 32 & $6.31 \mathrm{E}-01$ & $2.00 \mathrm{E}-02$ & 1.031 & $3.05 E+03$ & $-7.12 \mathrm{E}+02$ \\
\hline 33 & -01 & $2.00 \mathrm{E}-02$ & 1.06 & $3.22 E+03$ & $-9.64 E \div 02$ \\
\hline 34 & 2.51 & $2.00 \mathrm{E}-02$ & 1.101 & +03 & $-1.45 \mathrm{E}+03$ \\
\hline 35 & 1.5 & $2.00 \mathrm{E}-02$ & 1.1 & $E+03$ & $-1.86 E+03$ \\
\hline 36 & & $2.00 \mathrm{E}$ & 1.28 & $E+03$ & $-2.46 \mathrm{E}+03$ \\
\hline 37 & & $2.00 \mathrm{E}$ & 1.4 & $5.44 E+03$ & $-3.27 E+03$ \\
\hline 38 & & $2.00 \mathrm{E}-02$ & 1.71 & $6.74 E+03$ & $-3.89 E+03$ \\
\hline 39 & 0.0252 & 0.02 & 254.85 & 8299.6 & -4163 \\
\hline
\end{tabular}


Appendix B continued

ZPlotW Data File: Version 2.0

Raw Data 25 min

Sweep Frequency: Control Voltage

Open Circuit Potential (V): -0.0065

\begin{tabular}{|c|c|c|c|c|c|}
\hline bs & Freq $(\mathrm{Hz})$ & Ampl & Time(Sec) & $Z^{\prime}(a)$ & $Z^{\prime \prime}(\mathrm{b})$ \\
\hline 1 & $1.00 \mathrm{E}+06$ & $2.00 \mathrm{E}-02$ & 8. $13 E+00$ & $5.02 E+01$ & $-1.52 E+02$ \\
\hline 2 & $6.31 E+05$ & $2.00 \mathrm{E}-02$ & $1.25 \mathrm{E}+01$ & $5.59 \mathrm{E}+01$ & $-2.34 E+02$ \\
\hline 3 & $3.98 E+05$ & $2.00 \mathrm{E}-02$ & $1.50 \mathrm{E}+01$ & $8.03 E+01$ & $-3.70 E+02$ \\
\hline 4 & $2.51 E+05$ & $2.00 \mathrm{E}-02$ & $76 E+01$ & $56 \mathrm{E}+02$ & $-5.80 E+02$ \\
\hline 5 & +05 & $2.00 \mathrm{E}$ & & $51 E+02$ & $-8.54 \mathrm{E}+02$ \\
\hline 6 & +05 & 2.00 & & & $15 E+03$ \\
\hline 7 & $6.31 \mathrm{E}+04$ & $2.00 \mathrm{E}-02$ & $3.28 \mathrm{E}+01$ & $1.25 E+03$ & $1 E+03$ \\
\hline 8 & $98 E+04$ & $2.00 \mathrm{E}-02$ & $.54 \mathrm{E}+01$ & $1.83 E+03$ & $3 E+03$ \\
\hline 9 & $51 E+04$ & $2.00 \mathrm{E}-02$ & $3.80 \mathrm{E}+01$ & $2.26 \mathrm{E}+03$ & $-9.57 E+02$ \\
\hline 10 & $8 E+04$ & $2.00 \mathrm{E}-02$ & +01 & $.49 E+03$ & $-6.67 E+02$ \\
\hline 11 & $1.00 \mathrm{E}+04$ & $2.00 \mathrm{~B}$ & +01 & $2.59 E+03$ & $-4.40 E+02$ \\
\hline 12 & $I E+03$ & 2.00 & 01 & $2.64 \mathrm{E}+03$ & $-2.84 \mathrm{E}+02$ \\
\hline 13 & $8 \mathrm{E}+03$ & 2.00 & 01 & $.66 \mathrm{E}+03$ & $-1.82 E+02$ \\
\hline 14 & $2.51 E+03$ & 2.00 & 01 & $.67 E+03$ & $-1.17 \mathrm{E}+02$ \\
\hline 15 & $1.58 \mathrm{E}+03$ & 2.00 & 5.3 & $2.67 \mathrm{E}+03$ & $-7.56 \mathrm{E}+01$ \\
\hline 16 & $1.00 \mathrm{E} \div 03$ & 2.00 & 5.6 & $2.67 \mathrm{E}+03$ & $-4.99 E+01$ \\
\hline 17 & $6.31 E+02$ & 2.00 & 5.8 & $2.67 \mathrm{E}+03$ & $-3.44 E+01$ \\
\hline 18 & $3.98 \mathrm{E}+02$ & 2.00 & 6.1 & $2.67 E+03$ & $-2.5 l E+01$ \\
\hline 19 & $2.51 \mathrm{I}+02$ & 2.00 & 6.5 & $2.67 \mathrm{E}+03$ & $-2.05 E+01$ \\
\hline 20 & $1.58 E+02$ & 2.00 & & $2.67 \mathrm{E}+03$ & $-1.97 \mathrm{E}+01$ \\
\hline 21 & $1.00 E+02$ & $2.00 \mathrm{E}-02$ & 7.0 & $2.68 \mathrm{E}+03$ & $-2.17 E+01$ \\
\hline 22 & $6.31 E+01$ & $2.00 \mathrm{E}-02$ & $7.35 \mathrm{E}+01$ & $2.68 \mathrm{E}+03$ & $-2.67 \mathrm{E}+01$ \\
\hline 23 & $3.98 \mathrm{E}+01$ & $2.00 \mathrm{E}-02$ & $7.61 \mathrm{E}+01$ & $2.68 E+03$ & $-3.50 \mathrm{E}+01$ \\
\hline 24 & $2.51 E+01$ & $2.00 \mathrm{E}-02$ & 7.8 & $2.69 E+03$ & $-4.78 E+01$ \\
\hline 25 & $1.58 E+0 \mathrm{I}$ & $2.00 \mathrm{E}-02$ & $8.14 \mathrm{E}+01$ & $2.69 E+03$ & $-6.65 E+01$ \\
\hline 26 & $1.00 E+01$ & $2.00 \mathrm{E}-02$ & $E+01$ & $2.71 E+03$ & $-9.33 E+0 I$ \\
\hline 27 & $6.31 E+00$ & $2.00 \mathrm{E}-02$ & $8.67 \mathrm{E}+01$ & $2.72 E+03$ & $-1.31 E+02$ \\
\hline 28 & $3.98 E+00$ & 2.001 & $8.93 E+01$ & $2.74 \mathrm{E}+03$ & $-1.84 E+02$ \\
\hline 29 & $2.51 E+00$ & 2.00 & $9.26 \mathrm{E}+0 \mathrm{I}$ & $2.77 E+03$ & $-2.60 \mathrm{E}+02$ \\
\hline 30 & +00 & 2.00 & 9.5 & $2.82 E+03$ & $-3.72 E+02$ \\
\hline 31 & +00 & 2.00 & & $2.89 E+03$ & $-5.28 \mathrm{E}+02$ \\
\hline 32 & & & & $2.97 E+03$ & $-7.30 \mathrm{E}+02$ \\
\hline 33 & & & & $3.15 E+03$ & $-9.87 E+02$ \\
\hline 34 & -01 & 2.00 & & $3.39 E+03$ & $-1.49 E+03$ \\
\hline 35 & -01 & 2.00 & & $3.7 \mathrm{IE}+03$ & $-1.91 E+03$ \\
\hline 36 & I.00E-0I & 2.00 & & $4.39 E+03$ & $-2.57 \mathrm{E}+03$ \\
\hline 37 & $6.31 E-02$ & $2.00 \mathrm{E}-02$ & & $5.37 E+03$ & $-3.47 \mathrm{E}+03$ \\
\hline 38 & $3.98 \mathrm{E}-02$ & $2.00 \mathrm{E}-02$ & $1.71 E \div 02$ & $6.70 \mathrm{E}+03$ & $-4.21 E+03$ \\
\hline 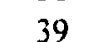 & $2.52 \mathrm{E}-02$ & 2.00 E-02 & $2.54 \mathrm{E}+02$ & $8.40 \mathrm{E} \div 03$ & $-4.57 E+03$ \\
\hline
\end{tabular}


ZPlotW Data File: Version 2.0

Raw Data $30 \mathrm{~min}$

Sweep Frequency: Control Voltage

Open Circuit Potential (V): -0.0065

\begin{tabular}{|c|c|c|c|c|c|}
\hline Obs. & Freq $(\mathrm{Hz})$ & Ampl & Time(Sec) & $Z^{\prime}(a)$ & $Z^{\prime \prime}(\mathrm{b})$ \\
\hline 1 & $1.00 \mathrm{E}+06$ & $2.00 \mathrm{E}-02$ & $8.18 E+00$ & $5.05 \mathrm{E}+01$ & $2 E+02$ \\
\hline 2 & $6.31 E+05$ & $2.00 \mathrm{E}-02$ & $1.25 E+01$ & $5.64 E+01$ & $-2.33 E+02$ \\
\hline 3 & $3.98 \mathrm{E}+05$ & $2.00 \mathrm{E}-02$ & $1.50 E+01$ & $8.15 E+01$ & $-3.70 E+02$ \\
\hline 4 & $2.51 \mathrm{E}+05$ & $2.00 \mathrm{E}-02$ & $1.76 \mathrm{E}+0 \mathrm{I}$ & $1.59 E+02$ & $-5.78 E+02$ \\
\hline 5 & $1.58 \mathrm{E}+05$ & $2.00 \mathrm{E}-02$ & $2.48 \mathrm{E}+0 \mathrm{I}$ & $3.56 \mathrm{E}+02$ & $-8.49 E+02$ \\
\hline 6 & $1.00 \mathrm{E}+05$ & $2.00 \mathrm{E}-02$ & $2.75 \mathrm{E}+01$ & $7.15 \mathrm{E}+02$ & $-1.14 E+03$ \\
\hline 7 & $6.31 E+04$ & 2.00 & & $1.25 \mathrm{E}+03$ & $-1.29 E+03$ \\
\hline 8 & 04 & 2.00 & & & $-1.19 E+03$ \\
\hline 9 & +04 & 2.00 & & & $-9.23 E+02$ \\
\hline 10 & $1.58 \mathrm{E}+04$ & 2.00 & 4.0 & 03 & $1 E+02$ \\
\hline 11 & $1.00 \mathrm{E}+04$ & $2.00 \mathrm{E}-02$ & $4.32 \mathrm{E}$ & $.54 E+03$ & $22 \mathrm{E}+02$ \\
\hline 12 & $6.31 E+03$ & 2.001 & +01 & $2.59 E+03$ & $-2.72 E+02$ \\
\hline 13 & $88 \mathrm{E} \div 03$ & 2.00 & 01 & $2.60 E+03$ & $-1.74 E+02$ \\
\hline 14 & $2.51 E+03$ & 2.00 & 01 & $2.61 \mathrm{E}+03$ & $-1.12 E+02$ \\
\hline 15 & $1.58 E+03$ & 2.00 & 5.3 & $2.61 E+03$ & $-7.29 E+01$ \\
\hline 16 & $1.00 E+03$ & 2.00 & 5.6 & $2.62 E+03$ & $-4.78 E+01$ \\
\hline 17 & $6.31 E+02$ & 2.00 & 5.8 & $2.62 E+03$ & $-3.30 E+01$ \\
\hline 18 & $3.98 \mathrm{E}+02$ & 2.00 & 6.1 & $2.62 \mathrm{E}-03$ & $-2.43 \mathrm{E}+01$ \\
\hline 19 & $2.51 \mathrm{E} \div 02$ & 2.00 & 01 & $2.62 E+03$ & $-2.01 \mathrm{E}+01$ \\
\hline 20 & $1.58 \mathrm{E}+02$ & 2.00 & 01 & $2.62 E+03$ & $-1.95 E+01$ \\
\hline 21 & $1.00 \mathrm{E}+02$ & 2.00 & 7.0 & $2.62 \mathrm{E}+03$ & $-2.17 \mathrm{E}+01$ \\
\hline 22 & $6.31 \mathrm{E}+01$ & 2.00 & 7.3 & $2.62 E+03$ & $-2.68 E+01$ \\
\hline 23 & $3.98 \mathrm{E}+01$ & $2.00 \mathrm{E}-02$ & 7.6 & $2.63 E+03$ & $-3.54 E+01$ \\
\hline 24 & $2.51 \mathrm{E}+01$ & $2.00 \mathrm{E}-02$ & 7.8 & $2.63 E+03$ & $-4.85 E+01$ \\
\hline 25 & $1.58 \mathrm{E}+01$ & $2.00 \mathrm{E}-02$ & +01 & $2.64 E \div 03$ & $-6.76 E+01$ \\
\hline 26 & $1.00 \mathrm{E}+01$ & $2.00 \mathrm{E}-02$ & $8.39 E+01$ & $2.65 E+03$ & $-9.49 E+01$ \\
\hline 27 & $6.31 E+00$ & $2.00 \mathrm{E}-02$ & $8.67 E+01$ & $2.67 \mathrm{E}+03$ & $-1.33 E+02$ \\
\hline 28 & $3.98 \mathrm{E}+00$ & $2.00 \mathrm{E}-02$ & $8.94 E+01$ & $2.69 E+03$ & $-1.88 \mathrm{E}+02$ \\
\hline 29 & $2.51 E+00$ & $2.00 \mathrm{E}-02$ & $9.27 \mathrm{E}+01$ & $2.72 \mathrm{E}+03$ & $-2.65 \mathrm{E}+02$ \\
\hline 30 & $1.58 \mathrm{E}+00$ & $2.00 \mathrm{E}-02$ & $9.57 \mathrm{E}+01$ & $2.77 \mathrm{E}+03$ & $-3.79 E+02$ \\
\hline 31 & $1.00 \mathrm{E}+00$ & 2.00 & 9.8 & $2.84 \mathrm{E} \div 03$ & $-5.25 \mathrm{E}+02$ \\
\hline 32 & 6.31 & 2.00 & & $2.93 \mathrm{E} \div 03$ & $-7.44 \mathrm{E}+02$ \\
\hline 33 & $3.98 \mathrm{E}-01$ & 2.00 & & $3.10 \mathrm{E}$ & $-1.01 E+03$ \\
\hline 34 & 2.51 & 2.00 & & $3.34 \mathrm{E}$ & $-1.52 \mathrm{E}+03$ \\
\hline 35 & 1.58 & 2.00 & & $3.68 \mathrm{E}$ & $-1.95 E+03$ \\
\hline 36 & 1.00 & & & $4.28 \mathrm{E}+03$ & $-2.82 E+03$ \\
\hline 37 & $6.31 \mathrm{E}-02$ & 2.00 & & $5.23 \mathrm{E}+03$ & $-3.46 \mathrm{E}+03$ \\
\hline 38 & $3.98 \mathrm{E}-02$ & $2.00 \mathrm{E}-02$ & $\div 02$ & $7 E \div 03$ & $-4.25 \mathrm{E}+03$ \\
\hline 39 & $2.52 \mathrm{E}-02$ & $2.00 \mathrm{E}-02$ & $2.58 \mathrm{E} \div 02$ & $8.47 \mathrm{E}+03$ & $-4.92 \mathrm{E} \div 03$ \\
\hline
\end{tabular}


Appendix B continued

ZPlotW Data File: Version 2.0

Raw Data Dayo_1

Sweep Frequency: Control Voltage

Open Circuit Potential (V): -0.0065

\begin{tabular}{|c|c|c|c|c|c|}
\hline & $\mathrm{Hz})$ & $n$ & Sec) & 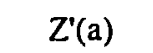 & $Z^{\prime \prime}(\mathrm{b})$ \\
\hline 1 & $1.00 \mathrm{E}+06$ & $.00 \mathrm{E}-02$ & $8.23 E+00$ & $6.72 \mathrm{E}+01$ & $\triangle 9 F+0$ \\
\hline 2 & $7.94 \mathrm{E}+05$ & $2.00 \mathrm{E}-02$ & $1.08 E+01$ & $7.75 E+01$ & $-1.82 E+02$ \\
\hline 3 & & $2.00 \mathrm{E}-02$ & & $.36 E+01$ & $-2.23 E+02$ \\
\hline 4 & +05 & $2.00 \mathrm{E}-02$ & & $20 \mathrm{E}+02$ & $-2.74 E+02$ \\
\hline 5 & -05 & $2.00 \mathrm{E}$ & $03 E+01$ & $3 E+02$ & $-3.30 E+02$ \\
\hline 6 & 105 & $2.00 \mathrm{E}-02$ & -01 & $5 E+02$ & $-3.87 E+02$ \\
\hline r & +05 & $2.00 \mathrm{E}-02$ & 01 & & $8 \mathrm{E}+02$ \\
\hline 8 & +05 & $2.00 \mathrm{E}-02$ & 01 & & $3 E+02$ \\
\hline 9 & 105 & $2.00 \mathrm{E}-02$ & & & $E+02$ \\
\hline 10 & .05 & 2.00 & & & $E+02$ \\
\hline il & 05 & 2.00 & & & $5 \mathrm{E}+02$ \\
\hline 12 & 04 & 2.00 & & & $76 \mathrm{E}+02$ \\
\hline 13 & 04 & 2.00 & & $E+02$ & $3 \mathrm{E}+02$ \\
\hline 14 & & 2.00 & & $E+02$ & $10 \mathrm{E}+02$ \\
\hline 15 & & .00 & & & $-2.22 E+02$ \\
\hline 16 & & 2.00 & & & $81 E+02$ \\
\hline 17 & & 200 & & & $46 \mathrm{E} \div 02$ \\
\hline 18 & & 200 & & & $7 E \div 02$ \\
\hline 19 & 4 & 2.00 & & & $7 \mathrm{E}+01$ \\
\hline 20 & & 2.00 & & & $-7.51 E+01$ \\
\hline 21 & & 00 & & & $10 \mathrm{E}+01$ \\
\hline 22 & 03 & .00 & & & $1 E+01$ \\
\hline 23 & 03 & .00 & & 02 & $6 E+01$ \\
\hline 24 & 03 & 2.00 & & & $0 \mathrm{E}+0 \mathrm{I}$ \\
\hline 25 & -03 & 2.00 & & 02 & $30 \mathrm{E}+0 \mathrm{I}$ \\
\hline 26 & -03 & 2.00 & & 02 & $-2.05 E+01$ \\
\hline 27 & +03 & 2.00 & & 02 & $-1.69 E+01$ \\
\hline 28 & +03 & 2.00 & 8.8 & +02 & $-1.42 E+01$ \\
\hline 29 & +03 & 2.00 & +01 & $.94 \mathrm{E}+02$ & $-1.21 E+01$ \\
\hline 30 & -03 & 2.00 & 9.3 & $9.95 E+02$ & $-1.05 E+01$ \\
\hline 31 & 1.00 & 2.00 & 9.6 & $.95 \mathrm{E}+02$ & $-9.39 E+00$ \\
\hline 32 & 7.9 & 2.00 & 9.9 & $5 E+02$ & $-8.69 E+00$ \\
\hline 33 & 6.31 & 2.00 & 1.0 & $E+02$ & $-8.33 E+00$ \\
\hline 34 & & 2.00 & 1.0 & 02 & $-8.3 ! E+00$ \\
\hline 35 & & 2.00 & & $E \div 02$ & $-8.63 E+00$ \\
\hline 36 & & 2.00 & & & $-9.24 \mathrm{E}+00$ \\
\hline 37 & $2.51 E+02$ & $2.00 \mathrm{E}-02$ & & & $-1.03 E+01$ \\
\hline 38 & $2.00 \mathrm{E}+02$ & $2.00 \mathrm{E}-02$ & $1.17 E+0$ & & $-1.16 \mathrm{E}+01$ \\
\hline & $1.58 E \div 02$ & $2.00 \mathrm{E}-02$ & $1.19 E+02$ & $E+02$ & $-1.33 E+01$ \\
\hline & $1.26 \mathrm{E}+02$ & $2.00 \mathrm{E}-0$ & $1.22 \mathrm{E} \div 0$ & $9.98 \mathrm{E}+02$ & $-1.55 E+0$ \\
\hline & & & & & \\
\hline
\end{tabular}


Appendix B continued

\begin{tabular}{|c|c|c|c|c|c|}
\hline 42 & $7.94 \mathrm{E}+0 \mathrm{I}$ & $2.00 \mathrm{E}-02$ & $1.27 E+02$ & $1.00 \mathrm{E}+03$ & $-2.16 \mathrm{E}+01$ \\
\hline 43 & $6.3|E+0|$ & $2.00 \mathrm{E}-02$ & $1.30 E+02$ & $1.00 E+03$ & $-2.56 \mathrm{E}+01$ \\
\hline 4 & $5.01 E+01$ & $2.00 \mathrm{E}-02$ & $1.32 \mathrm{E}+02$ & $1.00 \mathrm{E}+03$ & $-3.04 E+01$ \\
\hline 45 & $3.98 E+01$ & $.00 \mathrm{E}-02$ & $.35 \mathrm{E}+02$ & $1.01 E+03$ & $-3.63 E+01$ \\
\hline 46 & $.16 E+01$ & $2.00 \mathrm{E}-02$ & $1.37 E+02$ & $1.01 E+03$ & $-4.34 E+01$ \\
\hline 47 & $51 E+01$ & $2.00 \mathrm{E}-02$ & $1.40 E+02$ & $1.01 E+03$ & $-5.18 E+01$ \\
\hline 48 & $2.00 \mathrm{E}+0 \mathrm{I}$ & $2.00 \mathrm{E}-02$ & $1.43 E+02$ & $1.01 E+03$ & $-6.19 E+01$ \\
\hline 49 & $58 \mathrm{E}+01$ & $2.00 \mathrm{E}-02$ & $1.45 E+02$ & $1.02 E+03$ & $-7.4 I E+0 I$ \\
\hline 50 & +01 & $2.00 \mathrm{E}-02$ & & $E+03$ & $36 E+01$ \\
\hline 51 & $E+01$ & $2.00 \mathrm{E}-02$ & $1.51 E+02$ & $1.03 E+03$ & $06 E+02$ \\
\hline 52 & $E+\infty$ & $.00 \mathrm{E}-02$ & $1.53 E+02$ & $E+03$ & $6 \mathrm{E}+02$ \\
\hline 53 & +00 & $2.00 \mathrm{E}-02$ & $1.56 E+02$ & $1.05 E+03$ & $E+02$ \\
\hline 54 & +00 & $.00 \mathrm{E}-02$ & $1.59 E+02$ & +03 & $E+02$ \\
\hline 55 & +00 & $2.00 \mathrm{E}-02$ & $1.62 E+02$ & +03 & $E+02$ \\
\hline 56 & +00 & $2.00 \mathrm{E}-02$ & $1.65 E \div 02$ & +03 & $7 \mathrm{E}+02$ \\
\hline 57 & +00 & $2.00 \mathrm{E}-02$ & $1.68 E+02$ & 03 & $7 \mathrm{E}+02$ \\
\hline 58 & +00 & $2.00 \mathrm{E}-02$ & $1.70 E+02$ & 03 & $7 \mathrm{E}+02$ \\
\hline 59 & +00 & $2.00 \mathrm{E}-02$ & $1.73 E+02$ & 03 & $-4.40 E+02$ \\
\hline 60 & +00 & $2.00 \mathrm{E}-02$ & $1.76 \mathrm{E}+02$ & +03 & $-5.22 E+02$ \\
\hline 61 & +00 & $2.00 \mathrm{E}-02$ & $1.79 E+02$ & 1.23 & $-6.30 \mathrm{E}+02$ \\
\hline 62 & 7.5 & $2.00 \mathrm{E}-02$ & $1.82 E+02$ & $:+03$ & $-7.50 \mathrm{E}+02$ \\
\hline 63 & 6.3 & 2.00 & $1.86 \mathrm{E}+02$ & +03 & $-8.94 \mathrm{E}+02$ \\
\hline 64 & 5.0 & $2.00 \mathrm{E}-02$ & $1.88 E+02$ & $: 03$ & $-1.05 E+03$ \\
\hline 65 & $3.98 \mathrm{E}-01$ & $2.00 \mathrm{E}-02$ & $1.91 E \div 02$ & $E+03$ & $-1.26 \mathrm{E}+03$ \\
\hline 66 & & $2.00 \mathrm{E}-02$ & $1.95 E+02$ & +03 & $-1.50 \mathrm{E}+03$ \\
\hline 67 & & $2.00 \mathrm{E}-02$ & $2.00 \mathrm{E}+02$ & $:+03$ & $-1.81 E+03$ \\
\hline 68 & $00 E-01$ & $2.00 \mathrm{E}-02$ & $2.06 \mathrm{E}+02$ & $E+03$ & $1 E+03$ \\
\hline 69 & $1.58 \mathrm{E}-01$ & $2.00 \mathrm{E}-02$ & $2.13 E+02$ & $\div+03$ & $-2.56 \mathrm{E}+03$ \\
\hline 70 & $1.26 \mathrm{E}-01$ & $2.00 \mathrm{E}-02$ & $2.22 E+02$ & $2.27 \mathrm{E}+03$ & $-3.02 E+03$ \\
\hline 71 & $1.00 \mathrm{E}-01$ & $2.00 \mathrm{E}-02$ & $2.33 E+02$ & $2.60 E+03$ & $-3.54 E+03$ \\
\hline 72 & $7.94 E-02$ & $2.00 \mathrm{E}-02$ & $2.57 \mathrm{E}+02$ & $2.94 E+03$ & $-4.25 E+03$ \\
\hline 73 & $6.31 E-02$ & $2.00 \mathrm{E}-02$ & $2.74 \mathrm{E}+02$ & $3.40 \mathrm{E}+03$ & $-4.95 E+03$ \\
\hline 74 & & $2.00 \mathrm{E}-02$ & $2.94 E+02$ & $4.00 E+03$ & $-5.80 E+03$ \\
\hline 75 & & 2.00 & $3.48 E+02$ & $4.67 \mathrm{E}+03$ & $-6.84 E+03$ \\
\hline 76 & & & 3.81 & +03 & $-7.95 \mathrm{E}+03$ \\
\hline 77 & & & & $\div 03$ & $-9.16 E+03$ \\
\hline 78 & & & & +03 & +04 \\
\hline 79 & 02 & & & & \\
\hline 80 & -02 & $2.00 \mathrm{E}-02$ & $6.17 \mathrm{E}-02$ & +04 & \\
\hline 81 & -02 & & $7.18 \mathrm{E}+02$ & $1.35 \mathrm{E} \div 04$ & $6 E \div 04$ \\
\hline 82 & $7.94 \mathrm{E}-03$ & & $8.45 E+02$ & $1.61 E+04$ & $-1.59 \mathrm{E}+04$ \\
\hline 83 & 631502 & & & $1.89 E \div 04$ & $-1.70 E+04$ \\
\hline 84 & $5.01 \mathrm{E}-03$ & $2.00 \mathrm{E}-02$ & $1.21 E+03$ & $2.21 E+04$ & $-1.77 E+04$ \\
\hline
\end{tabular}


Appendix B continued

ZPlotW Data File: Version 2.0

Raw Data Day0_2

Sweep Frequency: Control Voltage

Open Circuit Potential (V): -0.0065

\begin{tabular}{|c|c|c|c|c|c|}
\hline Obs. & Freq $(\mathrm{Hz})$ & Ampl & Time(Sec) & $Z^{\prime}(\mathrm{a})$ & $Z^{\prime \prime}(b)$ \\
\hline 1 & $1.00 \mathrm{E}+06$ & $2.00 \mathrm{E}-02$ & $8.13 E+00$ & $4.79 E+01$ & $48 \mathrm{E}+02$ \\
\hline 2 & $7.94 \mathrm{E}+05$ & $2.00 \mathrm{E}-02$ & $1.07 E+01$ & $5.00 \mathrm{E}+01$ & $-1.82 E+02$ \\
\hline 3 & $6.31 E+05$ & $2.00 \mathrm{E}-02$ & $1.50 E+01$ & $5.34 \mathrm{E}+01$ & $-2.28 \mathrm{E}+02$ \\
\hline 4 & $5.01 E+05$ & $2.00 \mathrm{E}-02$ & 1.7 & $6.10 E+01$ & $-2.87 \mathrm{E}+02$ \\
\hline 5 & $3.98 E+05$ & $2.00 \mathrm{E}-02$ & 2.02 & $7.67 \mathrm{E}+01$ & $-3.62 E+02$ \\
\hline 6 & $3.16 E+05$ & $2.00 \mathrm{E}-02$ & & $1.04 \mathrm{E}+02$ & $-4.55 E+02$ \\
\hline 7 & +05 & 2.001 & & $9 E+02$ & $-5.68 \mathrm{E}+02$ \\
\hline 8 & +05 & 2.00 & & $2.17 E+02$ & $-7.00 \mathrm{E}+02$ \\
\hline 9 & +05 & 2.00 & & & \\
\hline 10 & & & & & \\
\hline 11 & 1.00 & 2.00 & 4.0 & $E+02$ & +03 \\
\hline 12 & $7.94 E+04$ & $2.00 \mathrm{E}-02$ & +01 & $9.30 \mathrm{E}+02$ & $-1.26 \mathrm{E}+03$ \\
\hline 13 & $6.31 E+04$ & $2.00 \mathrm{E}-02$ & $E+01$ & $1.22 \mathrm{E}+03$ & $-1.32 \mathrm{E}+03$ \\
\hline 14 & +04 & 2.00 & 5.0 & $1.52 E+03$ & $-1.32 \mathrm{E}+03$ \\
\hline 15 & +04 & 2.00 & 5.3 & $1.81 \mathrm{E}+03$ & $-1.25 E+03$ \\
\hline 16 & +04 & 2.00 & 5.6 & $2.06 E+03$ & $E+03$ \\
\hline 17 & +04 & 2.00 & +01 & $2.26 \mathrm{E}+03$ & $-9.90 \mathrm{E}+02$ \\
\hline 18 & 2.00 & 2.00 & 01 & $2.40 \mathrm{E}+03$ & $-8.37 E+02$ \\
\hline 19 & +04 & 2.00 & 01 & $2.50 \mathrm{E}+03$ & $-6.94 E+02$ \\
\hline 20 & +04 & 2.00 & 6.6 & $2.57 \mathrm{E}+03$ & $-5.67 E+02$ \\
\hline 21 & 04 & 2.00 & 6.8 & $2.61 \mathrm{E}+03$ & $-4.59 E+02$ \\
\hline 22 & +03 & 2.00 & & $2.64 \mathrm{E}+03$ & $-3.69 E+02$ \\
\hline 23 & 03 & 2.00 & & $E+03$ & $-2.97 \mathrm{E}+02$ \\
\hline 24 & +03 & 2.00 & 7.6 & +03 & $-2.37 \mathrm{E}+02$ \\
\hline 25 & 3.98 & 2.00 & 7.9 & +03 & $E+02$ \\
\hline 26 & $3.16 \mathrm{E}+03$ & $2.00 \mathrm{E}-02$ & 8.2 & $2.68 \mathrm{E}+03$ & $-1.52 E+02$ \\
\hline 27 & $2.51 E+03$ & $2.00 \mathrm{E}-02$ & 8.46 & $2.68 \mathrm{E}+03$ & $-1.22 \mathrm{E}+02$ \\
\hline 28 & $2.00 \mathrm{E}+03$ & $2.00 \mathrm{E}-02$ & $8.72 \mathrm{E}+01$ & $2.69 \mathrm{E}+03$ & $-9.81 E+01$ \\
\hline 29 & $1.58 \mathrm{E} \div 03$ & $2.00 \mathrm{E}-02$ & $8.98 \mathrm{E}+01$ & $2.69 E+03$ & $-7.90 \mathrm{E}+01$ \\
\hline 30 & $1.26 \mathrm{E}+03$ & $2.00 \mathrm{E}-02$ & $9.26 \mathrm{E}+01$ & $2.69 \mathrm{E}+03$ & $-6.47 \mathrm{E}+01$ \\
\hline 31 & $1.00 \mathrm{E}+03$ & $2.00 \mathrm{E}-02$ & $9.51 \mathrm{E}+01$ & $2.69 \mathrm{E}+03$ & $-5.29 \mathrm{E}+01$ \\
\hline 32 & $7.94 \mathrm{E} \div 02$ & $2.00 \mathrm{E}-02$ & $9.78 \mathrm{E}+01$ & $2.69 \mathrm{E}+03$ & $-4.40 \mathrm{E}+01$ \\
\hline 33 & +02 & 2.00 & $1.00 \mathrm{E}+02$ & $2.69 \mathrm{E}+03$ & $-3.72 E+01$ \\
\hline 34 & +02 & 2.00 & 1.0 & $2.69 \mathrm{E}+03$ & $-3.21 E+01$ \\
\hline 35 & +02 & 2.00 & 1.0 & $2.69 \mathrm{E}+03$ & $-2.83 E+01$ \\
\hline 36 & +02 & 2.00 & & $2.69 \mathrm{E}+03$ & $-2.56 \mathrm{E}+01$ \\
\hline 37 & +02 & 2.00 & I.1 & $2.68 \mathrm{E} \div 03$ & $-2.44 E+01$ \\
\hline 38 & $\div 02$ & $2.00 \mathrm{E}-02$ & & $2.68 \mathrm{E} \div 03$ & $-2.40 \mathrm{E}+01$ \\
\hline 39 & & 2.00 & & $2.68 \mathrm{E}+03$ & $-2.48 \mathrm{E}+01$ \\
\hline 40 & & $2.00 \mathrm{E}-02$ & & $2.68 E+03$ & $-2.64 E+01$ \\
\hline & $100 E+02$ & 2 & - & $2.68 E+03$ & 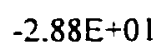 \\
\hline
\end{tabular}


Appendix B continued

\begin{tabular}{|c|c|c|c|c|c|}
\hline 2 & $E+01$ & 2 & $E+02$ & $E+03$ & $5 E+01$ \\
\hline 43 & $6.31 \mathrm{E}+01$ & $2.00 \mathrm{E}-02$ & $1.28 \mathrm{E}+02$ & $2.69 \mathrm{E}+03$ & $-3.68 \mathrm{E}+01$ \\
\hline 44 & $5.01 E+01$ & $2.00 \mathrm{E}-02$ & $1.31 \mathrm{E}+02$ & $2.69 E+03$ & $-4.25 \mathrm{E}+0 \mathrm{I}$ \\
\hline 45 & $3.98 \mathrm{E}+01$ & $2.00 \mathrm{E}-02$ & $1.34 \mathrm{E}+02$ & $2.69 E+03$ & $-4.89 E+0 I$ \\
\hline 46 & $3.16 \mathrm{E}+01$ & $2.00 \mathrm{E}-02$ & $1.36 E+02$ & $2.69 \mathrm{E}+03$ & $-5.73 E+0 I$ \\
\hline 47 & $2.51 E+01$ & $2.00 \mathrm{E}-02$ & $1.39 E+02$ & $2.70 \mathrm{E}+03$ & $-6.73 E+01$ \\
\hline 48 & $2.00 \mathrm{E}+01$ & $2.00 E-02$ & $1.41 E+02$ & $2.70 \mathrm{E}+03$ & $-7.93 E+01$ \\
\hline 49 & $1.58 \mathrm{E}+01$ & $2.00 \mathrm{E}-02$ & $1.44 E+02$ & $2.71 E+03$ & $-9.32 E+0 I$ \\
\hline 50 & $1.26 \mathrm{E}+01$ & $2.00 \mathrm{E}-02$ & $1.47 \mathrm{E}+02$ & $2.71 E+03$ & $-1.10 E+02$ \\
\hline 51 & $1.00 \mathrm{E}+0 \mathrm{l}$ & $2.00 \mathrm{E}-02$ & $1.49 E+02$ & $2.72 \mathrm{E}+03$ & $-1.29 E+02$ \\
\hline 52 & $7.94 \mathrm{E}+00$ & $2.00 \mathrm{E}-02$ & $1.52 E+02$ & $2.73 E+03$ & $-1.52 E+02$ \\
\hline 53 & $6.31 E+00$ & $2.00 \mathrm{E}-02$ & $1.55 E+02$ & $2.75 \mathrm{E}+03$ & $-1.79 E+02$ \\
\hline 54 & $5.01 E+00$ & $2.00 \mathrm{E}-02$ & $1.58 E+02$ & $2.76 \mathrm{E}+03$ & $-2.10 E+02$ \\
\hline 55 & $3.98 \mathrm{E}+00$ & $2.00 \mathrm{E}-02$ & $1.60 \mathrm{E}+02$ & $2.78 \mathrm{E}+03$ & $-2.47 \mathrm{E}+02$ \\
\hline 56 & $3.16 E+00$ & $2.00 \mathrm{E}-02$ & $1.63 E+02$ & $2.80 \mathrm{E}+03$ & $-2.89 E+02$ \\
\hline 57 & $2.51 E+00$ & $2.00 E-02$ & $1.66 \mathrm{E}+02$ & $2.83 E+03$ & $-3.39 E+02$ \\
\hline 58 & $2.00 \mathrm{E}+00$ & $2.00 \mathrm{E}$ & $1.69 E+02$ & $2.85 E+03$ & $-3.99 E+02$ \\
\hline 59 & 1.58 & 2.00 & $1.72 \mathrm{E}+02$ & $2.89 \mathrm{E}+03$ & $-4.65 \mathrm{E}+02$ \\
\hline 60 & $1.26 \mathrm{E}+00$ & $2.00 \mathrm{E}-02$ & $1.75 \mathrm{E}+02$ & $2.93 \mathrm{E}+03$ & $-5.49 E+02$ \\
\hline 51 & $1.00 E+00$ & $2.00 \mathrm{E}-02$ & $1.77 E+02$ & $2.98 \mathrm{E}+03$ & $-6.38 E+02$ \\
\hline 62 & $7.94 \mathrm{E}-01$ & $2.00 \mathrm{E}-02$ & $1.80 E+02$ & $3.04 E+03$ & $-7.48 \mathrm{E}+02$ \\
\hline 63 & 6.31 & 2.00 & +02 & $3.10 \mathrm{E}+03$ & $-8.83 E+02$ \\
\hline 64 & 5.01 & 2.00 & +02 & $3.19 E+03$ & $-1.02 E+03$ \\
\hline 65 & $3.98 \mathrm{E}-01$ & 2.00 & $1.90 \mathrm{E}+02$ & $3.25 \mathrm{E}+03$ & $-1.23 E+03$ \\
\hline 66 & $3.16 \mathrm{E}-01$ & $2.00 \mathrm{E}-02$ & $1.94 E+02$ & $3.39 E+03$ & $-1.42 E+03$ \\
\hline 67 & 2.51 & 2.00 E-02 & $1.99 \mathrm{E}+02$ & $3.48 \mathrm{E}+03$ & $-1.73 E+03$ \\
\hline 68 & 2.00 & 2.00 & $2.04 \mathrm{E}+02$ & $3.60 \mathrm{E}+03$ & $-1.98 E+03$ \\
\hline 69 & $1.58 \mathrm{E}-0 \mathrm{I}$ & 2.00 & $2.13 E+02$ & $3.78 \mathrm{E}+03$ & $-2.41 E+03$ \\
\hline 70 & $1.26 \mathrm{E}-0 \mathrm{I}$ & 2.00 & +02 & $3.95 \mathrm{E}+03$ & $-2.79 E+03$ \\
\hline 71 & $1.00 \mathrm{E}-01$ & $2.00 \mathrm{E}-02$ & $2.41 \mathrm{E}+02$ & $4.2 I E+03$ & $-3.36 \mathrm{E}+03$ \\
\hline 72 & $7.94 \mathrm{E}-02$ & $2.00 \mathrm{E}-02$ & $2.54 \mathrm{E}+02$ & $4.54 E+03$ & $-3.89 E+03$ \\
\hline 73 & $6.31 \mathrm{E}-02$ & $2.00 \mathrm{E}-02$ & $2.71 \mathrm{E}+02$ & $4.97 E+03$ & $-4.62 E+03$ \\
\hline 74 & $5.01 \mathrm{E}-02$ & $2.00 \mathrm{E}-02$ & $2.91 \mathrm{E}+02$ & $5.46 \mathrm{E}+03$ & $-5.52 \mathrm{E}+03$ \\
\hline 75 & $3.98 \mathrm{E}-02$ & $2.00 \mathrm{E}-02$ & $3.46 \mathrm{E}+02$ & $5.91 E+03$ & $-6.60 \mathrm{E}+03$ \\
\hline 76 & $3.16 \mathrm{E}-02$ & $2.00 \mathrm{E}-02$ & $3.80 \mathrm{E}+02$ & $6.60 \mathrm{E}+03$ & $-7.78 \mathrm{E}+03$ \\
\hline 77 & $2.51 \mathrm{E}-02$ & $2.00 \mathrm{E}-02$ & $4.20 \mathrm{E}+02$ & $7.43 \mathrm{E}+03$ & $-9.02 E+03$ \\
\hline 78 & $2.00 \mathrm{E}-02$ & $2.00 \mathrm{E}-02$ & $4.71 E+02$ & $8.53 E+03$ & $-1.05 \mathrm{E} \div 04$ \\
\hline 79 & $1.59 \mathrm{E}-02$ & $2.00 \mathrm{E}-02$ & $5.36 \mathrm{E}+02$ & $9.92 E+03$ & $-1.22 E+04$ \\
\hline 80 & $1.26 \mathrm{E}-02$ & $2.00 \mathrm{E}-02$ & $6.16 \mathrm{E}+02$ & $1.16 \mathrm{E}+04$ & $-1.40 E+04$ \\
\hline 81 & $1.00 \mathrm{E}-02$ & $2.00 \mathrm{E}-02$ & $7.17 \mathrm{E} \div 02$ & $1.37 E+04$ & $-1.61 E \div 04$ \\
\hline 82 & $7.94 \mathrm{E}-03$ & $2.00 \mathrm{E}-02$ & $8.44 E+02$ & $1.63 E \div 04$ & $-1.83 E+04$ \\
\hline 83 & $6.31 E-03$ & $2.00 \mathrm{E}-02$ & $1.00 \mathrm{E}+03$ & $1.93 \mathrm{E}+04$ & $-2.05 \mathrm{E}+04$ \\
\hline 84 & $5.01 \mathrm{E}-03$ & $2.00 \mathrm{E}-02$ & $1.20 E+03$ & $2.30 E+04$ & $-2.28 \mathrm{E}+04$ \\
\hline
\end{tabular}


Appendix B continued

ZPlotW Data File: Version 2.0

Raw Data Day 4

Sweep Frequency: Control Voltage

Open Circuit Potential (V): -0.0065

\begin{tabular}{|c|c|c|c|c|c|}
\hline & $\mathrm{Hz})$ & . & (Sec) & $Z^{\prime}(a)$ & $Z^{\prime \prime}(\mathbf{b})$ \\
\hline 1 & $1.00 \mathrm{E}+06$ & $2.00 \mathrm{E}-02$ & $1.18 E+01$ & $8.09 E+01$ & $22 E+0$ \\
\hline 2 & $7.94 \mathrm{E}+05$ & $2.00 \mathrm{E}-02$ & $.44 E+01$ & $9.73 E+01$ & $-1.43 E+02$ \\
\hline 3 & $6.31 E+05$ & 2.00 & & +02 & $E+02$ \\
\hline 4 & & 2.00 & & & 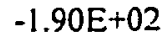 \\
\hline 5 & $8 \mathrm{E}+05$ & $2.00 \mathrm{E}$ & $40 \mathrm{E}+0 \mathrm{I}$ & $6 \mathrm{E}+02$ & $E+02$ \\
\hline 6 & $16 \mathrm{E}+05$ & 2.00 & $2.65 \mathrm{E}+01$ & $45 E+02$ & $4 E+02$ \\
\hline & $51 E+05$ & 2.00 & $:+01$ & $2.94 \mathrm{E}+02$ & $10 \mathrm{E}+02$ \\
\hline 8 & $00 \mathrm{E}+05$ & 2.00 & $E+01$ & $3.39 E+02$ & $-1.95 E+02$ \\
\hline 9 & -05 & 2.00 & +01 & $3.76 \mathrm{E}+02$ & $-1.74 E+02$ \\
\hline 10 & +05 & 2.00 & +01 & $E+02$ & $-1.49 E+02$ \\
\hline 11 & 1.00 & 2.00 & & $E+02$ & $-1.25 \mathrm{E}+02$ \\
\hline 12 & 7.94 & 2.00 & & & $-1.03 E+02$ \\
\hline 13 & 6.31 & & & & $34 E+0 !$ \\
\hline 14 & -04 & & & & $72 E+01$ \\
\hline 15 & .04 & 2.0 & -01 & & $-5.39 E+01$ \\
\hline 16 & 04 & & +01 & & $2 \mathrm{E}+0 \mathrm{l}$ \\
\hline 17 & 04 & 20 & +01 & $E+02$ & $4 E+0 l$ \\
\hline 18 & -04 & 20 & +01 & +02 & $4 E+01$ \\
\hline 19 & -04 & & & & $-2.18 \mathrm{E}+01$ \\
\hline 20 & -04 & 12 & +01 & & $-1.73 E+01$ \\
\hline 21 & 04 & 12 & +01 & & $-1.39 E+01$ \\
\hline 22 & 7.96 & 2.00 & +01 & & $-1.11 E+01$ \\
\hline 23 & 6.31 & 2.00 & +01 & & $-9.04 E+00$ \\
\hline 24 & $5.01 E+03$ & 2.00 & +01 & 4.6 & $-7.42 \mathrm{E}+00$ \\
\hline 25 & $3.98 \mathrm{E}+03$ & 2.00 & +01 & $E+02$ & $-6.23 E+00$ \\
\hline 26 & $3.16 \mathrm{E}+03$ & 2.00 & +01 & 02 & $-5.34 E+00$ \\
\hline 27 & $2.51 E+03$ & 2.00 & +01 & 02 & $-4.71 E+00$ \\
\hline 28 & 2.00 & 2.00 & +01 & $50 \mathrm{E}+02$ & $-4.32 \mathrm{E}+00$ \\
\hline 29 & 1.58 & 2.00 & 01 & $4.60 E+02$ & $-4.11 E+00$ \\
\hline 30 & 03 & 2.00 & +01 & $4.60 \mathrm{E}+02$ & $-4.07 \mathrm{E}+00$ \\
\hline 31 & 1.00 & 2.00 & +01 & $4.60 E+02$ & $-4.19 E \div 00$ \\
\hline 32 & & 2.0 & 01 & $E+02$ & $-4.49 E+00$ \\
\hline 33 & & & & 22 & $-4.97 E+00$ \\
\hline 34 & & & 10 & & $-5.62 E+00$ \\
\hline 35 & & & & & $-6.47 E+00$ \\
\hline 36 & & & & & $-7.52 E+00$ \\
\hline 37 & & & +02 & & $-8.93 E+00$ \\
\hline 38 & 02 & 2.0 & & $E+02$ & $-1.06 \mathrm{E}+01$ \\
\hline 39 & & 2.0 & $: 02$ & $4.62 \mathrm{E}+02$ & $-1.26 \mathrm{E}+01$ \\
\hline 4( & & $2.00 \mathrm{E}$ & $1.19 E+$ & $4.62 \mathrm{E}+02$ & $-1.50 \mathrm{E}+01$ \\
\hline & & & & & \\
\hline
\end{tabular}


Appendix B continued

\begin{tabular}{|c|c|c|c|c|c|}
\hline 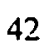 & $7.94 \mathrm{E}+01$ & $2.00 \mathrm{E}-02$ & $1.24 \mathrm{E}+02$ & $4.64 \mathrm{E}+02$ & $-2.14 \mathrm{E}+01$ \\
\hline 40 & $6.31 E+01$ & $2.00 \mathrm{E}-02$ & $1.27 \mathrm{E}+02$ & $4.66 \mathrm{E}+02$ & $-2.56 E+01$ \\
\hline 44 & $5.01 E+01$ & $2.00 \mathrm{E}-02$ & $1.29 E+02$ & $4.67 \mathrm{E}+02$ & $-3.07 E+01$ \\
\hline 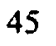 & $3.98 \mathrm{E}+01$ & $2.00 \mathrm{E}-02$ & $1.32 E+02$ & $4.69 E+02$ & $-3.67 E+01$ \\
\hline 46 & $3.16 E+01$ & $2.00 \mathrm{E}-02$ & $1.35 \mathrm{E}+02$ & $4.72 E+02$ & $-4.40 E+01$ \\
\hline 47 & $2.51 E+01$ & $2.00 \mathrm{E}-02$ & $1.37 \mathrm{E}+02$ & $4.75 E+02$ & $-5.26 E+01$ \\
\hline 48 & $2.00 E+01$ & $2.00 \mathrm{E}-02$ & $1.40 E+02$ & $4.79 E+02$ & $-6.28 E+01$ \\
\hline 49 & $1.58 \mathrm{E}+01$ & $2.00 \mathrm{E}-02$ & $1.42 E+02$ & $4.84 E+02$ & $-7.50 E+01$ \\
\hline 50 & $1.26 \mathrm{E}+0 \mid$ & $2.00 \mathrm{E}-02$ & $1.45 E+02$ & $4.89 \mathrm{E}+02$ & $-8.94 E+01$ \\
\hline 51 & $1.00 E+01$ & $2.00 \mathrm{E}-02$ & $1.48 \mathrm{E}+02$ & $4.96 \mathrm{E}+02$ & $-1.07 E+02$ \\
\hline 52 & $7.94 E+00$ & $2.00 \mathrm{E}-02$ & $1.51 E+02$ & $5.04 E+02$ & $-1.27 E+02$ \\
\hline 53 & $6.31 \mathrm{E}+00$ & $2.00 \mathrm{E}-02$ & $1.53 E+02$ & $5.13 E+02$ & $-1.51 E+02$ \\
\hline 3 & $5.01 E+00$ & $2.00 \mathrm{E}-02$ & $1.56 \mathrm{E}+02$ & $5.25 \mathrm{E}+02$ & $-1.80 E+02$ \\
\hline 5 & $3.98 \mathrm{E}+00$ & $2.00 \mathrm{E}-02$ & $1.59 E+02$ & $5.38 \mathrm{E}+02$ & $-2.14 E+02$ \\
\hline 56 & $3.16 \mathrm{E}+00$ & $2.00 \mathrm{E}-02$ & $1.58 \mathrm{E}+02$ & $5.54 E+02$ & $-2.54 \mathrm{E}+02$ \\
\hline 57 & $2.51 E+00$ & 2.00 E- 02 & $1.61 E+02$ & $5.73 E+02$ & $-3.03 E+02$ \\
\hline 58 & $2.00 \mathrm{E}+00$ & $2.00 \mathrm{E}-02$ & $1.64 E+02$ & $5.95 \mathrm{E}+02$ & $-3.6 ! E+02$ \\
\hline 59 & $1.58 \mathrm{E}+00$ & $2.00 \mathrm{E}-02$ & $1.67 \mathrm{E}+02$ & $6.20 \mathrm{E}+02$ & $-4.30 \mathrm{E}+02$ \\
\hline 60 & $1.26 \mathrm{E}+00$ & $2.00 \mathrm{E}-02$ & $1.75 E+02$ & $6.50 \mathrm{E}+02$ & $-5.14 E+02$ \\
\hline 61 & $1.00 \mathrm{E}+00$ & $2.00 \mathrm{E}-02$ & $1.77 \mathrm{E}+02$ & $6.87 E+02$ & $-6.13 E+02$ \\
\hline 62 & 7.94E-01 & $2.00 \mathrm{E}-02$ & $1.81 E+02$ & $7.30 \mathrm{E}+02$ & $-7.33 \mathrm{E}+02$ \\
\hline 63 & $6.3|E-0|$ & $2.00 \mathrm{E}-02$ & $1.86 E+02$ & $7.75 \mathrm{E}+02$ & $-8.80 E+02$ \\
\hline 64 & $5.0|E-0|$ & $2.00 \mathrm{E}-02$ & $1.88 E+02$ & $8.45 E+02$ & $-1.06 \mathrm{E}+03$ \\
\hline 65 & $3.98 \mathrm{E}-01$ & $2.00 \mathrm{E}-02$ & $1.91 E+02$ & $9.02 E+02$ & $-1.26 \mathrm{E}+03$ \\
\hline 66 & $3.16 \mathrm{E}-01$ & $2.00 \mathrm{E}-02$ & $1.95 \mathrm{E}+02$ & $9.98 E+02$ & $-1.53 E+03$ \\
\hline 67 & $2.51 \mathrm{E}-01$ & $2.00 \mathrm{E}-02$ & $1.99 E+02$ & $1.08 \mathrm{E}+03$ & $-1.83 E+03$ \\
\hline 68 & $2.00 \mathrm{E}-01$ & $2.00 \mathrm{E}-02$ & $2.05 \mathrm{E}+02$ & $1.22 \mathrm{E}+03$ & $-2.19 E+03$ \\
\hline 69 & $1.58 \mathrm{E}-01$ & $2.00 \mathrm{E}-02$ & $2.12 E+02$ & $1.38 \mathrm{E}+03$ & $-2.66 \mathrm{E}+03$ \\
\hline 70 & $1.26 \mathrm{E}-0 \mathrm{I}$ & $2.00 \mathrm{E}-02$ & $2.24 E+02$ & $1.54 \mathrm{E}+03$ & $-3.19 E+03$ \\
\hline 71 & $1.00 \mathrm{E}-01$ & $2.00 \mathrm{E}-02$ & $2.35 E+02$ & $1.77 \mathrm{E}+03$ & $-3.84 E+03$ \\
\hline 72 & $7.94 \mathrm{E}-02$ & $2.00 \mathrm{E}-02$ & $2.49 E+02$ & $2.04 E+03$ & $-4.60 E+03$ \\
\hline 73 & $6.31 E-02$ & $2.00 \mathrm{E}-02$ & $2.65 E+02$ & $2.38 \mathrm{E}+03$ & $-5.47 \mathrm{E}+03$ \\
\hline 74 & $5.01 E-02$ & $2.00 \mathrm{E}-02$ & $2.86 \mathrm{E} \div 02$ & $2.81 E+03$ & $-6.53 E+03$ \\
\hline 75 & $3.98 \mathrm{E}-02$ & $2.00 \mathrm{E}-02$ & $3.40 \mathrm{E}+02$ & $3.26 \mathrm{E}+03$ & $-7.86 \mathrm{E}+03$ \\
\hline 76 & $3.16 \mathrm{E}-02$ & $2.00 \mathrm{E}-02$ & $3.72 E \div 02$ & $3.89 E+03$ & $-9.43 E+03$ \\
\hline 77 & $2.51 \mathrm{E}-02$ & $2.00 \mathrm{E}-02$ & $4.13 E+02$ & $4.54 \mathrm{E}+03$ & $-1.13 E+04$ \\
\hline 78 & $2.00 \mathrm{E}-02$ & & 4.6 & $E+03$ & $-1.35 \mathrm{E}+04$ \\
\hline 79 & $1.59 \mathrm{E}-02$ & & & $E+03$ & $-1.63 E+04$ \\
\hline 80 & $1.26 \mathrm{E}-02$ & & & $E+03$ & $-1.95 E \div 04$ \\
\hline 81 & $1.00 \mathrm{E}-02$ & $2.00 \mathrm{E}-02$ & & $8.56 \mathrm{E}+03$ & $-2.35 \mathrm{E} \div 04$ \\
\hline 82 & $7.94 \mathrm{E}-03$ & $2.00 \mathrm{E}-02$ & $E+02$ & $1.02 E+04$ & $-2.84 E \div 04$ \\
\hline 83 & $6.31 E-03$ & $2.00 \mathrm{E}-02$ & $9.96 \mathrm{E} \div 02$ & $1.22 E+04$ & $-3.42 E+04$ \\
\hline 84 & $5.01 \mathrm{E}-03$ & $2.00 \mathrm{E}-02$ & $1.20 E+03$ & $1.47 \mathrm{E}+04$ & $-4.13 E+04$ \\
\hline 85 & $3.98 \mathrm{E}-03$ & $2.00 \mathrm{E}-02$ & $1.45 E+03$ & $1.79 E+04$ & $-4.98 E+04$ \\
\hline 86 & $3.16 \mathrm{E}-03$ & $2.00 \mathrm{E}-02$ & $1.77 \mathrm{E}+03$ & $2.21 \mathrm{I}+04$ & $-6.00 E+04$ \\
\hline & & & & & \\
\hline
\end{tabular}


Appendix B continued

ZPIotW Data File: Version 2.0

Raw Data Day 7

Sweep Frequency: Control Voltage

Open Circuit Potential (V): -0.0065

\begin{tabular}{|c|c|c|c|c|c|}
\hline Obs. & $\mathrm{Hz})$ & pl & (Sec) & $Z^{\prime}(\mathrm{a})$ & $Z^{\prime \prime}(b)$ \\
\hline 1 & $1.00 \mathrm{E}+06$ & $2.00 \mathrm{E}-02$ & $8.13 E+00$ & $7.35 \mathrm{E}+0 \mathrm{l}$ & $27 E+02$ \\
\hline 2 & $7.94 \mathrm{E}+05$ & $.00 \mathrm{E}-02$ & $.07 \mathrm{E}+0 \mathrm{I}$ & $3.80 \mathrm{E}+0 \mathrm{I}$ & $-1.52 \mathrm{E}+02$ \\
\hline 3 & $31 E+05$ & $.00 \mathrm{E}-02$ & $50 E+01$ & $1.10 E+02$ & $-1.82 \mathrm{E}+02$ \\
\hline 4 & $01 E+05$ & $.00 \mathrm{E}-02$ & $.76 \mathrm{E}+0 \mathrm{I}$ & $.41 E+02$ & $-2.13 E+02$ \\
\hline 5 & $98 \mathrm{E}+05$ & $.00 \mathrm{E}-02$ & $2.02 \mathrm{E}+01$ & $1.86 E+02$ & $-2.42 E+02$ \\
\hline 6 & $16 E+05$ & $.00 \mathrm{E}-02$ & & $2.42 \mathrm{E}+02$ & $-2.61 E+02$ \\
\hline 7 & $51 E+05$ & $.00 \mathrm{E}-02$ & & $3.03 E+02$ & $-2.68 \mathrm{E}+02$ \\
\hline 8 & +05 & $.00 \mathrm{E}-02$ & & $3.65 \mathrm{E}+02$ & $-2.61 E+02$ \\
\hline 9 & & 2 & & $4.20 E+02$ & $-2.4 I E+02$ \\
\hline 10 & & 2 & & $4.64 \mathrm{E}+02$ & $-2.13 \mathrm{E}+02$ \\
\hline 11 & & & & $4.98 \mathrm{E}$ & $-1.82 E+02$ \\
\hline 12 & & & & & $-1.52 E+02$ \\
\hline 13 & & & & & $E+02$ \\
\hline 14 & & & & & +02 \\
\hline 15 & & & & & \\
\hline 16 & & & & & $E+01$ \\
\hline 17 & +04 & $2.00+>-$ & & 2 & $E \div 01$ \\
\hline 18 & -04 & & & $5.65 \mathrm{E}$ & $-4.18 \mathrm{E} \div 01$ \\
\hline 19 & +04 & & & $5.67 E+02$ & $-3.32 \mathrm{E}+01$ \\
\hline 20 & & & & 02 & $-2.64 \mathrm{E}+01$ \\
\hline 21 & & & & $8 E+02$ & $E+01$ \\
\hline 22 & & & & $8 E+02$ & $-1.68 E+01$ \\
\hline 23 & & & & $8 E+02$ & $-1.36 \mathrm{E}+01$ \\
\hline 24 & & & & 22 & $-1.10 \mathrm{E}+01$ \\
\hline 25 & 03 & 0 & & 02 & $-9.09 E+00$ \\
\hline 26 & & & & $8 E+02$ & $-7.62 E+00$ \\
\hline 27 & -03 & & & $5.68 \mathrm{E}+02$ & $-6.52 E+00$ \\
\hline 28 & +03 & & & $5.68 \mathrm{E}+02$ & $-5.77 \mathrm{E}+00$ \\
\hline 29 & +03 & 2.0 & & $5.68 \mathrm{E}+02$ & $-5.27 E+00$ \\
\hline 30 & $6 \mathrm{E}+03$ & 2.0 & & $5.68 \mathrm{E}+02$ & $-5.05 \mathrm{E}+00$ \\
\hline 31 & $00 E+03$ & & & $5.69 \mathrm{E}+02$ & $-4.96 E+00$ \\
\hline 32 & $7.94 \mathrm{E}-02$ & $2.00 \mathrm{E}-02$ & & $5.69 E+02$ & $-5.12 \mathrm{E}+00$ \\
\hline 33 & $6.31 \mathrm{I}-02$ & $2.00 \mathrm{E}-02$ & $9.68 E+01$ & $5.69 E+02$ & $-5.50 E+00$ \\
\hline 34 & $01 E+02$ & 2.00 & $9.95 \mathrm{E}$ & $5.69 \mathrm{E}+02$ & $-6.05 \mathrm{E}+00$ \\
\hline 35 & +02 & 2.0 & & $5.70 \mathrm{E} \div 02$ & $-6.81 E \div 00$ \\
\hline 36 & +02 & 2.0 & & $5.70 \mathrm{E}+02$ & $-7.80 \mathrm{E}+00$ \\
\hline 37 & +02 & 2.0 & & $5.70 E+02$ & $-9.24 E+00$ \\
\hline 38 & $00 E+02$ & 2.00 & & $5.71 E+02$ & $-1.08 \mathrm{E}+01$ \\
\hline 39 & & & I. & $5.72 E+02$ & $-1.28 \mathrm{E}+01$ \\
\hline 40 & & & $\Gamma$ & $5.72 E+02$ & $-1.52 \mathrm{E}+0$ \\
\hline 41 & $1.00 E+02$ & $2.00 \mathrm{E}-02$ & 2 & $73 E+02$ & 1.8 \\
\hline
\end{tabular}


Appendix B continued

\begin{tabular}{|c|c|c|c|c|c|}
\hline & $E+01$ & 02 & $E+02$ & $E+02$ & $E+0 I$ \\
\hline & $6.31 \mathrm{IE}+0 \mathrm{l}$ & $2.00 \mathrm{E}-02$ & $1.25 E+02$ & $5.76 E+02$ & $-2.59 E+01$ \\
\hline & $5.01 E+01$ & $2.00 \mathrm{E}-02$ & $1.27 \mathrm{E}+02$ & $5.78 E+02$ & $-3.10 \mathrm{E}+01$ \\
\hline & $3.98 \mathrm{E}+0 \mathrm{I}$ & $2.00 \mathrm{E}-02$ & $1.30 \mathrm{E}+02$ & $5.80 \mathrm{E}+02$ & $-3.71 E+01$ \\
\hline 46 & $3.16 \mathrm{E}+01$ & $2.00 \mathrm{E}-02$ & $1.32 E+02$ & $5.82 E+02$ & $-4.45 \mathrm{E}+01$ \\
\hline 47 & $2.51 E+01$ & $2,00 \mathrm{E}-02$ & $1.35 \mathrm{E}+02$ & $5.85 E+02$ & $-5.34 E+01$ \\
\hline 48 & $2.00 \mathrm{E}+01$ & $2.00 \mathrm{E}-02$ & $1.37 E+02$ & $5.89 E+02$ & $-6.40 E+0 I$ \\
\hline 49 & $1.58 \mathrm{E}+0 \mid$ & 2.00E-02 & $1.40 E+02$ & $5.93 E+02$ & $-7.67 \mathrm{E}+0 \mathrm{I}$ \\
\hline 50 & $1.26 \mathrm{E} \div 01$ & $2.00 \mathrm{E}-02$ & $1.42 \mathrm{E}+02$ & $5.99 E+02$ & $-9.19 E+01$ \\
\hline 51 & $1.00 \mathrm{E}+01$ & $2.00 \mathrm{E}-02$ & $1.45 \mathrm{E}+02$ & $6.05 E+02$ & $-1.10 E+02$ \\
\hline 52 & $7.94 \mathrm{E}+00$ & $2.00 \mathrm{E}-02$ & $1.48 \mathrm{E}+02$ & $6.13 E+02$ & $-1.32 E+02$ \\
\hline 53 & $6.31 E+00$ & $2.00 \mathrm{E}-02$ & $1.50 \mathrm{E}+02$ & $6.22 \mathrm{E}+02$ & $-1.58 \mathrm{E}+02$ \\
\hline 54 & $5.01 E+00$ & $2.00 \mathrm{E}-02$ & $1.53 E+02$ & $6.33 E+02$ & $E+02$ \\
\hline 55 & $3.98 \mathrm{E}+00$ & $2.00 \mathrm{E}-02$ & $1.56 E+02$ & $6.46 \mathrm{E}+02$ & $-2.26 \mathrm{E}+02$ \\
\hline 56 & $3.16 \mathrm{E}+00$ & $2.00 \mathrm{E}-02$ & $1.59 E+02$ & $6.62 \mathrm{E}+02$ & $-2.71 E+02$ \\
\hline 57 & $2.51 E+00$ & 2.00 E-02 & $1.62 E+02$ & $6.80 E+02$ & $-3.25 E+02$ \\
\hline 58 & $2.00 \mathrm{E}+00$ & $2.00 \mathrm{E}-02$ & $1.69 E+02$ & $7.03 \mathrm{E}+02$ & $-3.90 E+02$ \\
\hline 59 & $1.58 \mathrm{E}+00$ & $2.00 \mathrm{E}-02$ & $1.72 E+02$ & $7.29 E+02$ & $-4.67 \mathrm{E}+02$ \\
\hline 60 & $1.26 \mathrm{E}+00$ & $2.00 \mathrm{E}-02$ & $1.75 E+02$ & $7.60 \mathrm{E}+02$ & $-5.62 E+02$ \\
\hline 61 & $1.00 \mathrm{E}+00$ & $2.00 \mathrm{E}-02$ & $1.78 E+02$ & $8.02 E+02$ & $-6.72 \mathrm{E}+02$ \\
\hline 62 & $7.94 E-01$ & 2.00E-02 & $1.81 E+02$ & $8.48 E+02$ & $-8.09 \mathrm{E}+02$ \\
\hline 63 & 6.3 & $2.005-02$ & $1.86 \mathrm{E}+02$ & $8.97 E \div 02$ & $-9.68 E+02$ \\
\hline 64 & 5.0 & 2.00 & $1.88 \mathrm{E}+02$ & $9.78 \mathrm{E}+02$ & $-1.16 \mathrm{E}+03$ \\
\hline 65 & $3.98 \mathrm{E}-01$ & 2.0 & $1.91 E+02$ & $1.04 \mathrm{E}+03$ & $-1.39 E+03$ \\
\hline 66 & 3.16 & 2.0 & $1.95 \mathrm{E}+02$ & $E+03$ & $-1.68 \mathrm{E} \div 03$ \\
\hline 67 & 2.5 & 2.0 & $2.00 \mathrm{E}+02$ & $E+03$ & $-2.02 E \div 03$ \\
\hline 68 & 2.0 & 2.0 & $2.05 E \div 02$ & $E+03$ & $-2.39 E+03$ \\
\hline 69 & $1.58 \mathrm{E}-01$ & 2.00 & $2.13 E+02$ & $1.59 \mathrm{E} \div 03$ & $-2.90 \mathrm{E} \div 03$ \\
\hline 70 & $1.26 \mathrm{E}-01$ & 2.00 & $2.21 E+02$ & $1.78 \mathrm{E}+03$ & $-3.48 E+03$ \\
\hline 71 & $1.00 \mathrm{E}-01$ & $2.00 \mathrm{E}-02$ & $2.32 \mathrm{E}+02$ & $2.02 \mathrm{E}+03$ & $-4.11 E+03$ \\
\hline 72 & $7.94 \mathrm{E}-02$ & $2.00 \mathrm{E}-02$ & $2.45 \mathrm{E}-02$ & $2.34 E+03$ & $-4.90 \mathrm{E}+03$ \\
\hline 73 & $6.31 \mathrm{E}-02$ & 2.00E-02 & $2.62 E+02$ & $2.70 \mathrm{E}+03$ & $-5.85 E+03$ \\
\hline 74 & $5.01 \mathrm{E}-02$ & $2.00 \mathrm{E}-02$ & $2.83 E+02$ & $3.11 E+03$ & $-7.00 \mathrm{E}+03$ \\
\hline 75 & $3.98 E-02$ & $2.00 \mathrm{E}-02$ & $3.37 \mathrm{E} \div 02$ & $3.46 \mathrm{E}+03$ & $-8.39 \mathrm{E} \div 03$ \\
\hline 76 & 3. $16 \mathrm{E}-02$ & $2.00 \mathrm{E}-02$ & $3.69 E \div 02$ & $3.94 \mathrm{E}+03$ & $-1.01 \mathrm{E}+04$ \\
\hline 77 & $2.5 \mid \mathrm{E}-02$ & 2.00E-02 & $4.10 E+02$ & $4.45 E+03$ & $-1.21 E \div 04$ \\
\hline 78 & $2.00 \mathrm{E}-02$ & $2.00 \mathrm{E}-02$ & $4.61 E-02$ & $5.07 E+03$ & $-1.46 \mathrm{E}+04$ \\
\hline 79 & $1.59 \mathrm{E}-02$ & $2.00 \mathrm{E}-02$ & $5.29 E \div 02$ & $5.81 E+03$ & $-1.77 \mathrm{E}+04$ \\
\hline 80 & $1.26 \mathrm{E}-02$ & $2.00 \mathrm{E}-02$ & $6.09 E \div 02$ & $6.71 E+03$ & $-2.12 E+04$ \\
\hline 81 & $1.00 \mathrm{E}-02$ & $2.00 \mathrm{E}-02$ & $7.10 \mathrm{E} \div 02$ & $7.80 E+03$ & $-2.58 E-04$ \\
\hline 82 & $7.94 \mathrm{E}-03$ & $2.00 \mathrm{E}-02$ & $8.37 E \div 02$ & $9.15 E+03$ & $-3.14 E+04$ \\
\hline 83 & $6.31 \mathrm{E}-03$ & $2.00 \mathrm{E}-02$ & $9.97 \mathrm{E}+02$ & $1.09 E+04$ & $-3.83 E+04$ \\
\hline 84 & $5.01 \mathrm{E}-03$ & $2.00 \mathrm{E}-02$ & $1.20 E-03$ & $1.30 E \div 04$ & $-4.66 E \div 04$ \\
\hline 85 & $3.98 \mathrm{E}-03$ & $2.00 \mathrm{E}-02$ & $1.45 E-03$ & $1.58 \mathrm{E}+04$ & $-5.68 \mathrm{E} \div 04$ \\
\hline 86 & $3.16 \mathrm{E}-03$ & $2.00 \mathrm{E}-02$ & $1.77 E-03$ & $1.94 E+04$ & $-6.91 E \div 04$ \\
\hline
\end{tabular}


Appendix B continued

ZPlotW Data File: Version 2.0

Raw Data Day 14

Sweep Frequency: Control Voltage

Open Circuit Potential (V): -0.0065

\begin{tabular}{|c|c|c|c|c|c|}
\hline & Freq(Hz) & Ampl & Sec) & $Z^{\prime}(a)$ & (W) \\
\hline 1 & $1.00 \mathrm{E}+06$ & $2.00 \mathrm{E}-02$ & $128 \mathrm{~F}+01$ & $42 \mathrm{E}+01$ & $38 \mathrm{E}+0$ \\
\hline 2 & $7.94 \mathrm{E}+05$ & $2.00 \mathrm{E}-02$ & $1.54 \mathrm{E}+01$ & $1.00 \mathrm{E}+02$ & $-1.62 E+02$ \\
\hline 3 & $6.31 E+05$ & $2.00 \mathrm{E}-02$ & & $24 \mathrm{E}+02$ & $91 E+02$ \\
\hline 4 & +05 & 2.001 & & $9 E+02$ & \\
\hline 5 & $98 \mathrm{E}+05$ & $2.00 \mathrm{E}$ & & $07 E+02$ & \\
\hline 6 & $16 \mathrm{E}+05$ & 2.00 & & & \\
\hline 7 & $51 E+05$ & 2.00 & & & \\
\hline 8 & $00 E+05$ & $2.00 \mathrm{E}$ & & & \\
\hline 9 & $58 \mathrm{E}+05$ & $2.00 \mathrm{E}$ & & 22 & $x_{2}+2$ \\
\hline 10 & $26 \mathrm{E}+05$ & $2.00 \mathrm{E}-02$ & 01 & +02 & $-1.98 \mathrm{E}+0$ \\
\hline 11 & $1.00 \mathrm{E}+05$ & $2.00 \mathrm{E}-02$ & 01 & $E+02$ & $68 \mathrm{E}+0$ \\
\hline 12 & $94 \mathrm{E} \div 04$ & $2.00 \mathrm{E}-02$ & & $: 02$ & $39 E+02$ \\
\hline 13 & $31 E+04$ & $2.00 \mathrm{E}$ & & +02 & $4 \mathrm{E}+02$ \\
\hline 14 & $01 E+04$ & $2.00 \mathrm{E}$ & & $E+02$ & $-9.21 E+01$ \\
\hline 15 & $3.98 \mathrm{E}+04$ & $.00 \mathrm{E}$ & & $E+02$ & $-7.41 \mathrm{E} \div 01$ \\
\hline 16 & $16 E+04$ & $.00 \mathrm{E}$ & & $5 E+02$ & $-5.94 E+0$ \\
\hline 17 & $1 E+04$ & .001 & & $5.58 \mathrm{E}+02$ & $-4.74 E+0$ \\
\hline 18 & +04 & $.00 \mathrm{E}$ & & $\mathrm{OE}+02$ & $-3.77 E+0$ \\
\hline 19 & +04 & 12 & & $1 E+02$ & $-3.00 \mathrm{E}+0$ \\
\hline 20 & +04 & 00 & & $\div 02$ & $-2.38 \mathrm{E}+01$ \\
\hline $2 !$ & $0 \mathrm{E}+04$ & 12 & & $: 02$ & $-1.90 \mathrm{E}+0$ \\
\hline 22 & $4 E+03$ & $200 \mathrm{H}$ & & 02 & $-1.51 \mathrm{E}+0$ \\
\hline 23 & $6.31 E+03$ & $2 \cap 0 F_{-} \cap 2$ & & 02 & $3 E+0$ \\
\hline 24 & $5.01 E \div 03$ & $2.00 \mathrm{E}-02$ & & +02 & $-9.97 E+00$ \\
\hline 25 & $3.98 \mathrm{E} \div 03$ & $2.00 \mathrm{E}-02$ & & +02 & $5 \mathrm{E}+00$ \\
\hline 26 & $16 \mathrm{E}+03$ & $2.00 \mathrm{E}-02$ & & $E+02$ & $-6.94 E+00$ \\
\hline 27 & $2.51 E+03$ & $2.00 \mathrm{E}-02$ & 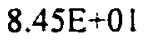 & $E+02$ & $-5.98 E+00$ \\
\hline 28 & $2.00 \mathrm{E}+03$ & $2.00 \mathrm{E}-02$ & +01 & $5.61 \mathrm{E}+02$ & $-5.35 \mathrm{E}+00$ \\
\hline 29 & $1.58 \mathrm{E}+03$ & $2.00 \mathrm{E}-02$ & $+0 !$ & $5.61 \mathrm{E}+02$ & $-4.92 E+00$ \\
\hline 30 & $1.26 \mathrm{E}+03$ & $2.00 \mathrm{E}$ & 9.2 & $5.62 \mathrm{E}+02$ & $-4.73 E+0$ \\
\hline 31 & +03 & 2.00 & & $E+02$ & $-4.67 \mathrm{E} \div 00$ \\
\hline 32 & & & & $\div 02$ & $-4.85 E+0$ \\
\hline 33 & & & & & $-5.27 E+0$ \\
\hline 34 & & & & & $-5.83 E+00$ \\
\hline 35 & & & & & $-6.61 E \div 00$ \\
\hline 36 & & & & & $2 E+00$ \\
\hline 37 & & & & & $-9.05 E+00$ \\
\hline 38 & & & & & $-1.06 \mathrm{E}+01$ \\
\hline 39 & 02 & & & & $-1.26 \mathrm{E}+01$ \\
\hline 40 & $26 \mathrm{E}+02$ & 2.00 & & & \\
\hline & & $0 \mathrm{E}-02$ & $1.23 \mathrm{E}+02$ & 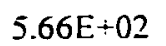 & $-1.79 E+0$ \\
\hline
\end{tabular}


Appendix B continued

\begin{tabular}{|c|c|c|c|c|c|}
\hline 42 & $7.94 \mathrm{E}+01$ & $2.00 \mathrm{E}-02$ & $1.25 \mathrm{E}+02$ & $5.67 E+02$ & $-2.16 \mathrm{E}+01$ \\
\hline 43 & $6.31 \mathrm{E}+01$ & $2.00 \mathrm{E}-02$ & $1.28 \mathrm{E}+02$ & $5.68 \mathrm{E}+02$ & $-2.59 E+01$ \\
\hline 14 & $5.01 E+01$ & $2.00 \mathrm{E}-02$ & $1.31 E+02$ & $5.70 \mathrm{E}+02$ & $-3.10 \mathrm{E}+01$ \\
\hline 15 & $3.98 \mathrm{E}+01$ & $2.00 \mathrm{E}-02$ & $33 E+02$ & $5.72 E+02$ & $-3.72 E+01$ \\
\hline 46 & $3.16 \mathrm{E}+01$ & $2.00 \mathrm{E}-02$ & $5 E+02$ & $4 \mathrm{E}+02$ & $-4.48 \mathrm{E}+01$ \\
\hline 47 & $2.51 \mathrm{E}+01$ & $2.00 \mathrm{E}-02$ & & $5.77 \mathrm{E}+02$ & $-5.38 E+0 l$ \\
\hline 40 & $2.00 \mathrm{E}+01$ & $.00 \mathrm{E}-02$ & $1 E+02$ & $0 \mathrm{E}+02$ & $-6.48 E+0 l$ \\
\hline 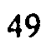 & $58 \mathrm{E}+0 \mathrm{l}$ & 00E-02 & $3 E+02$ & $5.85 E+02$ & $-7.78 \mathrm{E}+0 \mathrm{l}$ \\
\hline נט & $1.26 \mathrm{E}+01$ & $.00 \mathrm{E}-02$ & $.46 \mathrm{E}+02$ & $5.90 E+02$ & $-9.34 \mathrm{E}+0 \mathrm{I}$ \\
\hline 51 & $1.00 \mathrm{E}+01$ & $2.00 \mathrm{E}-02$ & $1.48 \mathrm{E}+02$ & $5.96 \mathrm{E}+02$ & $-1.12 E+02$ \\
\hline 52 & $7.94 \mathrm{E}+00$ & 2.00 E-02 & $1 E+02$ & $6.04 E+02$ & $5 E+02$ \\
\hline 53 & $6.31 \mathrm{E}+00$ & $2.00 \mathrm{E}-02$ & $E+02$ & $6.13 E+02$ & $-1.62 E+02$ \\
\hline 54 & $.01 E+00$ & $2.00 \mathrm{E}-02$ & $E+02$ & $6.24 \mathrm{E}+02$ & $4 E+02$ \\
\hline 55 & +00 & $2.00 \mathrm{E}-02$ & $E+02$ & $6.37 \mathrm{E}+02$ & $3 E+02$ \\
\hline 56 & $+\infty$ & 2.00 & $E+02$ & $E+02$ & $9 E+02$ \\
\hline 57 & +00 & -02 & $E+02$ & +02 & $5 \mathrm{E}+02$ \\
\hline 58 & $.00 E \div 00$ & -02 & $E+02$ & $\div 02$ & $-4.02 E+02$ \\
\hline 59 & $1.58 \mathrm{E}+00$ & $2.00 \mathrm{E}-02$ & $E+02$ & $E+02$ & $-4.85 E+02$ \\
\hline 60 & $=00$ & $2.00 \mathrm{E}-02$ & $E+02$ & $E+02$ & $-5.82 \mathrm{E}+02$ \\
\hline 61 & $1.00 \mathrm{E}+00$ & $2.00 \mathrm{E}-02$ & $E+02$ & $E+02$ & $-6.99 E+02$ \\
\hline 62 & $7.94 \mathrm{E}-01$ & $2.00 \mathrm{E}-02$ & $E+02$ & $: 02$ & $-8.38 \mathrm{E}+02$ \\
\hline 63 & -01 & $E .02$ & $\div 02$ & $: 02$ & $-1.01 E+03$ \\
\hline 64 & $5.01 E-01$ & $2.00 \mathrm{E}-02$ & $E+02$ & $:+02$ & $2 E \div 03$ \\
\hline 65 & $3.98 \mathrm{E}-0 \mathrm{I}$ & $2.00 \mathrm{E}-02$ & $E+02$ & $: 03$ & $5 E+03$ \\
\hline 66 & $3.16 \mathrm{E}-01$ & $2.00 \mathrm{E}-02$ & $E+02$ & $: 03$ & $7 E+03$ \\
\hline 67 & $2.51 \mathrm{E}-01$ & $2.00 \mathrm{E}-02$ & $E+02$ & +03 & $1 E+03$ \\
\hline 68 & $2.00 \mathrm{E}-01$ & $2.00 \mathrm{E}-02$ & $E+02$ & $:+03$ & $2 \mathrm{E} \div 03$ \\
\hline 69 & $1.58 \mathrm{E}-01$ & $2.00 \mathrm{E}-02$ & $.19 E+02$ & +03 & $4 E+03$ \\
\hline 70 & $1.26 \mathrm{E}-01$ & $2.00 \mathrm{E}-02$ & $.28 \mathrm{E} \div 02$ & $: 03$ & $6 E+03$ \\
\hline 71 & $1.00 \mathrm{E}-01$ & $2.00 \mathrm{E}-02$ & $.39 \mathrm{E}+02$ & $: 03$ & $-4.33 E+03$ \\
\hline 72 & $7.94 \mathrm{E}-02$ & $2.00 \mathrm{E}-02$ & $2.52 \mathrm{E}+02$ & $2.39 E+03$ & $-5.16 \mathrm{E}+03$ \\
\hline 73 & $6.31 \mathrm{E}-02$ & $2.00 \mathrm{E}-02$ & $2.69 \mathrm{E}+02$ & $2.77 \mathrm{E}+03$ & $-6.16 E+03$ \\
\hline 74 & $5.01 \mathrm{E}-02$ & $2.00 \mathrm{E}-02$ & $.14 \mathrm{E}+02$ & $3.12 \mathrm{E}+03$ & $-7.40 \mathrm{E}+03$ \\
\hline 75 & 3.9 & $2.00 \mathrm{E}-02$ & $.39 \mathrm{E}+02$ & $3.55 \mathrm{E}+03$ & $-8.89 E+03$ \\
\hline 76 & & & & $: 03$ & $-1.06 \mathrm{E}+04$ \\
\hline 77 & & & & +03 & $-1.27 \mathrm{E} \div 04$ \\
\hline 78 & & & & & $-1.53 E \div 04$ \\
\hline 79 & 02 & 2.0 & & & $\div 04$ \\
\hline 80 & -02 & 2.0 & 02 & +03 & $5 E \div 04$ \\
\hline 81 & -02 & 2.0 & $: 02$ & $\div 03$ & $74 E-04$ \\
\hline 82 & $7.94 \mathrm{E}-03$ & $2.00 \mathrm{E}-02$ & $.37 E+02$ & $9.74 \mathrm{E}+03$ & $-3.34 \mathrm{E} \div 04$ \\
\hline 83 & $6.31 \mathrm{E}-03$ & $2.00 \mathrm{E}-02$ & $9.97 E+02$ & $1.15 E+04$ & $-4.07 \mathrm{E}+04$ \\
\hline 0 & $5.01 E-03$ & $2.00 \mathrm{E}-02$ & $D E+03$ & $E+04$ & $-4.96 E+04$ \\
\hline 8 & $3.98 \mathrm{E}-03$ & $2.00 \mathrm{E}-02$ & $E \div 03$ & $E+04$ & $-6.08 E+04$ \\
\hline 0 & $3.16 \mathrm{E}-03$ & $2.00 \mathrm{E}-02$ & $2.01 E+03$ & $2.00 \mathrm{E}+04$ & $-7.38 \mathrm{E}+04$ \\
\hline
\end{tabular}


ZPlotW Data File: Version 2.0

Raw Data Day 21

Sweep Frequency: Control Voltage

Open Circuit Potential (V): -0.0065

\begin{tabular}{|c|c|c|c|c|c|}
\hline \#Obs. & Freq(Hz) & Ampl & Time(Sec) & $Z^{\prime}(a)$ & $Z^{\prime \prime}(b)$ \\
\hline 1 & $1.00 E+06$ & $2.00 \mathrm{E}-02$ & $8.17 \mathrm{E}+00$ & $8.12 E \div 01$ & $-1.13 E+02$ \\
\hline 2 & $7.94 E+05$ & $2.00 \mathrm{E}-02$ & $1.07 E+01$ & $9.73 E+0 l$ & $-1.30 E+02$ \\
\hline 3 & $6.3 ! E+05$ & $2.00 \mathrm{E}-02$ & $1.51 \mathrm{E}+01$ & $1.20 E+02$ & $-1.48 E+02$ \\
\hline 4 & $5.01 \mathrm{E}+05$ & $2.00 \mathrm{E}-02$ & $1.77 \mathrm{E}+01$ & $1.50 E+02$ & $-1.65 E+02$ \\
\hline 5 & $3.98 \mathrm{E}+05$ & $2.00 \mathrm{E}-02$ & $2.03 E+01$ & $1.88 \mathrm{E}+02$ & $-1.75 E+02$ \\
\hline 6 & $3.16 \mathrm{E}+05$ & $2.00 \mathrm{E}-02$ & $2.29 E+01$ & $2.28 \mathrm{E}+02$ & $-1.76 \mathrm{E}+02$ \\
\hline 7 & $2.51 E+05$ & $2.00 \mathrm{E}-02$ & $2.54 \mathrm{E}+01$ & $2.67 \mathrm{E}+02$ & $-1.68 \mathrm{E}+02$ \\
\hline 8 & $2.00 E+05$ & $2.00 \mathrm{E}-02$ & $2.80 \mathrm{E}+0 \mathrm{I}$ & $3.01 E+02$ & $-1.52 E+02$ \\
\hline 9 & $1.58 \mathrm{E}+05$ & $2.00 \mathrm{E}-02$ & $3.07 \mathrm{E}+01$ & $3.28 \mathrm{E} \div 02$ & $-1.33 E+02$ \\
\hline 10 & $1.26 E+05$ & $2.00 \mathrm{E}-02$ & & $3.47 \mathrm{E}+02$ & $-1.12 E+02$ \\
\hline 11 & $1.00 E+05$ & $2.00 \mathrm{E}-02$ & & $3.61 E+02$ & $-9.31 E+01$ \\
\hline 12 & $7.94 \mathrm{E}+04$ & $2.00 \mathrm{E}-02$ & $3.83 \mathrm{E}+01$ & $3.70 E+02$ & $-7.60 E+01$ \\
\hline 13 & $6.31 E+04$ & $2.00 \mathrm{E}-02$ & $4.36 \mathrm{E}+0 \mathrm{I}$ & $3.76 \mathrm{E}+02$ & $-6.15 \mathrm{E}+01$ \\
\hline 14 & $5.01 E+04$ & $2.00 \mathrm{E}-02$ & $4.61 E+01$ & $3.79 E+02$ & $-4.94 \mathrm{E}+01$ \\
\hline 15 & $3.98 E+04$ & $2.00 \mathrm{E}-02$ & $4.87 \mathrm{E}+01$ & $3.82 E+02$ & $-3.96 \mathrm{E}+01$ \\
\hline 16 & $3.16 \mathrm{E}+04$ & $2.00 \mathrm{E}-02$ & $5.12 \mathrm{E}+01$ & $3.83 E+02$ & $-3.17 \mathrm{E}+01$ \\
\hline 17 & $2.51 \mathrm{E}+04$ & $2.00 \mathrm{E}-02$ & $5.37 \mathrm{E}+01$ & $3.84 \mathrm{E}+02$ & $-2.53 \mathrm{E}+01$ \\
\hline 18 & $2.00 \mathrm{E}+04$ & $2.00 \mathrm{E}-02$ & $5.62 \mathrm{E}+01$ & $3.85 \mathrm{E}+02$ & $-2.01 E+01$ \\
\hline 19 & $1.58 E+04$ & $2.00 \mathrm{E}-02$ & $5.88 \mathrm{E}+01$ & $3.85 E+02$ & $-1.61 \mathrm{E}+01$ \\
\hline 20 & $1.26 \mathrm{E} \div 04$ & $2.00 \mathrm{E}$ & $6.13 \mathrm{E}+01$ & $3.85 \mathrm{E}+02$ & $-1.28 \mathrm{E}+01$ \\
\hline 21 & $1.00 E+04$ & $2.00 \mathrm{~B}$ & $E+01$ & $3.85 \mathrm{E}+02$ & $-1.02 \mathrm{E} \div 0 \mathrm{l}$ \\
\hline 22 & $7.94 E+03$ & $2.00 \mathrm{E}-02$ & $6.64 \mathrm{E}+0 \mathrm{l}$ & $3.85 E+02$ & $-8.26 \mathrm{E}+00$ \\
\hline 23 & $6.31 E+03$ & $2.00 \mathrm{E}-02$ & $6.90 \mathrm{E}+01$ & $3.85 \mathrm{E}+02$ & $-6.78 E+00$ \\
\hline 24 & $5.01 E+03$ & $2.00 \mathrm{E}-02$ & +01 & $3.85 E+02$ & $-5.61 \mathrm{E}+00$ \\
\hline 25 & $3.98 E+03$ & $2.00 \mathrm{E}-02$ & $7.41 \mathrm{E}+01$ & $3.85 E+02$ & $-4.79 E+00$ \\
\hline 26 & $3.16 \mathrm{E}+03$ & $2.00 \mathrm{E}-02$ & $E+01$ & $3.85 E+02$ & $-4.18 E+00$ \\
\hline 27 & $2.51 \mathrm{E}+03$ & $2.00 \mathrm{E}-02$ & $7.92 \mathrm{E}+01$ & $3.84 \mathrm{E}+02$ & $-3.77 \mathrm{E}+00$ \\
\hline 28 & $2.00 \mathrm{E}+03$ & $2.00 \mathrm{E}-02$ & $8.18 E+01$ & $3.84 E+02$ & $-3.53 \mathrm{E}+00$ \\
\hline 29 & $1.58 \mathrm{E}+03$ & $2.00 \mathrm{E}-02$ & $8.44 \mathrm{E} \div 01$ & $3.84 E+02$ & $-3.46 E \div 00$ \\
\hline 30 & $1.26 \mathrm{E}+03$ & $2.00 \mathrm{E}-02$ & $8.71 E+01$ & $3.84 \mathrm{E}+02$ & $-3.51 E \div 00$ \\
\hline 31 & $1.00 \mathrm{E} \div 03$ & $2.00 \mathrm{E}-02$ & $8.96 \mathrm{E}+0 \mathrm{I}$ & $3.84 \mathrm{E}+02$ & $-3.70 \mathrm{E}+00$ \\
\hline 32 & $7.94 \mathrm{E} \div 02$ & $2.00 \mathrm{E}-02$ & $9.24 \mathrm{E}+01$ & $3.84 E+02$ & $-4.03 E \div 00$ \\
\hline 33 & $6.31 E \div 02$ & $2.00 \mathrm{E}-02$ & $9.50 \mathrm{E}+01$ & $3.85 \mathrm{E}+02$ & $-4.53 E \div 00$ \\
\hline 34 & $5.01 E+02$ & $2.00 \mathrm{E}-02$ & $9.77 \mathrm{E} \div 01$ & $3.85 \mathrm{E}+02$ & $-5.16 E \div 00$ \\
\hline 35 & $3.98 \mathrm{E} \div 02$ & $2.00 \mathrm{E}-02$ & $1.00 \mathrm{E}-02$ & $3.85 E+02$ & $-5.98 E \div 00$ \\
\hline 36 & $3.16 E+02$ & $2.00 \mathrm{E}-02$ & $1.03 E+02$ & $3.85 E+02$ & $-7.01 E+00$ \\
\hline 37 & $2.51 E+02$ & $2.00 \mathrm{E}-02$ & $1.07 \mathrm{E}+02$ & $3.85 E \div 02$ & $-8.31 E+00$ \\
\hline 38 & $2.00 E+02$ & $2.00 \mathrm{E}-02$ & $1.10 \mathrm{E}+02$ & $3.86 E+02$ & $-9.90 \mathrm{E}+00$ \\
\hline 39 & $1.58 E+02$ & $2.00 \mathrm{E}-02$ & $1.12 \mathrm{E}+02$ & $3.86 \mathrm{E} \div 02$ & $-1.18 E \div 01$ \\
\hline 40 & $1.26 \mathrm{E}+02$ & $2.00 \mathrm{E}-02$ & $1.15 E \div 02$ & $3.87 \mathrm{E} \div 02$ & $-1.41 E+01$ \\
\hline 41 & $1.00 E \div 02$ & $2.00 \mathrm{E}-02$ & $1.18 \mathrm{E}-02$ & $3.88 E+02$ & $-1.69 E+01$ \\
\hline
\end{tabular}


Appendix B continued

\begin{tabular}{|c|c|c|c|c|c|}
\hline 42 & $7.94 \mathrm{E} \div 01$ & $2.00 \mathrm{E}-02$ & $1.20 \mathrm{E}+02$ & $3.89 E+02$ & $-2.03 E+01$ \\
\hline 43 & $6.31 E+01$ & $2.00 \mathrm{E}-02$ & $1.23 E+02$ & $3.90 \mathrm{E}+02$ & $-2.44 E+01$ \\
\hline 44 & $5.01 E+01$ & $2.00 \mathrm{E}-02$ & $1.25 E+02$ & $3.91 E+02$ & $-2.92 E+01$ \\
\hline 45 & $3.98 \mathrm{E}+0 \mathrm{I}$ & $2.00 \mathrm{E}-02$ & $1.28 E+02$ & $3.93 E+02$ & $-3.5 I E+0 I$ \\
\hline 46 & $3.16 \mathrm{E}+01$ & $2.00 \mathrm{E}-02$ & $1.31 E+02$ & $3.96 E+02$ & $-4.21 E+01$ \\
\hline 47 & $2.51 \mathrm{E}+0 \mathrm{l}$ & $2.00 \mathrm{E}-02$ & $1.33 E+02$ & $3.99 E+02$ & $-5.05 E+01$ \\
\hline 48 & $2.00 \mathrm{E}+0 \mathrm{I}$ & $2.00 \mathrm{E}-02$ & $1.36 \mathrm{E}+02$ & $4.02 \mathrm{E}+02$ & $-6.05 E+01$ \\
\hline 49 & $1.58 \mathrm{E}+01$ & $2.00 \mathrm{E}-02$ & $1.38 E+02$ & $4.06 \mathrm{E}+02$ & $-7.24 \mathrm{E}+0 \mathrm{I}$ \\
\hline 50 & $1.26 \mathrm{E}+01$ & $2.00 \mathrm{E}-02$ & $1.41 E+02$ & $4.12 E+02$ & $-8.66 E+0 l$ \\
\hline 1 & $1.00 E+01$ & $2.00 \mathrm{E}-02$ & $1.44 \mathrm{E}+02$ & $4.18 \mathrm{E}+02$ & $-1.03 E+02$ \\
\hline 52 & $7.94 \mathrm{E}+00$ & $2.00 \mathrm{E}-02$ & $1.46 \mathrm{E}+02$ & $4.25 \mathrm{E}+02$ & $-1.24 E+02$ \\
\hline 53 & $6.31 E+00$ & $2.00 \mathrm{E}-02$ & $1.49 E+02$ & $4.34 E+02$ & $-1.47 E+02$ \\
\hline 54 & $5.01 E+00$ & 2.00E-02 & $1.52 E+02$ & $4.45 E+02$ & $-1.76 E+02$ \\
\hline 55 & $3.98 E+00$ & $2.00 \mathrm{E}-02$ & $1.55 E+02$ & $4.57 \mathrm{E}+02$ & $-2.10 E+02$ \\
\hline 56 & $3.16 \mathrm{E}+00$ & $2.00 \mathrm{E}-02$ & $1.58 \mathrm{E}+0 ?$ & $4.71 E+02$ & $-2.51 E+02$ \\
\hline 57 & $2.51 E+00$ & $2.00 \mathrm{E}-02$ & $1.61 E+02$ & $4.88 E+02$ & $-3.00 E+02$ \\
\hline 58 & $2.00 \mathrm{E}+00$ & $2.00 \mathrm{E}-02$ & $1.64 \mathrm{E}+02$ & $5.08 \mathrm{E}+02$ & $-3.60 E+02$ \\
\hline 59 & $1.58 \mathrm{E}+00$ & $2.00 \mathrm{E}-02$ & $1.67 E+02$ & $5.31 \mathrm{E}+02$ & $-4.31 E+02$ \\
\hline 60 & $1.26 \mathrm{E}+00$ & $2.00 \mathrm{E}-02$ & $1.70 E+02$ & $5.58 \mathrm{E}+02$ & $-5.17 E+02$ \\
\hline 61 & $1.00 \mathrm{E}+00$ & 2.00E-02 & $1.77 \mathrm{E}+02$ & $5.92 E+02$ & $-6.2 ! E+02$ \\
\hline 62 & $7.94 \mathrm{E}-0 \mathrm{I}$ & $2.00 \mathrm{E}-02$ & $1.80 E+02$ & $6.34 \mathrm{E}+02$ & $-7.49 E+02$ \\
\hline 63 & $6.31 \mathrm{E}-01$ & $2.00 \mathrm{E}-02$ & $1.85 \mathrm{E}+02$ & $6.78 \mathrm{E}+02$ & $-8.99 E+02$ \\
\hline 64 & $5.01 E-01$ & $2.00 \mathrm{E}-02$ & $1.87 \mathrm{E}+02$ & $7.42 \mathrm{E}+02$ & $-1.09 E+03$ \\
\hline 65 & $3.98 \mathrm{E}-01$ & $2.00 \mathrm{E}-02$ & $1.90 \mathrm{E}+02$ & $8.06 \mathrm{E}+02$ & $-1.30 \mathrm{E}+03$ \\
\hline 66 & $3.16 \mathrm{E}-01$ & $2.00 \mathrm{E}-02$ & $1.94 E+02$ & $8.89 \mathrm{E}+02$ & $-1.58 \mathrm{E}+03$ \\
\hline 67 & $2.51 \mathrm{E}-0 \mathrm{I}$ & $2.00 \mathrm{E}-02$ & $1.99 E+02$ & $9.90 \mathrm{E} \div 02$ & $-1.88 E+03$ \\
\hline 68 & $2.00 \mathrm{E}-01$ & $2.00 \mathrm{E}-02$ & $2.05 E+02$ & $1.12 E \div 03$ & $-2.29 \mathrm{E}+03$ \\
\hline 69 & $1.58 \mathrm{E}-01$ & $2.00 \mathrm{E}-02$ & $2.12 \mathrm{E}+02$ & $1.26 \mathrm{E}+03$ & $-2.76 \mathrm{E}+03$ \\
\hline 70 & $1.26 \mathrm{E}-0 \mathrm{I}$ & $2.00 \mathrm{E}-02$ & $2.20 \mathrm{E}+02$ & $1.44 E+03$ & $-3.30 E+03$ \\
\hline 71 & $1.00 \mathrm{E}-01$ & $2.00 \mathrm{E}-02$ & $2.31 \mathrm{E}+02$ & $1.69 E+03$ & $-3.95 E+03$ \\
\hline 72 & $7.94 E-02$ & 2.00E-02 & $2.45 \mathrm{E}+02$ & $1.98 E \div 03$ & $-4.77 E+03$ \\
\hline 73 & $6.31 \mathrm{E}-02$ & $2.00 \mathrm{E}-02$ & $2.70 \mathrm{E}+02$ & $2.24 \mathrm{E}+03$ & $-5.72 E+03$ \\
\hline 74 & 5.01 & $E-02$ & $2.91 E+02$ & $2.61 E+03$ & $-6.90 \mathrm{E}+03$ \\
\hline 75 & 3.98 & & $E+02$ & $E+03$ & $-8.25 E+03$ \\
\hline 76 & & & & +03 & $-9.93 E+03$ \\
\hline 77 & & & & +03 & $\div 04$ \\
\hline 78 & 2.00 & $2.00 \mathrm{E}-02$ & $4.80 E \div 02$ & +03 & $\div 04$ \\
\hline 79 & $1.59 \mathrm{E}-02$ & -02 & $E+02$ & 03 & $E \div 04$ \\
\hline 80 & $1.26 \mathrm{E}-02$ & $2.00 \mathrm{E}-02$ & $6.25 E+02$ & $6.38 E+03$ & $-2.13 E+04$ \\
\hline 81 & $1.00 \mathrm{E}-02$ & $2.00 \mathrm{E}-02$ & $7.26 \mathrm{E}+02$ & $7.51 E-03$ & $-2.59 E+04$ \\
\hline 82 & $7.94 E-03$ & $2.00 \mathrm{E}-02$ & $8.53 E+02$ & $8.92 \mathrm{E} \div 03$ & $-3.17 E+04$ \\
\hline 83 & $6.31 \mathrm{E}-03$ & $2.00 \mathrm{E}-02$ & $1.01 E+03$ & $1.07 \mathrm{E} \div 04$ & $-3.88 E+04$ \\
\hline 84 & $5.01 \mathrm{E}-03$ & $2.00 \mathrm{E}-02$ & $1.21 E+03$ & $1.29 \mathrm{E} \div 04$ & $-4.74 E \div 04$ \\
\hline 85 & $3.98 \mathrm{E}-03$ & $2.00 \mathrm{E}-02$ & $1.47 \mathrm{E}+03$ & $1.57 \mathrm{E}-04$ & $-5.80 E+04$ \\
\hline 86 & $3.16 \mathrm{E}-03$ & $2.00 \mathrm{E}-02$ & $1.79 E+03$ & $1.93 E+04$ & $-7.1 I E+04$ \\
\hline
\end{tabular}


Appendix C: Experimental and Simulated (Using Equivalent Circuit with Two CPEs) Nyquist and Bode Plot Response of SS 316 and DI Water System
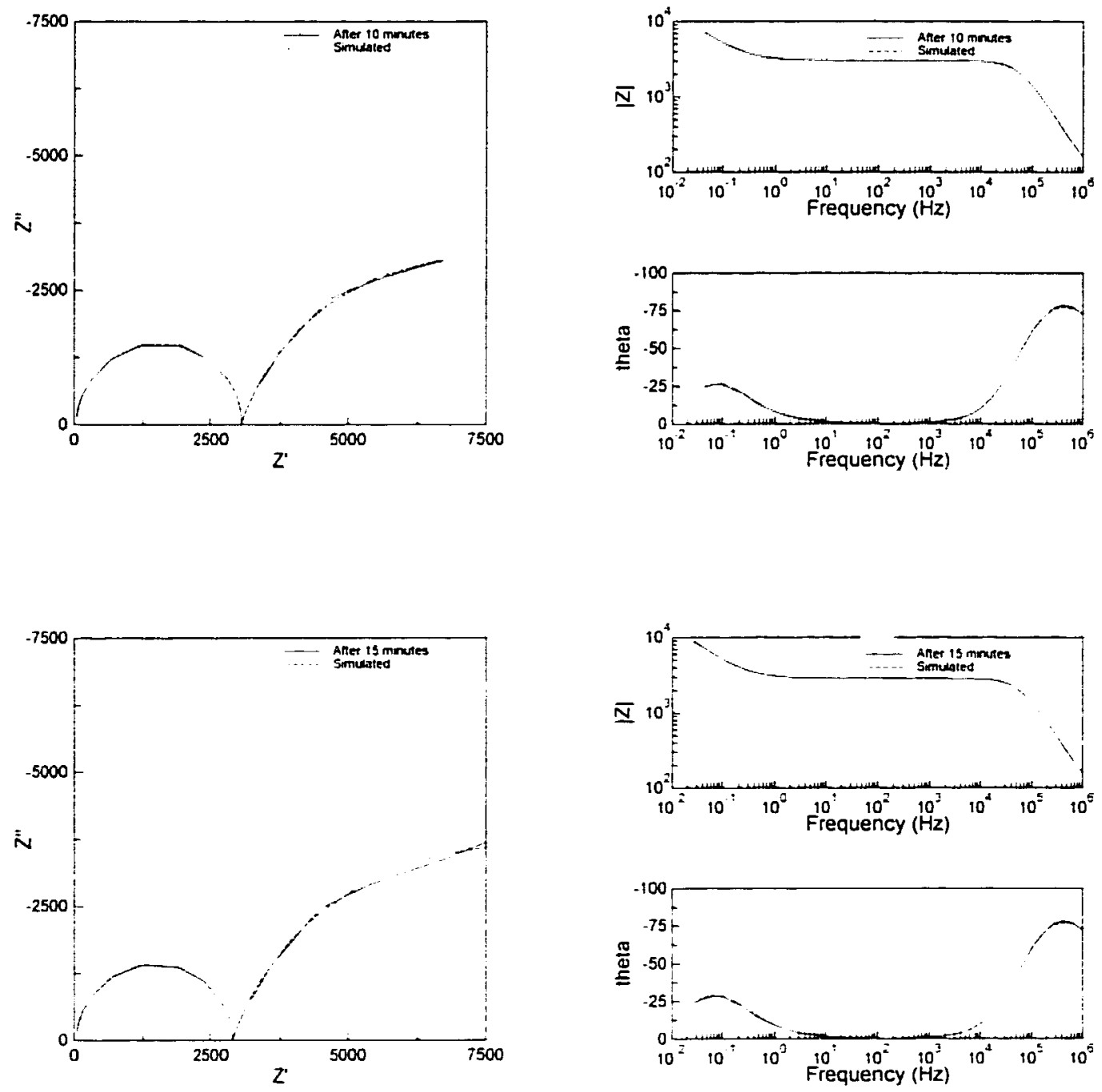
Appendix C contimued
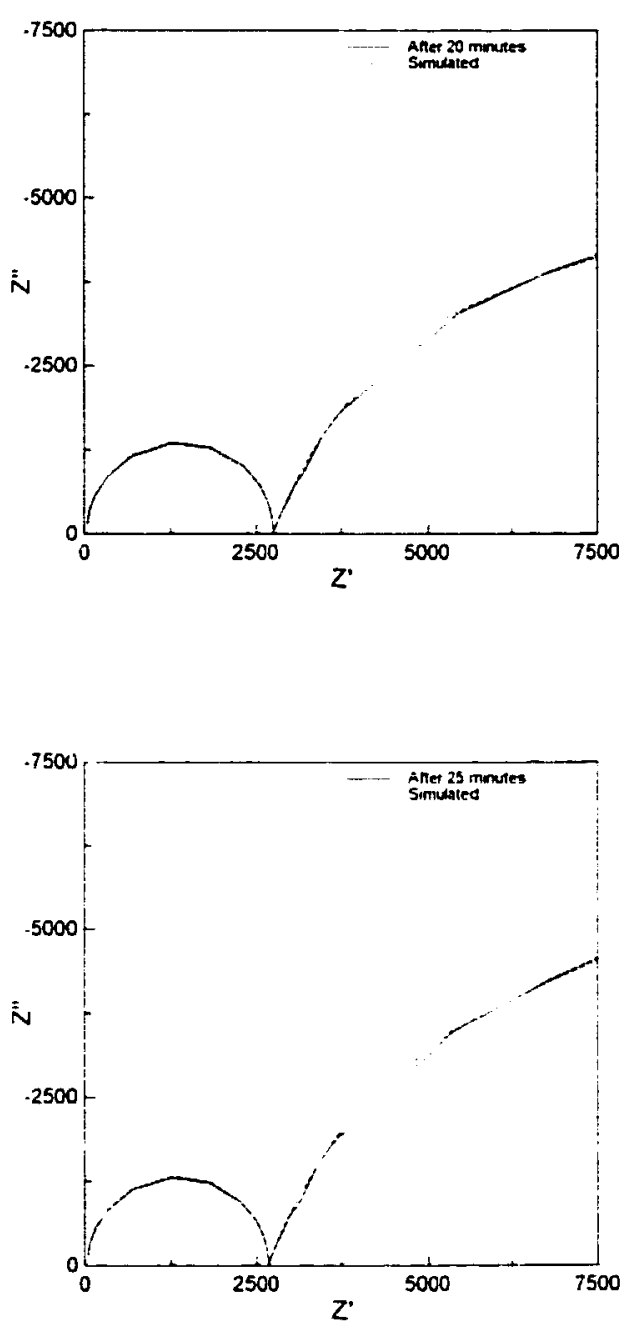
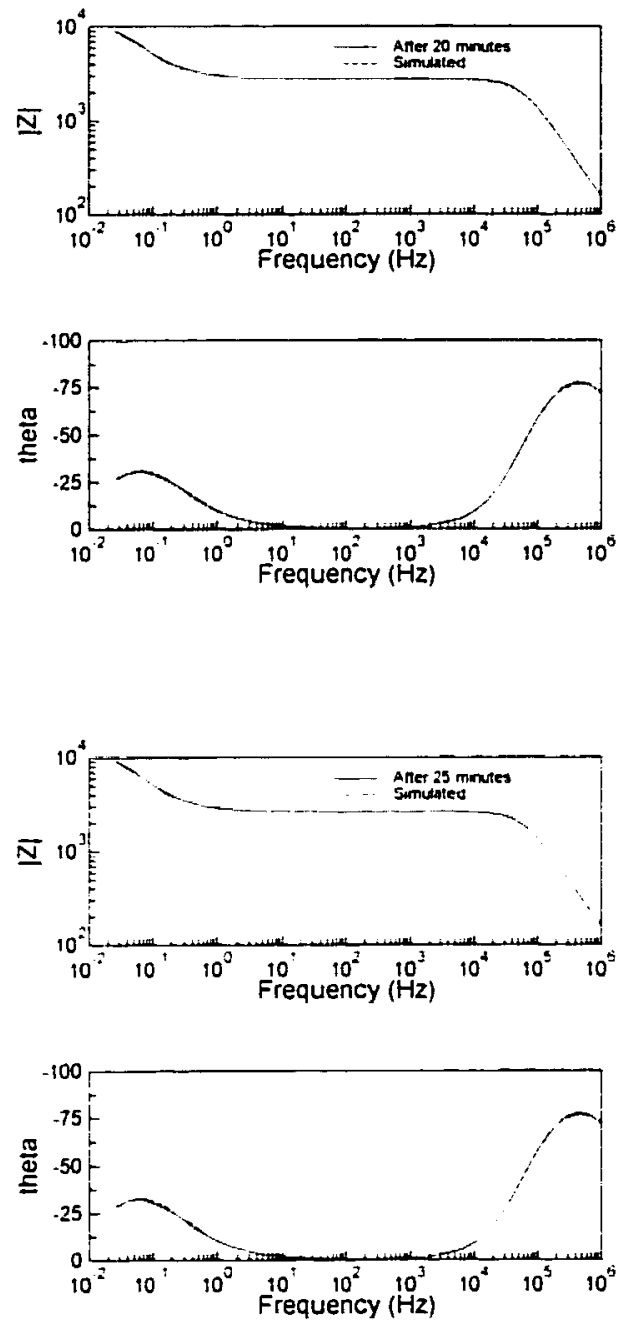


\section{Appendix $\mathrm{C}$ continued}
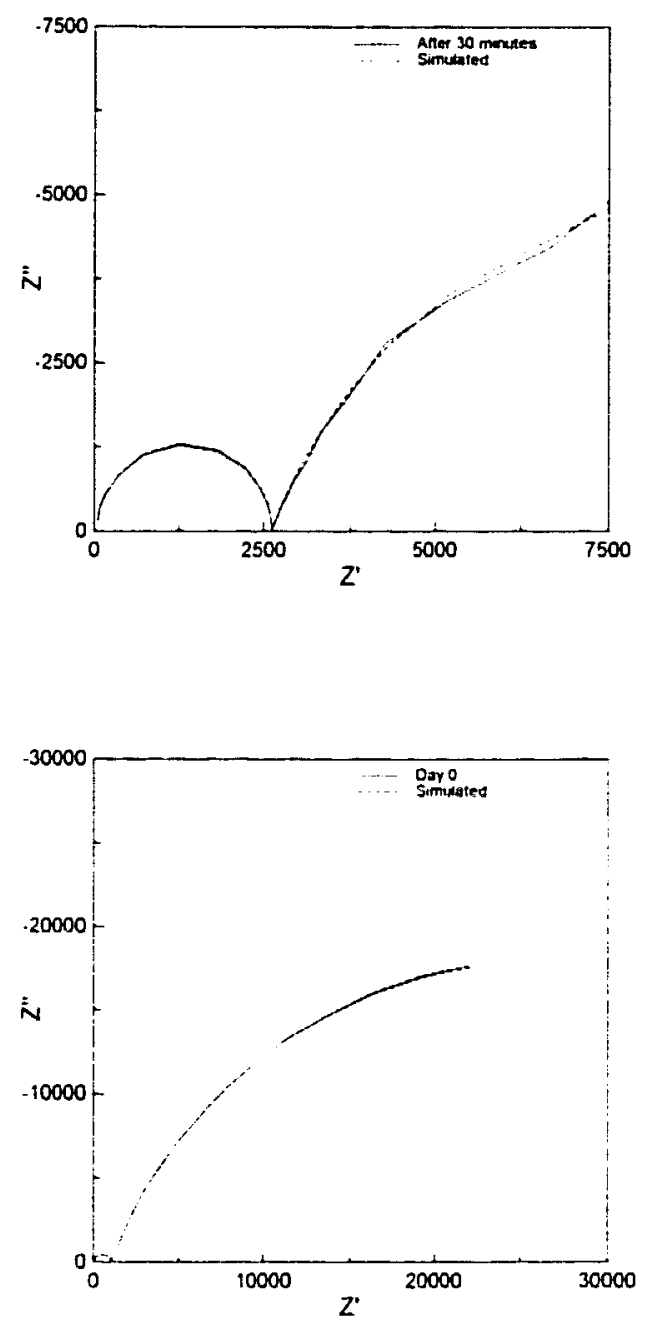
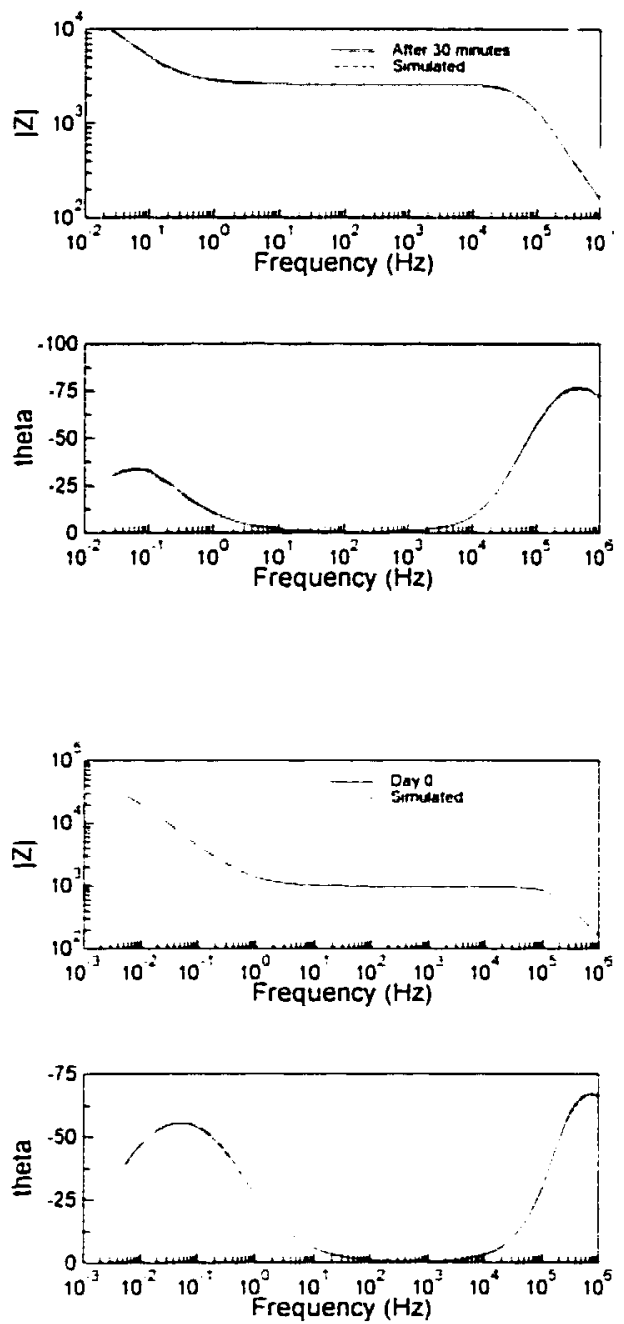
Appendix $C$ continued
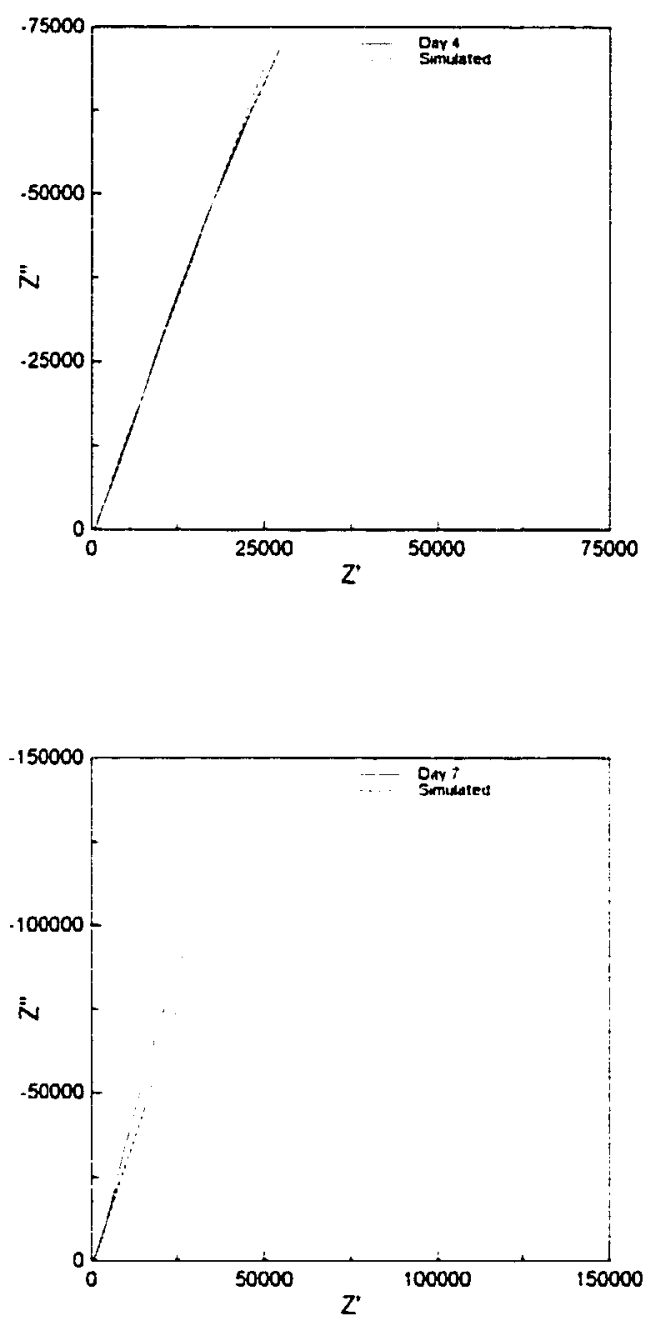
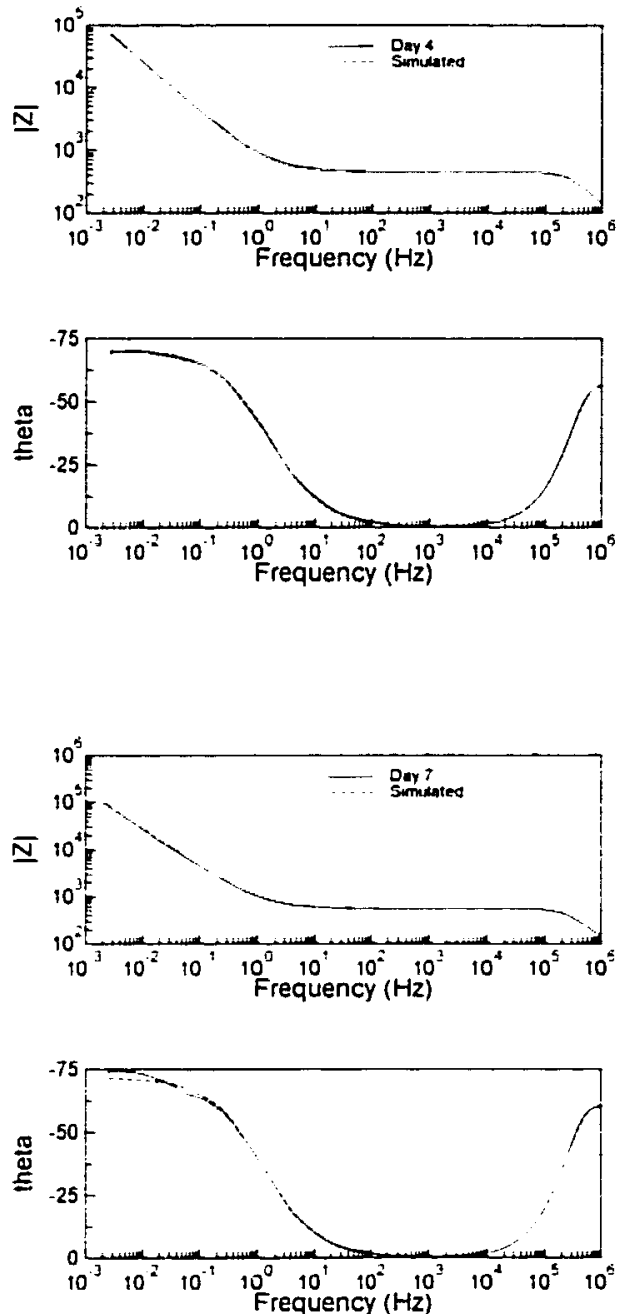

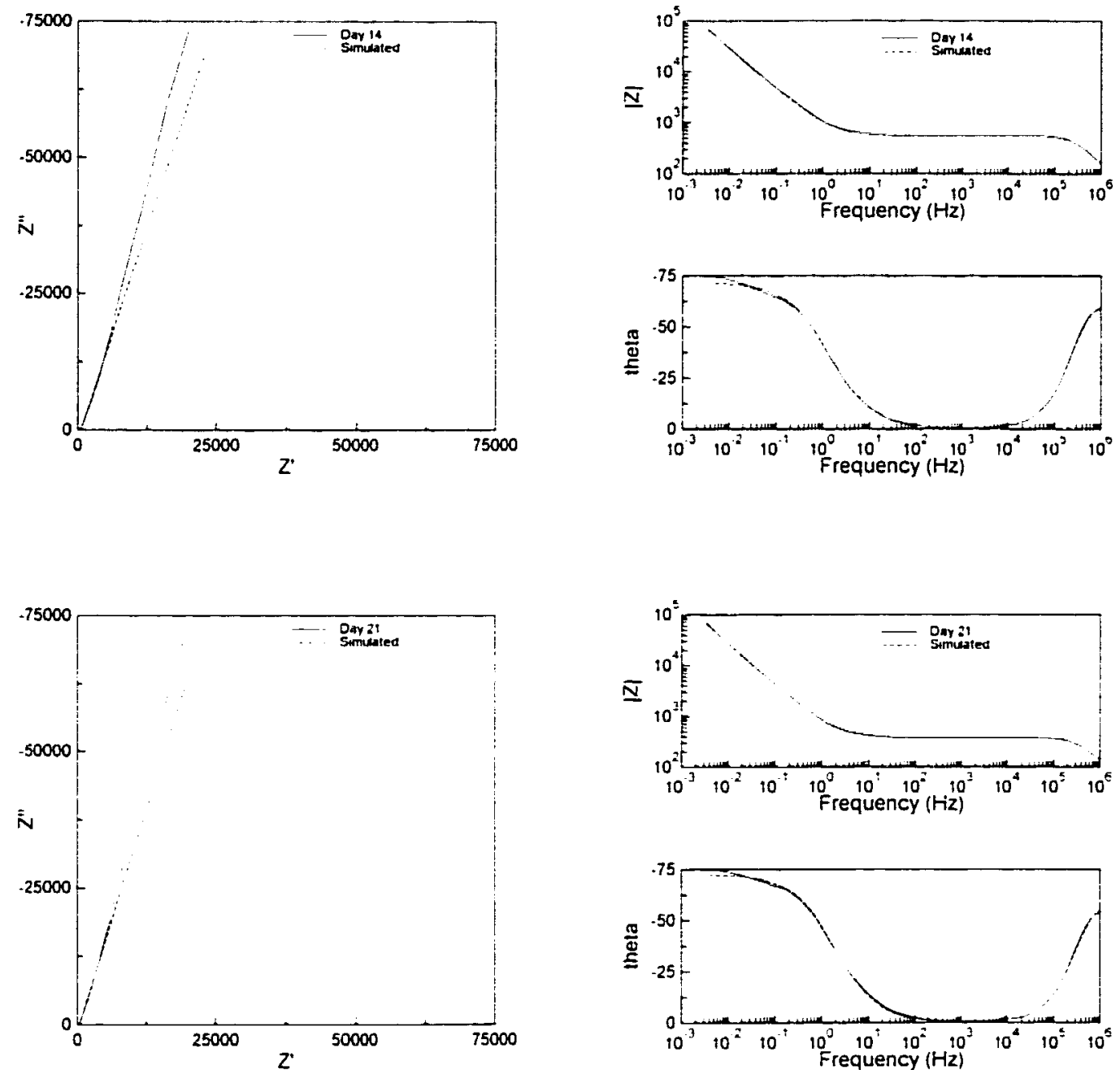
